\title{
Estimação da Volatilidade Diária com Dados de Alta Freqüência: Aplicações ao Cálculo do Valor em Risco do IBOVESPA
}

Alberto Foltran Berti

\author{
DISSERTAÇÃO APRESENTADA \\ $\mathrm{AO}$ \\ INSTITUTO DE MATEMÁTICA E ESTATÍSTICA \\ DA \\ UNIVERSIDADE DE SÃO PAULO \\ PARA \\ OBTENÇÃO DO GRAU DE MESTRE \\ EM ESTATÍSTICA
}

Área de Concentração: Estatística

Orientador: Prof. Dr. Pedro A. Morettin

São Paulo, 29 de abril de 2005. 


\section{Estimação da Volatilidade Diária com Dados de Alta Frequiência: Aplicações ao Cálculo do Valor em Risco do IBOVESPA}

Este exemplar corresponde à redação final da tese devidamente corrigida e defendida por Alberto Foltran Berti e aprovada pela comissão julgadora

Banca examinadora:

Prof. Dr. Pedro A. Morettin (orientador) - IME - USP

Prof. Dr. Clélia M. C. Toloi - IME - USP

Prof. Dr. Denisard C. O. Alves - FEA - USP 


\section{Agradecimentos}

Ao meu orientador Prof. Morettin pela paciência e dedicação ao longo desse projeto.

Aos professores Clélia e Denisard pela leitura crítica do texto.

Aos professores Elisabeti, Nelson, Silvia E., Silvia F. e ao meu ex-chefe Sérgio pela confiança e apoio principalmente no início do mestrado.

Aos meus pais, Antônia e Carlos, pelo apoio que me deram durante toda a vida. Sem eles nada seria possível.

A todos os meus amigos, colegas de trabalho e professores que contribuíram pela minha formação acadêmica e profissional. 


\title{
Resumo
}

Este trabalho tem como objetivo a avaliação empírica da previsão de volatilidade do índice BOVESPA, tanto de modelos tradicionais em base diária, como algumas adaptações para a inclusão da informação intradiária, com a intenção de obter melhores previsões no horizonte de um dia à frente. A intuição dessa análise vem da observação de casos onde há grandes variações de preços intradiários, mas em que o preço de fechamento é próximo ao do dia anterior, e, portanto, os modelos tradicionais em bases diárias não capturam esta volatilidade. Os modelos empregados aqui são os da família GARCH e os de memória longa FARIMA. Também foram feitas aplicações no cálculo do Valor em Risco (VaR). A conclusão do trabalho aponta a viabilidade do uso dos dados intradiários para realizar previsões de horizonte diário, e mais, há indícios de que podem melhorar a acurácia das previsões.

\begin{abstract}
The goal of this project is to access empirically the forecasting of the volatility of the Bovespa index, using traditional daily models as well models using intraday information, with the purpose of improving one-step ahead forecasts. The idea is that daily models may not capture the intraday variation of prices. The models we use are those of ARCH and FARIMA families. We also applied the methodology to VaR calculations. The overall conclusion is that the intraday information is useful to improve the accuracy of daily forecasts.
\end{abstract}




\section{Conteúdo}

1 Introdução 1

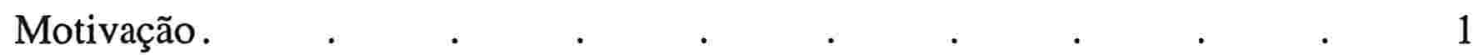

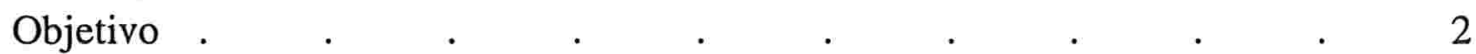

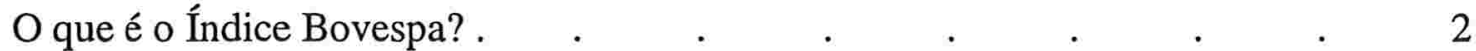

2 Descrição dos dados 3

2.1 Filtragem dos Dados Intradiários . $\quad . \quad$. $\quad . \quad$. 3

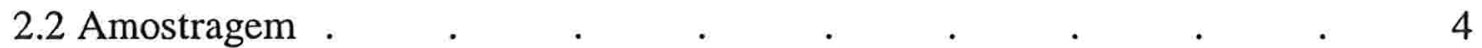

2.3 Definição de Retorno. $\quad$. $\quad$. $\quad$. $\quad$. $\quad$. . . . $\quad$. 6

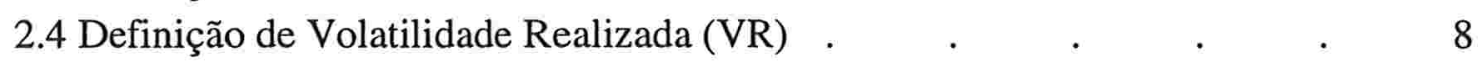

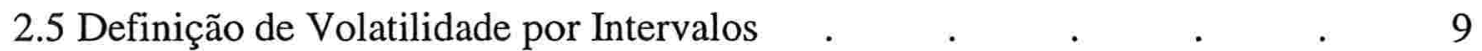

3 Fatos Estilizados $\quad 11$

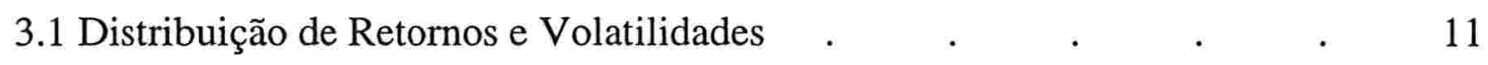

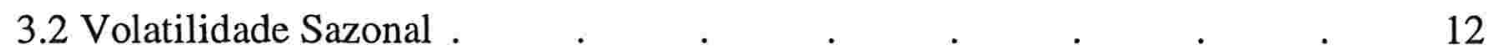

4 Modelagem da Volatilidade $\quad 15$

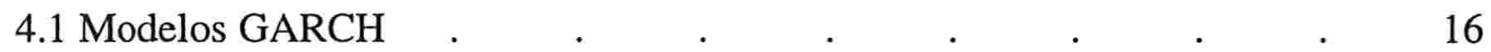

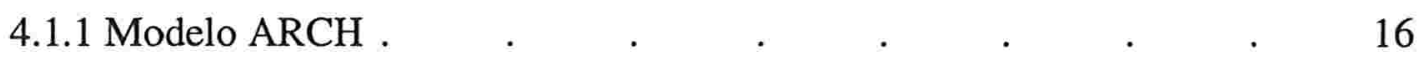

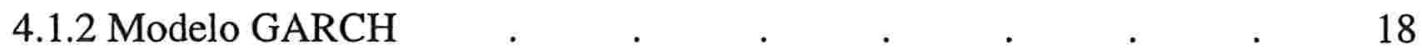

4.1.3 Representação ARMA de um modelo GARCH 19

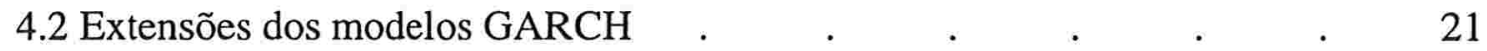

4.2.1 Modelo TGARCH . . . . . . . . $\quad$. 22

4.2.2 Modelo EGARCH $\quad . \quad$. $\quad . \quad$. $\quad . \quad$. $\quad . \quad$. 23

4.2.3 Modelo PGARCH . . . . . . . 23

4.3 Modelo RiskMetrics . $\quad$. $\quad$. $\quad . \quad$. . 24

4.4 Modelos de Memória Longa $\quad$. $\quad$. $\quad . \quad$. $\quad 25$

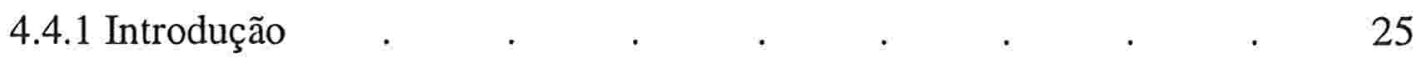

4.4.2 Modelos FARIMA . . . . . . . 25

4.5 Modelo GARCH diário com volatilidade intradiária $\quad$. . . $\quad$. 26

4.6 Volatilidade diária utilizando GARCH intradiário . . . . $\quad 27$ 
5 Risco de Mercado

5.1 Introdução

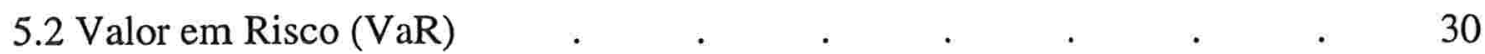

5.3 Estimação do VaR paramétrico . . . . . . . . $\quad . \quad 32$

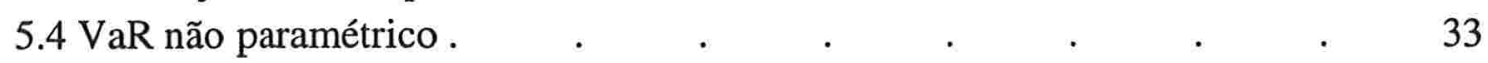

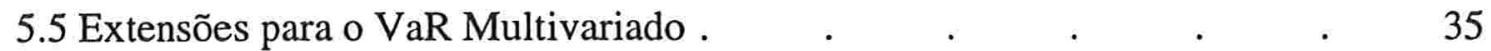

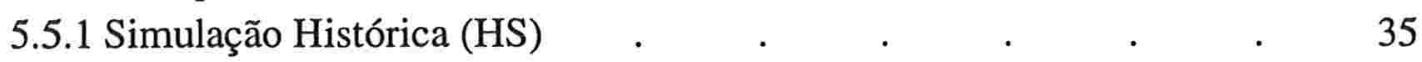

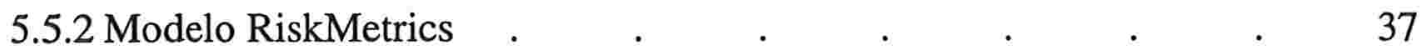

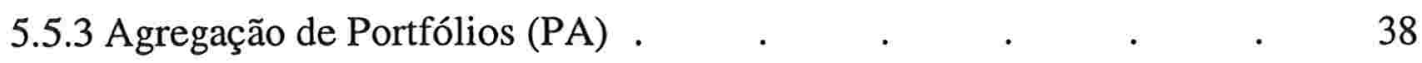

6 Back-Testing $\quad 41$

6.1 Avaliação das estimativas de volatilidade $\quad . \quad$. $\quad . \quad$. $\quad$. $\quad$. 42

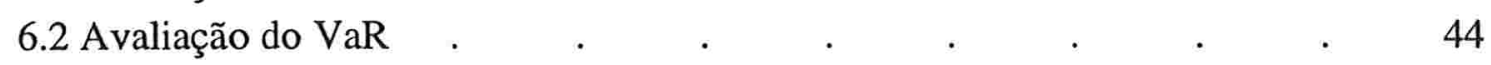

7 Resultados Empíricos $\quad 46$

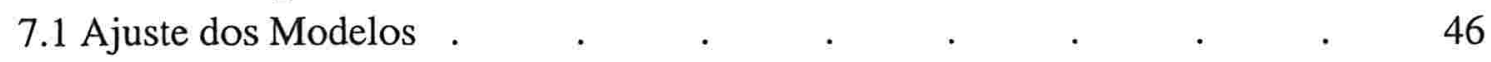

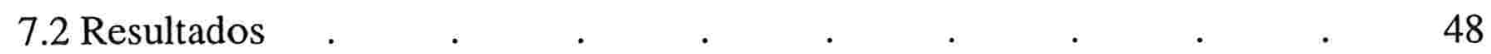

7.2.1 Resultados da avaliação da previsão da volatilidade . . $\quad$. 48

7.2.2 Resultados da avaliação da previsão do VaR . $\quad$. $\quad$. $\quad$. 52

8 Conclusões

Apêndices $\quad 62$

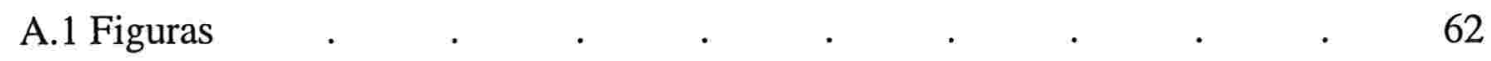

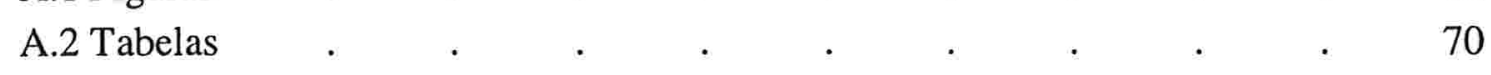

$\begin{array}{ll}\text { Referências } & 74\end{array}$ 


\section{Introdução}

\section{Motivação}

Como observado por Giot (2000), ao analisar os preços de um ativo numa bolsa de valores, por exemplo, observam-se casos em que a variação entre o preço de fechamento do dia anterior e o dia atual é desprezível, mas durante o dia há uma grande oscilação nos preços. Analistas e traders percebem esse aumento da volatilidade, no entanto, esta não é capturada pelos tradicionais modelos de Risco, que se baseiam apenas em informações diárias. Para ilustrar, considere o dia 08/09/1998: o fechamento do Índice BOVESPA em relação ao dia anterior teve uma variação de apenas $-0,3 \%$, no entanto, a diferença entre o valor máximo e o mínimo desse dia foi de $7,5 \%$.

Na literatura, é comum o uso do nome "dados de alta-freqüência" devido a maior frequiência em que os dados são amostrados, mas também será adotado o termo intradiário, que tem a vantagem de ser um termo mais familiar ao mercado financeiro.

Existe uma extensa bibliografia internacional sobre análise de dados intradiários, contudo, há poucas publicações sobre séries financeiras brasileiras que abordam esse assunto (veja, por exemplo: Barbosa (2002), Moreira e Lemgruber (2004) e Mota e Fernandes (2004)) e, por isso, ainda há muito trabalho para ser desenvolvido. Mais escassos ainda são os dados históricos intradiários disponíveis.

Há diversas modelagens de volatilidade possíveis, com cotações dos preços históricos, volatilidade implícita, etc. Por exemplo, Tsay (2002) descreve em seu livro modelos que levam em consideração o tempo entre um negócio e outro, modelando a atividade do mercado e modelos logísticos para explicar o comportamento dos preços com variáveis explicativas, como tempo, volume, preço etc. 


\section{Objetivo}

Foram considerados apenas modelos que levam em conta os preços históricos diários e intradiários na tentativa de melhorar o desempenho da previsão da volatilidade diária, que tem aplicações práticas diretas, como precificação de derivativos, cálculo do Valor em Risco (VaR), alocação ótima de ativos, etc. Este trabalho se propõe a analisar empiricamente os modelos de volatilidade, com uma atenção especial ao cálculo do Valor em Risco com aplicações ao Índice Bovespa, com o intuito de fornecer uma contribuição prática, sem se ater a discussões teóricas extensas. Tem como inspiração o artigo de Hol e Koopman (2002), em que são analisados modelos de volatilidade do retorno do índice de ações americanas Standard \& Poor's 100.

\section{O que é o Índice Bovespa?}

O Índice Bovespa (daqui em diante será denominado IBVSP) é o mais importante indicador do desempenho médio das cotações do mercado de ações brasileiro. O peso de cada ação no índice é dado pela sua participação relativa no volume total negociado na bolsa, que é reavaliada quadrimestralmente. Sua relevância advém do fato de o IBVSP retratar o comportamento dos principais papéis negociados na BOVESPA (Bolsa de Valores de São Paulo) e também de sua tradição, pois o índice manteve a integridade de sua série histórica e não sofreu modificações metodológicas desde sua implementação, em 1968.

No Capítulo 2 são apresentadas algumas definições básicas que serão utilizadas ao longo do texto, e também são apresentados os dados, que serão analisados de forma descritiva no Capítulo 3. O Capítulo 4 descreve diversos modelos de volatilidade (diária e intradiária) que fornecerão previsões de volatilidade que serão utilizadas no cálculo do Risco de Mercado no Capítulo 5. Estes modelos por sua vez, serão comparados segundo as metodologias discutidas no Capítulo 6. Os resultados são descritos no Capítulo 7 e as conclusões apresentadas no Capítulo 8. 


\section{Descrição dos dados}

Os dados intradiários originais são obtidos de 1.381 dias úteis (veja Figura A.1), com cotações intradiárias do IBVSP e duas frequêencias de amostragens:

- 15 minutos, de 02/01/98 até 31/10/02 com 1.189 dias úteis, sendo que cada dia possui em geral de 29 a 33 observações, totalizando 35.277 observações,

- 30 segundos, de 01/11/02 até 13/08/03 com 192 dias úteis, sendo que cada dia possui em geral de 865 a 872 observações, totalizando 166.236 observações.

Além do conjunto de dados intradiários acima, foi utilizado um segundo conjunto de dados com cotações de abertura, fechamento, máximo e mínimo do IBVSP. Este segundo grupo de dados, apesar de, a rigor, serem também dados intradiários, serão denominados dados de intervalos, como forma de diferenciá-los do primeiro grupo, que possuirá um tratamento especial.

\subsection{Filtragem dos Dados Intradiários}

No intuito de utilizar modelos econométricos mais simples, a duração do pregão foi fixada em 7 horas, com a padronização do período das 10:00 às 17:00 ou das 11:00h às 18:00h, dependendo do horário de verão, o que corresponde à duração normal do pregão de viva vós, período em que é maior o volume de negociações. Para manter esse padrão, os dados originais sofreram alguns ajustes:

- foram excluídos todos os dados anteriores ao dia 06/04/98 por apresentarem período irregular e com duração inferior a 7 horas, além de diversos dados discrepantes. 
- foram excluídos os dados da negociação eletrônica. Após o fim do pregão viva vós, inicia-se a negociação eletrônica, que hoje possui em torno de $20 \%$ das negociações, segundo a Bovespa. No entanto, esse mercado é pulverizado entre pequenos investidores com baixo poder de influência, pois qualquer um desses participantes não possui volume financeiro suficiente para influenciar todo o mercado, ao contrário dos grandes investidores (bancos e empresas) que podem fazer grandes posições de compra e venda de ações capazes de influenciar todo o mercado.

- foi excluída a primeira hora de negociação nos casos em que o pregão viva vós possuía duração de 8 horas. Decidiu-se excluir a primeira hora pois esta possui menor volume e menor importância do que a última hora de negociação, que seria a outra possibilidade.

- nos casos de falta de dados de abertura ou fechamento, foram preenchidos com os respectivos dados disponíveis no histórico de cotações diárias do IBVSP provenientes da BLOOMBERG.

- foram excluídos os dias com expediente reduzido, com duração inferior a cinco horas. Já nos dias com duração entre cinco e sete horas, realizou-se uma interpolação linear simples para completar o período de sete horas. Em geral, o expediente reduzido ocorreu em datas especiais, como Quarta-feira de Cinzas e Vésperas de Natal e Ano Novo, jogos da copa mundial de futebol, falhas no suprimento de energia elétrica, etc.

- foi utilizado filtro manual, com auxílio gráfico, onde foram detectados alguns poucos pontos aberrantes (em 1998), que tinham sinais claros de erros de digitação, como uma casa decimal a mais ou inversão da posição do número. Nesses casos optou-se pela correção do número mais provável e, quando não foi possível, foi substituído pela interpolação linear dos pontos adjacentes.

\subsection{Amostragem}

Após o processo de filtragem acima, padronizou-se o período de pregão em sete horas. No entanto, ainda há duas freqüências de amostragem e, portanto é necessário a escolha de uma 
freqüência de forma que não seja tão alta a ponto das propriedades da série sejam distorcidas por aspectos da microestrutura de mercado (ausência de transação, preço discreto, negociações não sincronizadas, etc). Andersen e Bollerslev (1998) concluíram que com o aumento da freqüência de amostragem dos dados maior é a acurácia da medida da volatilidade (analisaram até a freqüência de 5 minutos). Enquanto Giot e Laurent (2004) encontraram como adequado o intervalo de 15 minutos para índices de ações, Oomen (2001) argumenta que 25 minutos é o intervalo adequado.

Além da discussão teórica acima, do ponto de vista prático, a maior parte dos dados está amostrada a cada quinze minutos (cerca de 86\%). Devido a isso, no período de 01/11/02 até 13/08/03, em que a freqüência era a cada trinta segundos, também foram consideradas amostras a cada quinze minutos, resultando em cotações do IBVSP amostrados a cada 15 minutos, de 06/04/98 até 13/08/03, ou seja, 1309 dias com 29 observações intradiárias cada um, totalizando 37.961 pontos.

Os dados de intervalos, cotações de abertura, fechamento, máximo e mínimo do IBVSP, também foram considerados no mesmo conjunto de dias dos dados intradiários acima, de forma que as análises desses dados sejam comparáveis.

Para que seja possível avaliar corretamente a performance dos modelos, a amostra acima (dos dois conjuntos) foi dividida em duas, denominadas de "amostra base" e a outra de "amostra de teste".

A "amostra base" será utilizada para ajuste dos modelos, e compreende o período de 06/04/98 até 12/09/01, com 838 dias (cerca de 66\% do total). Já a "amostra de teste" é constituída pelo restante dos dados, do dia 13/09/01 até 13/08/03, com 471 dias (cerca de 34\% do total), e será utilizada para a análise de "Back-Testing", que se destina à avaliação da previsão dos modelos fora da amostra de ajuste dos modelos. Escolheu-se o início em 13/09/01, com intuito de avaliar o desempenho dos modelos no período de grande volatilidade após os ataques terroristas de 11 de setembro de 2001, mas desconsiderando o próprio dia, já que esse evento é totalmente imprevisível (Nota: Como o pregão foi encerrado antecipadamente no dia 11/09/01, este ponto foi excluído, ficando o impacto do retorno no dia 12/09/01 e, portanto, 13/09/01 é o primeiro retorno que não considera a cota do dia 11). Além desse evento, particularmente o 
mercado financeiro brasileiro sofreu um período de maior volatilidade em 2002 devido à apreensão dos investidores internacionais com a possibilidade de medidas severas do governo do presidente Lula. Todavia, não se compara ao período de volatilidade que iniciou-se com a crise da Ásia em outubro de 1997 seguido pela moratória da Rússia em agosto de 1998 (veja Figuras A.1, A.2 e A.3).

\subsection{Definição de Retorno}

Denote por $P_{t}$ o preço de um ativo no instante t, por exemplo um dia de negócios. Supondo que não haja dividendos pagos no período, a variação de preços entre os instantes $t$-1 e $t$ é dada por $\Delta P_{t}=P_{t}-P_{t-1}$ e a variação relativa de preços ou retorno líquido simples (ou taxa de retorno) deste ativo entre os mesmos instantes é definido por (expresso em porcentagem):

$$
R_{t}=100 \cdot \frac{\Delta P_{t}}{P_{t-1}}
$$

Denotando $p_{t}=\ln P_{t}$ (logaritmo neperiano), define-se o retorno composto continuamente ou simplesmente log-retorno como (expresso em porcentagem):

$$
r_{t}=100 \cdot \ln \frac{P_{t}}{P_{t-1}}=100 \cdot \ln \left(1+R_{t}\right)=100\left(p_{t}-p_{t-1}\right)
$$

Daqui em diante, $r_{t}$ será chamado simplesmente de retorno.

Na prática, é preferível trabalhar com retornos, que são livres de escala, do que com preços, pois os primeiros têm propriedades estatísticas mais interessantes, como estacionariedade e ergodicidade (Morettin, 2004).

Através da expansão de Taylor, pode-se mostrar que para $u$ pequeno, $\ln (1+u) \approx u$, do que segue que os retornos simples $R_{t}$ e os logaritmos dos retornos $r_{t}$ serão em geral valores 
próximos, com a vantagem do último ter melhores propriedades matemáticas e estatísticas. Por exemplo, o logaritmo do produto é a soma dos logaritmos de cada parcela (que é uma propriedade extremamente útil no mapeamento dos fatores de risco de um instrumento financeiro para o cálculo do $\mathrm{VaR}$ ), se uma variável aleatória possui distribuição log-normal, o logaritmo da variável possui distribuição normal, etc.

Portanto, será utilizado (2.1) para o cálculo dos retornos diários (denotado também por $\log (1 \mathrm{~d})$, veja Figura A.2) e, para os retornos intradiários, será utilizada a seguinte extensão:

$$
r_{t, d}=100\left(p_{t, d}-p_{t, d-1}\right)
$$

onde:

$\mathrm{d}=1, \ldots, 28$ e $\mathrm{t}=1, \ldots, 1308$

$r_{t, d}$ denota o retorno intradiário do período $d$ do dia $t$,

$p_{t, d}$ é o logaritmo da cotação intradiária do período $d$ do dia $t$.

Um dia de negócio consiste em 28 retornos intradiários e um retorno overnight. Este último incorpora as informações relativas ao intervalo entre o fechamento do pregão do dia anterior e a abertura do pregão do dia em questão, sendo definido de forma similar aos retornos intradiários:

$$
r_{t, 0}=100\left(p_{t, 0}-p_{t-1,28}\right),
$$

onde:

$r_{t, 0}$ é o retorno overnight do dia $t$,

$p_{t, 0}$ é o logaritmo da primeiro cotação do dia $t$,

$p_{t-1,28}$ é o logaritmo da última cotação do dia $t-1$,

Note que também é possível escrever o retorno diário definido em (2.1) como $p_{t, 28}$ $p_{t-1,28}$. 
Para facilitar a notação no texto, o retorno intradiário de cada 15 minutos (veja Figura A.2) referentes às equações (2.2) e (2.3) também será denotado por $\log (15 \mathrm{~m})$ ).

Também é definido o retorno horário (denotado também por $\log (1 \mathrm{~h})$ ), veja Figura A.2), que é a soma de quatro retornos intradiários a cada 15 minutos definidos acima, totalizando uma hora. A exceção é o primeiro retorno, pois como o número de retornos intradiários (29) não é múltiplo do número de horas em um dia (7), para contornar esse problema define-se o primeiro retorno horário como a soma de cinco retornos, que é o retorno overnight somado com os quatro primeiros retornos intradiários do dia, ou seja:

$$
\begin{array}{ll}
q_{t, h}=\sum_{k=1}^{4} r_{t, 4(h-1)+k}, & \text { para } h=2, \ldots, 7 ; \\
q_{t, 1}=r_{t, 0}+\sum_{k=1}^{4} r_{t, k}, \quad & \text { para } h=1,
\end{array}
$$

onde

$$
\begin{aligned}
& q_{t, h} \text { é o retorno intradiário da hora } h(1, \ldots, 7) \text { e dia } t(1, \ldots, 1308), \\
& r_{t, d} \text { é definido em (2.2) e (2.3). }
\end{aligned}
$$

\subsection{Definição de Volatilidade Realizada (VR)}

Andersen e Bollerslev (1998) mostram que o quadrado do retorno diário, apesar de ser uma estimativa não viesada da variância, provê uma pobre aproximação da volatilidade realizada diária e que estimações mais acuradas podem ser obtidas com a soma dos quadrados dos retornos intradiários. Mais especificamente, eles definiram volatilidade realizada no mercado de câmbio como a soma dos 288 retornos de 5 minutos ao quadrado. Adaptando para os retornos a cada 15 minutos, utilizados também por Giot e Laurent (2004), define-se a volatilidade realizada no dia $\mathrm{t}$ como: 


$$
\tilde{\sigma}_{t, 1}^{2}=r_{t, 0}^{2}+\sum_{d=1}^{28} r_{t, d}^{2}, \quad \mathrm{t}=1, \ldots, 1308
$$

com $r_{t, 0}$ e $r_{t, d}$ definidos nas equações (2.2) e (2.3). No entanto, alguns dias foram excluídos no processo de filtragem no Capítulo 2, então, na equação acima para os dias subseqüentes à exclusão, o retorno overnight $r_{t, 0}$ contém retornos de mais de um dia, o que distorce a estimativa da volatilidade realizada desses dias. Para contornar esse problema, será desconsiderado $r_{t, 0}$ de (2.6) quando o dia t-1 tiver sido excluído, ou seja,

$$
\tilde{\sigma}_{t, 2}^{2}=\left\{\begin{array}{l}
\sum_{d=1}^{28} r_{t, d}^{2} \text { se o dia } \mathrm{t}-1 \text { foi excluído } \\
r_{t, 0}^{2}+\sum_{d=1}^{28} r_{t, d}^{2} \text { caso contrário. }
\end{array}\right.
$$

Daqui em diante toda menção a volatilidade realizada ou VR (veja Figura A.3) se refere a equação (2.7).

\subsection{Definição de Volatilidade por Intervalos (GK)}

Apesar da volatilidade realizada prover as melhores estimativas (Andersen e Bollerslev, 1998), não é fácil obter dados intradiários históricos (de forma que seja possível o cálculo de 2.7), principalmente de ativos brasileiros. No entanto, dados de abertura, fechamento, máximo e mínimo são facilmente obtidos em qualquer provedor de informação, o que conduz a estimação da volatilidade segundo Garman e Klass (1980). Mais precisamente, será utilizada uma variante freqüentemente adotada na literatura, que utiliza o logaritmo dos preços ao invés dos preços.

Defina

$O$, o logaritmo do preço de abertura no dia $t$; 
$C_{t}$ o logaritmo do preço de fechamento no dia $t$

$H_{t}$ o logaritmo do preço máximo no dia $t$;

$L_{t}$ o logaritmo do preço mínimo no dia $t$;

e a normalização pelo preços de abertura: $u_{t}=H_{t}-O_{t}, d_{t}=L_{t}-O_{t}, c_{t}=C_{t}-O_{t}$.

O estimador não viesado da variância para o dia $t$ de Garman e Klass (1980), que segundo os autores é pelo menos oito vezes mais eficiente (o critério utilizado foi o razão da variância desses dois estimadores) que o estimador clássico $r_{t}^{2}=\left(C_{t}-C_{t-1}\right)^{2}$, é dado por:

$$
\hat{\sigma}_{t, G K}^{2}=\frac{a\left(O_{t}-C_{t-1}\right)}{f}+(1-a) \frac{\hat{\sigma}_{t, G K^{*}}^{2}}{1-f},
$$

onde:

$$
\hat{\sigma}_{t, G K^{*}}^{2}=0,511\left(u_{t}-d_{t}\right)^{2}-0,019\left[c_{t}\left(u_{t}-d_{t}\right)-2 u_{t} d_{t}\right]-0,383 c_{t}^{2},
$$

$a$ é uma constante com valor 0,12 , que minimiza a variância do estimador $\hat{\sigma}_{t, G K^{*}}^{2}$, segundo Garman e Klass;

$f$ é a fração do dia que o mercado está fechado (foi utilizado o valor de 0,192 que é fixado pelo S-plus).

No texto, o modelo (2.8) será referido como volatilidade por Garman Klass (veja Figura A.3), ou simplesmente por GK. 


\section{Fatos Estilizados}

Alguns fatos estilizados conhecidos em séries financeiras diárias são mais visíveis em séries intradiárias, como por exemplo, caudas pesadas, distribuições não normais, etc.

Todas as análises descritivas abaixo foram feitas no período da "amostra base".

\subsection{Distribuição de Retornos e Volatilidades}

Um fato estilizado conhecido das séries financeiras é a cauda pesada. Pode-se verificar isso pela medida de curtose (excesso) que tem como referência a distribuição normal, com valor zero, e valores positivos indicam que a distribuição possui caudas mais pesadas que a gaussiana. $\mathrm{Na}$ Tabela 3.1, verifica-se que a série de retornos diária possui um alto valor de curtose, que aumenta à medida que a freqüência aumenta, que é outro fato estilizado importante.

Há também a medida de assimetria que tem valor zero para distribuições simétricas. Para freqüências menores que um dia encontra-se assimetria negativa, e positiva para um dia. Essas duas medidas são indicações que as séries não apresentam distribuição normal (de forma bem mais amena para VR e GK, conforme pode ser observado pelas Figuras A.4 e A.5), o que é confirmado pelos testes de Jarque e Bera (1987) e pelo do teste modificado de Shapiro-Wilks por Royston (1982) (este último não foi possível calcular para amostras muito grandes).

Verifica-se na Figura A.7 a presença tímida de autocorrelação nos retornos, de forma mais amena para a freqüência diária, tornando-se mais evidente para freqüências mais altas, o que é confirmado pelo teste de autocorrelação Ljung e Box (1978), onde é rejeitada a hipótese nula de ruído branco (ver Tabela 3.1 abaixo). 
Tabela 3.1 Estatísticas descritivas das séries analisadas

\begin{tabular}{|c|c|c|c|c|c|c|c|}
\hline & $\log (15 m)$ & $\log (15 \mathrm{~m}) \mathrm{DS}$ & $\log (1 h)$ & $\log (1 \mathrm{~h}) \mathrm{DS}$ & $\log (1 d)$ & $\log (V R)$ & $\log (G K)$ \\
\hline & 24301 & 24301 & 5865 & 5865 & 837 & 837 & 837 \\
\hline Mínimo & $-10,15$ & $-15,09$ & $-10,69$ & $-9,50$ & $-17,27$ & $-1,50$ & $-1,89$ \\
\hline 1 Quartil & $-0,16$ & $-0,44$ & $-0,40$ & $-0,48$ & $-1,47$ & 0,49 & 0,33 \\
\hline Média & 0,00 & $-0,01$ & 0,00 & $-0,01$ & $-0,01$ & 1,11 & 0,99 \\
\hline Mediana & 0,00 & 0,01 & 0,01 & 0,01 & $-0,04$ & 0,99 & 0,93 \\
\hline 3 Quartil & 0,16 & 0,44 & 0,41 & 0,49 & 1,41 & 1,58 & 1,56 \\
\hline Máximo & 7,93 & 11,57 & 13,30 & 7,58 & 28,82 & 4,93 & 5,67 \\
\hline Desvio Padrão & 0,43 & 1,00 & 0,97 & 1,00 & 2,84 & 0,91 & 1,03 \\
\hline Assimetria & $-0,73$ & $-0,17$ & $-0,24$ & $-0,14$ & 1,16 & 0,80 & 0,56 \\
\hline Curtose & 42,90 & 16,17 & 17,64 & 7,56 & 16,33 & 1,21 & 1,30 \\
\hline Ljung-Box* & 666,6 & 793,3 & 48,55 & 72,81 & 30,90 & 2626 & 1569 \\
\hline Ljung-Box (quadrado)* & 1389 & 7092 & 972,1 & 2746,0 & 106,0 & & \\
\hline Jarque-Bera* & 1864750 & 264824 & 75964 & 13962 & 9385 & 138,5 & 101,2 \\
\hline Shapiro-Wilks* & n.d. & n.d. & n.d. & n.d. & 0,929 & 0,956 & 0,974 \\
\hline
\end{tabular}

Já o quadrado dos retornos exibe autocorrelação mais evidente (que também é confirmado pelo teste de Ljung e Box na Tabela 3.1), principalmente para dados intradiários (ver Figura A.8). Como os retornos ao quadrado medem o segundo momento da série temporal, este resultado indica que a variância da série condicional pode alterar-se ao longo do tempo, ou equivalentemente, a série temporal pode apresentar agrupamentos de volatilidade ao longo do tempo ou heteroscedasticidade condicional. Como essa autocorrelação para dados intradiários é sazonal, tem-se que a volatilidade intradiária também é sazonal.

\subsection{Volatilidade Sazonal}

Analisando o correlograma dos quadrados dos retornos na Figura A.9, verifica-se uma clara sazonalidade tanto para os retornos de 15 minutos, como para o horário, enquanto os retornos diários não apresentam esse comportamento, como pode ser verificado na Figura A.9. O ciclo, que é dado pelo pico dessas autocorrelações, é de 29 para dados de 15 minutos e 7 para dados horários, ou seja, ambos possuem periodicidade diária. 
Para capturar essa sazonalidade na volatilidade intradiária, será calculado um fator sazonal, definido como a média da soma quadrática dos retornos para cada período (horário e de 15 minutos), por dia da semana:

$$
\phi_{d, w}=\left(\frac{1}{m s} \sum_{y=1}^{m s} r_{y, d, w}^{2}\right)^{1 / 2},
$$

onde:

$\phi_{d, w}$ denota a volatilidade sazonal do período $d=1, \ldots, n s(n s=7$ para dados horários ou $n s=29$ para dados a cada 15 minutos) da semana $w=1, \ldots, 5$ (sendo que 1 é definido como segunda-feira);

$$
r_{y, d, w}^{2} \text { é o y-ésimo retorno ao quadrado (horário como em } 2.4 \text { e } 2.5 \text { ou } 2.2 \text { e } 2.3
$$

para cada 15 minutos) do período $d$, semana w, com $y=1, \ldots, m s$;

$m s$ número de retornos do $d$-ésimo período da $w$-ésima semana.

Segue-se que a volatilidade sazonal média por período é dada por:

$$
\phi_{d}=\left(\frac{1}{5} \sum_{w=1}^{5} \phi_{d, w}^{2}\right)^{1 / 2}
$$

Pode-se observar na Figura A.6 que há um padrão de sazonalidade em forma de "U”, que é típico de séries de ações, com um início de negociação com maior volatilidade, reduzindo expressivamente até o horário do almoço onde é menor o movimento de mercado, para depois voltar a subir, não chegando, entretanto ao mesmo patamar de volatilidade da abertura. Não há grandes diferenças do fator entre os dias da semana, o que sugere que não há efeito do dia da semana.

Com o fator sazonal, pode-se retirar a sazonalidade dos retornos intradiários, o que será útil mais adiante, conforme o procedimento determinístico utilizado por Giot (2000), 


$$
r_{t, d}^{*}=\frac{r_{t, d}}{\phi_{d}}
$$

onde:

$r_{t, d}^{*}$ é o retorno intradiário desazonalizado do período $d$ do dia $t$;

$r_{t, d}$ é o retorno intradiário do período $d$ do dia $t$;

$\phi_{d}$ é o fator sazonal do período d (definido em 3.2).

Note que $\phi_{d}$ é calculado com base na amostra base, mantido fixo para qualquer $t$.

Após o processo a retirada da sazonalidade por (3.3), pode-se verificar que o correlograma do quadrado dos retornos não apresenta mais ciclos (ver Figura A.9), o que indica que a sazonalidade foi retirada com sucesso. Também pode ser observado nos histogramas da Figura A.4 que as distribuições dos retornos dessazonalizados são mais próximas da distribuição normal, o mesmo observado na Tabela 3.1, com redução da curtose e da assimetria para valores mais relativamente próximos da distribuição gaussiana, mas ainda mantendo desvios significativos desta. 


\section{Modelagem da Volatilidade}

A variabilidade de um ativo financeiro é usualmente referida como "volatilidade", que é um conceito muito importante em diferentes áreas da teoria e prática financeira, como gerenciamento de risco, seleção de portfólio e precificação de opções. Em termos estatísticos, volatilidade é usualmente medida pela variância, ou pelo desvio padrão.

Modelagem e previsão da volatilidade do mercado de ações é objeto de estudos e grandes debates dos últimos 50 anos, com uma extensa e crescente literatura sobre o assunto (Brooks e Persand, 2003). Essa por sua vez, contém conclusões conflitantes da superioridade dos modelos, inclusive quando são comparados modelos mais complexos em relação aos mais simples (veja, por exemplo, Hansen e Lunde, 2004). Essa dificuldade de comparação pode ser parcialmente explicada pelo fato de que a volatilidade não é algo observável.

Uma observação interessante nesse ponto é com relação a uma crítica comum dos traders, que afirmam que os modelos econométricos não podem prover previsões de volatilidade melhor que a volatilidade implícita calculadas a partir dos preços das opções, que teoricamente são baseadas nas expectativas futuras dos participantes do mercado, e não somente no "passado".

No entanto, não há consenso entre os pesquisadores de qual é o melhor modelo. Por exemplo, Chong (2004) verificou que em períodos de estabilidade, modelos de VaR baseados em volatilidade implícita tendem a superestimar o risco, enquanto apresentaram mais falhas em períodos de turbulência do que em relação aos modelos de volatilidade GARCH. Já Pong, Shackleton, Taylor e Xu, (2004) encontraram resultados tão bons com volatilidade implícita como aqueles utilizando dados históricos de volatilidade realizada. De qualquer forma não se pode desprezar a informação contida nos dados históricos, mesmo porque a baixa liquidez do mercado de opções brasileiro torna pouco viável o uso prático da volatilidade implícita em um 
sistema de risco e, portanto, não será analisado esse tipo de modelo nesse trabalho, apesar de seu grande apelo financeiro.

Serão tratados aqui os modelos GARCH que já são amplamente utilizados na modelagem de volatilidade, assim como algumas extensões, além do modelo EWMA do RiskMetrics, que por ser simples e amplamente utilizado, é um importante Benchmark. Também é avaliado o modelo de memória longa FARIMA, que é relativamente mais desconhecido, mas é crescente o seu uso em dados intradiários.

Todos os modelos aqui foram estimados por máxima verossimilhança através do módulo S+FinMetrics do pacote estatístico S-PLUS.

\subsection{Modelos GARCH}

Os modelos ARIMA de Box e Jenkins (1970) concentram-se na modelagem e previsão da média condicional ou primeiro momento de séries temporais, e não estão preocupados com a variância condicional ou o segundo momento dos mesmos. Entretanto, é bem conhecido que em mercados financeiros, grandes variações de preços tendem ser seguidos por grandes alterações, o mesmo acontecendo com pequenas variações.

Serão introduzidos aqui os modelos univariados auto-regressivos com heteroscedasticidade condicional generalizados (GARCH), que são capazes de modelar a variação da volatilidade no tempo e capturar muitos dos fatos estilizados do comportamento da volatilidade usualmente observados em séries temporais financeiras.

\subsubsection{O Modelo ARCH (Autoregressive Conditional Herocedasticity)}

Segundo Zivot e Wang (2003), a autocorrelação do quadrado dos retornos (como a reportada na figura A.9), ou heteroscedasticidade condicional, pode ser modelada usando um 
processo autoregressivo (AR) para os quadrados dos retornos. Por exemplo, seja $r_{t}$ uma série temporal de retornos financeiros, estacionária, então $r_{t}$ pode ser expressa como a soma da média da série e de um ruído branco (se não houver nenhuma autocorrelação significante em $r_{t}$ ):

$$
r_{t}=c+\varepsilon_{t},
$$

onde $c$ é a média de $r_{t}$, e $\varepsilon_{t}$ são variáveis aleatórias i.i.d. com média zero. Para permitir heteroscedasticidade condicional, assuma que a variância condicional é dado por $\operatorname{Var}\left(\varepsilon_{t} \mid \Omega_{t-1}\right)=h_{t}^{2}, \operatorname{com} \Omega_{t-1}$ denotando a informação até o instante t-1 seja dado por:

$$
h_{t}^{2}=a_{0}+a_{1} \varepsilon_{t-1}^{2}+\ldots+a_{p} \varepsilon_{t-p}^{2} .
$$

Como $\varepsilon_{t}$ possui média zero, $\operatorname{Var}\left(\varepsilon_{t} \mid \Omega_{t-1}\right)=E\left(\varepsilon_{t}^{2} \mid \Omega_{t-1}\right)=h_{t}^{2}$, então a equação acima pode ser rescrita como:

$$
\varepsilon_{t}^{2}=a_{0}+a_{1} \varepsilon_{t-1}^{2}+\ldots+a_{p} \varepsilon_{t-p}^{2}+u_{t}
$$

onde $u_{t}=\varepsilon_{t}^{2}-h_{t}^{2}$ é uma variável aleatória não correlacionada com média zero e variância não constante. A equação acima representa um processo AR(p) para $\varepsilon_{t}^{2}$ e o modelo em (4.1) e (4.2) é conhecido como modelo auto-regressivo com heteroscedasticidade condicional de Engle (1982), que é usualmente referido como $\mathrm{ARCH}(\mathrm{p})$. Uma formulação alternativa do modelo $\mathrm{ARCH}$ é:

$$
\begin{aligned}
& r_{t}=c+\varepsilon_{t}, \\
& \varepsilon_{t}=z_{t} h_{t}, \\
& h_{t}^{2}=a_{0}+a_{1} \varepsilon_{t-1}^{2}+\ldots+a_{p} \varepsilon_{t-p}^{2},
\end{aligned}
$$


onde $z_{t}$ é um variável aleatória i.i.d. com distribuição normal padrão (no modelo básico). A representação acima é conveniente para derivação de propriedades do modelo, assim como para especificação da função de verossimilhança para estimação.

\subsubsection{Modelo GARCH (Generalized ARCH)}

Se o teste ML (Engle,1982) para efeitos ARCH é significante para as séries temporais, um possível procedimento seria estimar um modelo ARCH e obter estimativas da volatilidade heteroscedástica. Entretanto, na prática é freqüentemente encontrado um grande número de lags $p$, e conseqüentemente um grande número de parâmetros é necessário para obter um bom ajuste.

Um modelo mais parcimonioso proposto por Bollerslev (1986) substitui o AR em (4.2) e, junto com (4.1), é conhecido como a generalização do modelo $\mathrm{ARCH}$ ou simplesmente $\operatorname{GARCH}(\mathrm{p}, \mathrm{q})$ :

$$
\begin{aligned}
& r_{t}=c+\varepsilon_{t}, \\
& \varepsilon_{t}=z_{t} h_{t} \\
& h_{t}^{2}=a_{0}+\sum_{i=1}^{p} a_{i} \varepsilon_{t-1}^{2}+\sum_{j=1}^{q} b_{j} h_{t-1}^{2},
\end{aligned}
$$

para $t=1, \ldots, T, c$ é a média condicional, $h_{t}^{2}=\operatorname{Var}\left(\varepsilon_{t} \mid \Omega_{t-1}\right)$ é a variância condicional, $a_{i}>0(i=0, \ldots, p)$ e $b_{j}>0(j=1, \ldots, q)$ para garantir que a variância condicional $h_{t}^{2}$ seja sempre positiva.

Os parâmetros desconhecidos $c, a_{i}(i=0, \ldots, p)$ e $b_{j}(j=1, \ldots, q)$ podem ser estimados usando estimação de máxima verossimilhança (uma referência básica é Hamilton, 1994). No modelo $\operatorname{GARCH}(\mathrm{p}, \mathrm{q})$, a variância condicional de $\varepsilon_{t}, h_{t}^{2}$ depende do quadrado dos resíduos dos 
$p$ períodos anteriores, e da variância condicional nos $q$ períodos anteriores (quando $q=0,0$ modelo GARCH reduz-se a um modelo ARCH).

Caso as séries de retornos exibam a presença de auto-correlação, há a necessidade de eliminá-las por meio do ajuste de um modelo linear (Morettin, 2004), por exemplo da família ARMA e, posteriormente com os resíduos deste é modelado um GARCH, obtendo-se assim o modelo conhecido como $\operatorname{ARMA}(\mathrm{r}, \mathrm{s})-\mathrm{GARCH}(\mathrm{p}, \mathrm{q})$. Portanto, a equação da média (4.1) é modelada como:

$$
r_{t}=\phi_{o}+\sum_{i=1}^{r} \phi_{i} r_{t-1}+\sum_{j=1}^{s} \theta_{j} \varepsilon_{t-j}+\varepsilon_{t}
$$

onde $\phi_{i}$, com $i=0, . ., r$ e $\theta_{j}, \operatorname{com} j=1, \ldots, s$ são os parâmetros de um modelo ARMA(r,s) de Box e Jenkins (1970).

Segundo Zivot e Wang (2003), geralmente um modelo GARCH $(1,1)$ é adequado para obter um bom ajuste para séries temporais financeiras, que possui somente três parâmetros na variância condicional:

$$
h_{t}^{2}=a_{0}+a_{1} \varepsilon_{t-1}^{2}+b_{1} h_{t-1}^{2}
$$

O coeficiente $a_{1}$ mede a extensão em que um choque no retorno hoje afeta a volatilidade do retorno do dia seguinte, enquanto $b_{1}$ mede a persistência da volatilidade.

\subsubsection{Representação ARMA de um modelo GARCH}

Assim como um modelo ARCH pode ser expresso como um modelo AR nos quadrados dos resíduos, Zivot e Wang (2003) mostram que um modelo GARCH pode ser expresso como 
um modelo ARMA nos quadrados dos resíduos. Considerando um modelo $\operatorname{GARCH}(1,1)$ em (4.7), pode-se reescrever como:

$$
\varepsilon_{t}^{2}=a_{0}+\left(a_{1}+b_{1}\right) \varepsilon_{t-1}^{2}+u_{t}-b_{1} u_{t-1}
$$

que é um modelo "ARMA $(1,1)$ " $\operatorname{com} u_{t}=\varepsilon_{t}^{2}-E\left(\varepsilon_{t}^{2} \mid \Omega_{t-1}\right)$ sendo uma variável aleatória não correlacionada com média zero e variância não constante.

Dada a representação ARMA do modelo GARCH, muitas propriedades do modelo GARCH são deduzidas facilmente do correspondente modelo ARMA para $\varepsilon_{t}^{2}$. Por exemplo, para o modelo GARCH(1,1) como em (4.7), ser estacionário requer que $a_{1}+b_{1}<1$. Assumindo a premissa que $\varepsilon_{t}^{2}$ seja estacionário, pode ser demonstrado que a variância incondicional de $\varepsilon_{t}$ para o modelo GARCH(1,1) é

$$
\operatorname{Var}\left(\varepsilon_{t}\right)=E\left(\varepsilon_{t}^{2}\right)=\frac{a_{0}}{1-a_{1}-b_{1}}
$$

A soma $a_{1}+b_{1}$ mede a taxa pela qual o impacto de um choque no retorno hoje se propaga ao longo do tempo. Um alto valor para esta soma significa que choques no retorno têm impacto fortemente persistente sobre a volatilidade, ou seja, um choque no retorno hoje deverá afetar significativamente a volatilidade do retorno em um ponto razoavelmente distante do futuro.

Para o modelo geral $\operatorname{GARCH}(\mathrm{p}, \mathrm{q})$, é necessário a restrição $\sum_{i=1}^{p} a_{i}+\sum_{j=1}^{q} b_{j}<1$ para que o processo seja estacionário e a variância incondicional de $\varepsilon_{t}$ é dada por:

$$
\operatorname{Var}\left(\varepsilon_{t}\right)=\frac{a_{0}}{1-\left(\sum_{i=1}^{p} a_{i}+\sum_{j=1}^{q} b_{j}\right)}
$$




\subsection{Extensões dos modelos GARCH}

Pesquisadores vêm criando diversas variações do modelo GARCH básico (4.5) desde sua criação em 1982 por Engle. Para se ter uma idéia da dimensão das variações, Hansen e Lunde (2004) compararam 330 diferentes modelos GARCH para a previsão de volatilidade de retorno de séries financeiras.

Em geral, essas modificações baseiam-se em alguns aspectos no modelo que podem ser melhorados para que sejam capturadas certas características e dinâmicas de uma série temporal financeira. Por exemplo, devido às boas propriedades matemáticas e simplicidade, em geral é amplamente utilizado a premissa da normalidade dos erros nos modelos GARCH, no entanto essa premissa pode não ser apropriada, já que um fato estilizado importante das séries financeiras, como também foi verificado para o IBVSP no Capítulo 3, é que os retornos possuem caudas mais pesadas do que as da distribuição normal. Uma das distribuições que possuem essa característica (caudas pesadas) é a t-Student, que, portanto também será utilizada na distribuição dos erros dos modelos da família GARCH (além da tradicional distribuição Normal) na tentativa de representar melhor essas características das séries e obter melhores previsões de volatilidade.

Outro ponto importante é que somente os quadrados dos resíduos entram na equação de um modelo GARCH, de modo que o sinal dos resíduos ou dos choques não afeta a volatilidade condicional. Entretanto, um fato estilizado na volatilidade de séries financeiras é que notícias ruins (choques negativos) tendem a ter um impacto maior do que notícias boas (choques positivos). Esta assimetria pode ser devida ao efeito alavancagem (Black, 1976), que consiste no fato que quando o preço de uma ação cai, aumenta a volatilidade dos retornos dos acionistas. Outra fonte de assimetria é a aversão ao risco (Morettin, 2004), pois com o aumento de volatilidade, reduz-se a demanda por uma ação, com conseqüente decréscimo de seu valor e mais aumento da volatilidade.

Hansen e Lunde (2004), ao estudarem diversos modelos de volatilidade do retorno da ação IBM, encontraram evidências que modelos com efeitos assimétricos são melhores que os simétricos. Nesse texto serão utilizados os modelos EGARCH, PGARCH e TGARCH (com 
efeitos assimétricos) na tentativa de modelar essa assimetria devida ao impacto de novas notícias (retornos).

\subsubsection{Modelo TGARCH (Threshold GARCH).}

É também conhecido na literatura como modelo GJR devido ao fato de também ter sido proposto por Glosten, Jagannathan e Rankle (1993). Aqui, a volatilidade é modelada por

$$
h_{t}^{2}=a_{0}+\sum_{i=1}^{p} a_{i} \varepsilon_{t-i}^{2}+\sum_{i=1}^{p} \gamma_{i} S_{t-i} \varepsilon_{t-i}^{2}+\sum_{i=1}^{q} b_{j} h_{t-j}^{2},
$$

onde

$$
S_{t-i}=\left\{\begin{array}{l}
1 \text { se } \varepsilon_{\mathrm{t}-\mathrm{i}}<0 \\
0 \text { se } \varepsilon_{\mathrm{t}-\mathrm{i}} \geq 0
\end{array}\right.
$$

Assim, o fato de $\varepsilon_{t-i}$ estar acima ou abaixo do valor limiar de zero, $\varepsilon_{t-1}^{2}$ tem diferentes efeitos na variância condicional $h_{t}^{2}$ : quando $\varepsilon_{t-i}$ é negativo, o efeito total é dado por $\left(a_{i}+\gamma_{i}\right) \varepsilon_{t-i}^{2}$ e quando $\varepsilon_{t-i}$ é positivo, o efeito total é dado por $a_{i} \varepsilon_{t-i}^{2}$. Portanto espera-se que $\gamma_{i}$ seja significativamente positivo para que a notícia ruim tenha impacto maior.

É importante observar que, quando $\gamma_{i}$ é nulo, o modelo TGARCH se transforma num GARCH. Assim, este último nada mais é que um caso particular do modelo TGARCH e, portanto, nada se perde, em termos de estimação, com o uso do modelo TGARCH no lugar do GARCH. Novamente, é importante ressaltar que restrições sobre o vetor de parâmetros são necessárias para assegurar o sinal positivo da variância condicional. 
Nelson (1991) propôs o modelo EGARCH, com a volatilidade modelada por

$$
h_{t}^{2}=\exp \left(a_{0}+\sum_{i=1}^{p} a_{i} \frac{\left|\varepsilon_{t-1}\right|+\gamma \varepsilon_{t-i}}{h_{t-1}}+\sum_{j=1}^{q} b_{j} h_{t-j}^{2}\right) .
$$

Note que, quando $\varepsilon_{t-i}$ é positivo ou há "notícias boas", o efeito total de $\varepsilon_{t-i}$ é $\left(1+\gamma_{i}\right)\left|\varepsilon_{t-i}\right|$, mas, quando $\varepsilon_{t-i}$ é negativo ou há "notícias ruins", o efeito total de $\varepsilon_{t-i}$ é $\left(1-\gamma_{i}\right) \mid \varepsilon_{t-i}$ ।. Como notícias ruins podem ter impactos maiores na volatilidade, espera-se que o valor de $\gamma_{i}$ seja negativo.

Uma vantagem desse modelo diante do anterior é que o uso da função logarítmica assegura a positividade da volatilidade, sem a necessidade de qualquer restrição sobre o vetor de parâmetros. Ao contrário do que ocorre com o TGARCH, o GARCH não pode mais ser derivado como um caso particular do EGARCH por meio de restrições sobre os parâmetros deste modelo. Dessa forma, mesmo quando o efeito de assimetria seja significativo, não é possível concluir, com base apenas neste resultado, que o EGARCH seja mais eficiente na estimação da volatilidade, uma vez que sua forma paramétrica pode prover um ajustamento aos dados inferior ao da família GARCH.

\subsubsection{Modelo PGARCH (Power GARCH)}

O modelo PGARCH proposto por Ding, Granger e Engle (1993), é dado por

$$
h_{t}^{d}=a_{0}+\sum_{i=1}^{p} a_{i}\left(\left|\varepsilon_{t-i}\right|+\gamma_{i} \varepsilon_{t-1}\right)^{d}+\sum_{j=1}^{q} b_{j} h_{t-j}^{d},
$$


onde $d$ é um expoente positivo, e $\gamma_{i}$ denota o coeficiente de assimetria. Note que quando $d=2$ e $\gamma_{i}=0$, a equação acima se reduz ao modelo básico GARCH (4.5). O modelo (4.12) será denotado por PGARCH(p,q), $d$ também será estimado por máxima verossimilhança.

\subsection{Modelo RiskMetrics}

O modelo EWMA (Exponencially Weighted Moving Average), sugerido pelo RiskMetrics (1996), é um dos métodos de estimação de volatilidade mais utilizados para cáculo de risco. Aqui, a volatilidade é estimada por

$$
\sigma_{t}^{2}=\lambda \sigma_{t-1}^{2}+(1-\lambda) r_{t-1}^{2}
$$

com $0<\lambda<1$.

Substituindo-se $\sigma_{t-1}^{2}$ recursivamente na equação, verifica-se que o modelo exponencial atribui pesos que declinam geometricamente conforme se recua no tempo, dando mais importância às informações mais recentes:

$$
\sigma_{t}^{2}=(1-\lambda)\left(r_{t-1}^{2}+\lambda r_{t-2}^{2}+\lambda^{2} r_{t-3}^{2}+\ldots .\right)
$$

Note que (4.13) é um caso particular do modelo $\operatorname{GARCH}(1,1) \operatorname{com} a_{1}=1-\lambda, b_{1}=\lambda \mathrm{e}$, portanto, $a_{1}+b_{1}=1$. Como $a_{1}+b_{1}$ corresponde ao coeficiente $\operatorname{AR}(1)$ na representação ARMA do modelo GARCH (veja seção 4.1.3), a restrição $a_{1}+b_{1}=1$ implica que o modelo GARCH é não estacionário. Engle e Bollerslev (1986) nomearam esse modelo como Integrated GARCH (IGARCH).

RiskMetrics sugere o uso de $\lambda=0.94$, que será utilizado nas previsões, e denominado por "modelo RiskMetrics". Há vários trabalhos, inclusive para séries de dados do mercado 
financeiro brasileiro, que apontam que o valor fixado de $\lambda=0.94$ produz boas estimativas de volatilidade. O motivo de $\lambda$ ser fixo é explicado no Capítulo 5.

\subsection{Modelos de Memória Longa}

\subsubsection{Introdução}

Muitas séries financeiras possuem a característica que um choque não esperado pode ter um longo efeito, chamado de persistência ou memória longa, que pode ocorrer tanto no primeiro momento, ou nível, como nos momentos mais altos, como a volatilidade. A persistência no primeiro momento de uma série temporal pode ser confirmada através do teste de raiz unitária ou teste de estacionariedade do nível, enquanto a persistência na volatilidade é usualmente exemplificada por um ajuste de alta ordem de um modelo GARCH.

\subsubsection{Modelos FARIMA}

Em estudos empíricos da volatilidade realizada (veja Figura A.3) é mostrado que a série de volatilidade realizada definida em (2.7) pode ser considerada gerada por um processo lognormal, ou seja o logaritmo desta série possui distribuição normal. Essa nova série de logaritmos possui a característica conhecida como "memória longa", para a qual o correlograma decai mais lentamente do que uma exponencial com o aumento do lag.

O modelo FARIMA $(1, \mathrm{~d}, 1)$ com média $\mu$ é dado por:

$$
(1-\phi L)(1-L)^{d}\left(y_{t}-\mu\right)=(1+\theta L) \varepsilon_{t}
$$


onde $d, \phi$ e $\theta$ são fixos e desconhecidos e $\varepsilon_{t}$ é um ruído branco com distribuição normal de média zero e variância $\sigma^{2}$. Há as seguintes restrições nos parâmetros $0<d<0,5 ;|\phi|<1$; $|\theta|<1$ e $\sigma^{2}>0 .(1-L)^{d}$ é o filtro fracionário de diferença (para $d=1$ tem-se $\left.(1-L) x_{t}=x_{t}-x_{t-1}\right)$, que é definido a seguir para qualquer real $d>-1$ :

$$
(1-L)^{d}=\sum_{i=0}^{\infty}\left(\begin{array}{l}
d \\
i
\end{array}\right)(-1)^{i} L^{i}
$$

com coeficientes binomiais

$$
\left(\begin{array}{l}
d \\
i
\end{array}\right)=\frac{d !}{i !(d-i) !}=\frac{\Gamma(d+1)}{\Gamma(i+1) \Gamma(d-i+1)},
$$

onde $\Gamma$ é a função Gama.

Os modelos FARIMA(p,d,q) introduzidos independentemente por Granger e Jouyeux (1980) e Hosking (1981) são uma generalização dos processos ARIMA popularizados nos anos 70 por Box e Jenkins (1970).

Além do ajuste do modelo $\operatorname{FARIMA}(\mathrm{p}, \mathrm{d}, \mathrm{q})$ na série de volatilidade realizada (VR definida em 2.7), também foi feito o experimento empírico para a série de volatilidade de Garman-Klass (GK) de (2.8).

\subsection{Modelo GARCH diário com volatilidade intradiária}

A idéia aqui é verificar se os dados intradiários não podem fornecer informação adicional aos dados diários. Para tanto, conforme utilizado por Hol e Koopman (2002), o modelo $\operatorname{GARCH}(1,1)$ é estendido para incluir a volatilidade intradiária $\tilde{\sigma}_{t-1}^{2}$, que é a volatilidade 
realizada de (2.7), incorporando essa informação na equação da variância condicional. A equação (4.5) pode então ser reescrita como:

$$
h_{t}^{2}=a_{0}+a_{1} \varepsilon_{t-1}^{2}+b_{1} \sigma_{t-1}^{2}+\beta \tilde{\sigma}_{t-1}^{2} \text {. }
$$

Note que como $\tilde{\sigma}_{t-1}^{2}$ é sempre positivo, está garantido que a variância condicional é sempre positiva (dadas as restrições usuais).

Será também considerada a estimação de (4.16) com $\tilde{\sigma}_{t-1}^{2}$ sendo a volatilidade por Garman-Klass definida em (2.8), além de (4.16) ser estendida para os modelos EGARCH (4.11), PGARCH (4.12) e TGARCH (4.10).

\subsection{Volatilidade diária utilizando GARCH intradiário}

Essa análise empírica baseia-se na teoria que afirma ser possível obter estimativas dos parâmetros mais eficientes de um processo de baixa freqüência através de intervalo de amostragem de alta freqüência (Bollerslev et al., 1994).

O procedimento adotado é ajustar modelos GARCH em dados intradiários de frequiências de uma hora e de 15 minutos, e com estes realizar previsões de volatilidade nessas frequiências com $\mathrm{k}$ passos à frente até cobrir o período de um dia $(\mathrm{k}=7$ para dados horários e $\mathrm{k}=29$ para dados a cada 15 minutos), agregando-se essas previsões para obter a volatilidade diária

$$
\hat{h}_{T}^{2}(k)=\sum_{p=1}^{k} \hat{h}_{T, p}^{2},
$$

onde:

$\hat{h}_{T}(k)$ é a estimativa da volatilidade para $\mathrm{k}$ períodos, dado a informação até o instante T;

$\hat{h}_{T, p}$ é a estimativa da volatilidade de horizonte $\mathrm{p}$ dado a informação até o instante $\mathrm{T}$, utilizando as expressões de volatilidade condicionais de $(4.5,4.10,4.11$ e 4.12). 
Entretanto, (4.17) só vale para um GARCH puro. No caso de um modelo ARMA(r,s)GARCH(p,q), para se obter a previsão de volatilidade para e k períodos, dada a informação até o instante T, vale a seguinte proposição (Tsay, 2002),

$$
\hat{h}_{T}^{2}(k)=\sum_{p=1}^{k}\left(\sum_{j=0}^{k-p} \psi_{j}\right)^{2} \hat{h}_{T, p}^{2},
$$

onde $\psi_{j}$ são os pesos da representação $M A(\infty)$ do processo $\operatorname{ARMA}(\mathrm{r}, \mathrm{s})$ de (4.6).

No entanto, a priori, não se pode ajustar um modelo GARCH diretamente aos dados originais, pois estes apresentam forte sazonalidade conforme visto no Capítulo 3. Será necessário retirar a sazonalidade, antes de ajustar o modelo $\mathrm{GARCH}$, e para isso foi utilizado o procedimento determinístico (3.3) sugerido por Giot (2000). Segundo o mesmo autor, procedimentos mais complexos não obtiveram ganhos expressivos, portanto será mantido o mais simples possível. No entanto, sem tal procedimento de dessazonalização da série, as previsões dos modelos GARCH produzem péssimas estimativas, que não serão reportadas para manter o texto mais conciso. Também não será utilizado um fator sazonal diferente por dia da semana, pois conforme os gráficos na Figura A.6 não são encontradas diferenças significantivas entre os dias da semana, além do fato de Moreira e Lemgruber (2004) terem encontrado estimativas piores quando utilizaram tal procedimento em dados intradiários.

É importante lembrar que após obter as previsões de volatilidade $h_{t, d}^{*}$ dos modelos GARCH dos retornos dessazonalizados, é necessário re-introduzir a sazonalidade através de

$$
h_{t}=h_{t, d}^{*} \cdot \phi_{d},
$$

onde $\phi_{d}$ é o fator sazonal definido em 3.2 e $h_{t}$ é a volatilidade sazonalizada. Finalmente pode-se calcular a agregação da volatilidade utilizando (4.17) ou (4.18). 


\section{Risco de Mercado}

\subsection{Introdução}

Há vários tipos de riscos envolvidos nas transações financeiras, no entanto será abordado aqui somente um tipo de risco, conhecido como risco de mercado, que é devido a flutuações de preços e/ou taxas de ativos, índices e juros.

Uma das ferramentas largamente utilizadas para a gestão de riscos de mercado é o Valor em Risco, (ou simplesmente VaR de Value at Risk) que é definido como uma medida de variação potencial máxima esperada no valor do portfólio com uma dada probabilidade e um determinado período de tempo (RiskMetrics, 1996). O VaR foi impulsionado pela divulgação pública da metodologia RisMetrics em 1994 e pela facilidade de entendimento, principalmente da alta gerência, já que se resume em um único número uma interpretação prática de risco de mercado de todo as posições de um portfólio de uma instituição. É claro que os modelos de VaR não são perfeitos, necessitando de outras ferramentas para complementá-lo para um bom gerenciamento de risco, como por exemplo o Stress-Test. Para o leitor que desejar ter uma visão mais geral do gerenciamento de Risco, uma sugestão é o livro do Jorion (2001) ou o documento técnico do RiskMetrics (1996) e sua atualização por Mina e Xiao (2001).

Dentre os modelos de VaR, serão analisados dois tipos, o VaR por simulação histórica e o VaR paramétrico, este último com atenção especial. Note que é fechado ainda mais o escopo desse trabalho, especializando-se no cálculo da volatilidade (discutido no tópico anterior), que é uma das principais informações para o cálculo do VaR paramétrico, além das correlações entre os diversos ativos que compõem a carteira. 


\subsection{Valor em Risco (VaR)}

O VaR é uma medida de perda financeira com probabilidade $\alpha$, sobre um horizonte de tempo fixado $k$, sob condições normais de mercado.

O horizonte de tempo é geralmente fixado em um dia, e teoricamente costuma ser considerado como o tempo necessário para liquidar a posição, o que pode não ser verdade para os ativos que não possuírem liquidez. Por outro lado, horizontes longos dificultam a avaliação do modelo (Backtesting) por necessitarem amostras maiores que nem sempre são disponíveis ou por quebra de conjecturas econômicas ou simplesmente pelo fato que a existência do ativo é recente. É importante frisar que o processo de validação do modelo é tão importante quanto o próprio modelo em si, pois um erro de modelagem pode levar uma empresa a assumir riscos acima de sua capacidade o que, em situações adversas, podem provoca perdas que prejudiquem a sua saúde financeira e, em casos extremos, até acarretar a sua falência. Já a escolha do nível de significância depende do grau de aversão ao risco do administrador.

Seja $C(t)$ o valor financeiro de uma carteira no instante $t$, então a variação de valor com horizonte $k$ pode ser definida como

$$
\Delta C(k)=C(t+k)-C(t)
$$

Pode-se definir o VaR com probabilidade $\alpha$ para um horizonte k, dada a informação até o instante $t, \operatorname{VaR}(t, k, \alpha)$, como:

$$
P(\Delta C(k) \leq \operatorname{VaR}(t, k, \alpha))=\alpha,
$$

Por simplificação, considere inicialmente que a carteira seja composta por um único ativo. Utilizando-se da aproximação $R_{t} \approx r_{t}$ visto no Capítulo 2 , pode-se reescrever a equação (5.2) de forma que o VaR seja definido como uma perda relativa a uma unidade monetária. 
Considere também que se tenha uma posição comprada (a perda financeira ocorre com a queda dos preços, ou seja $r_{t}<0$ ), tem-se

$$
P\left(r_{t}(k) \leq \operatorname{VaR}(t, k, \alpha)\right)=\alpha=F(\operatorname{VaR})
$$

$\log 0$

$$
\operatorname{VaR}(t, k, \alpha)=F^{-1}(\alpha)
$$

onde $\operatorname{VaR}(t, k, \alpha)$ é o VaR de uma posição comprada e $F(\cdot)$ a função de distribuição acumulada (f.d.a) de $r_{t}$. Para a posição vendida (a perda financeira ocorre com a alta dos preços, ou seja $r_{t}>0$ ) tem-se:

$$
P\left(r_{t}(k) \geq \operatorname{VaR}(t, k, \alpha)\right)=1-\alpha=F(\operatorname{VaR}),
$$

logo

$$
\operatorname{VaR}(t, k, \alpha)=F^{-1}(1-\alpha)
$$

Por exemplo, freqüentemente, F é suposta como $N\left(\mu_{t}, \sigma_{t}^{2}\right)$, tem-se que

$$
\begin{array}{ll}
\operatorname{VaR}(t, k, \alpha)=\mu_{t}+z_{\alpha} \sigma_{t}, & \text { (para uma posição comprada) } \\
\operatorname{VaR}(t, k, \alpha)=\mu_{t}+z_{1-\alpha} \sigma_{t}, & \text { (para uma posição vendida) }
\end{array}
$$

onde $z_{\alpha}$ é o $\alpha$-percentil da distribuição normal padrão.

Como foi visto no Capítulo 4, uma das distribuições que melhor representa as séries financeiras é a t-Student. Supondo então $F \sim t(v)$, tem-se que 


$$
\begin{aligned}
& \operatorname{VaR}(t, k, \alpha)=\mu_{t}+\frac{t_{\alpha}(v) \sigma_{t}}{\sqrt{v(v-2)}}, \text { (para uma posição comprada) } \\
& \operatorname{VaR}(t, k, \alpha)=\mu_{t}+\frac{t_{1-\alpha}(v) \sigma_{t}}{\sqrt{v(v-2)}}, \text { (para uma posição vendida) }
\end{aligned}
$$

onde $t_{\alpha}(v)$ é o $\alpha$-quantil de da distribuição $t(v)$ (t-Student com $v$ graus de liberdade ).

As equações acima fornecem o VaR conhecido como VaR paramétrico, no entanto, em geral não se conhecem os verdadeiros valores de $\mu$ e $\sigma$ e, portanto, é necessário estimá-los. Uma possibilidade é estimá-los por modelos apresentados no Capítulo 4, o que será discutido no próximo tópico.

\subsection{Estimação do VaR paramétrico}

Para calcular o VaR baseado nos modelos $\operatorname{ARMA}(\mathrm{r}, \mathrm{s})-\mathrm{GARCH}(\mathrm{p}, \mathrm{q})$ apresentados no Capítulo 4, a idéia basicamente é substituir nas expressões (5.5) e (5.6) a previsão de volatilidade de uma das expressões de (4.5), (4.10), (4.11) ou (4.12) e a previsão da média pela equação (4.6).

Se for suposto que $z_{t} \sim D(0,1)$, tem-se então que

$$
r_{t+1} \mid \Omega_{t} \sim D\left(\hat{r}_{t}(1), \hat{h}_{t}^{2}(1)\right)
$$

onde $\hat{r}_{t}(1)$ e $\hat{h}_{t}^{2}(1)$ são as previsões a um passo a frente (um dia) da média e da variância. Aqui, $D(\cdot)$ é a distribuição dos erros, e nesse trabalho, são utilizadas a Normal e a t-Student. 
Se for utilizada a previsão de volatilidade por modelos EWMA dado por (4.13), é assumido que na expressão (5.5) a média é nula, obtendo-se assim a metodologia RiskMetrics de cálculo do VaR para um único ativo.

De forma análoga, no caso dos modelos FARIMA, foi utilizada a previsão da volatilidade realizada e por Garman-Klass como estimativa de $\hat{h}_{t}^{2}(1)$ e, também, foi assumido que a média é zero, já que esse modelo não faz a estimação da média dos retornos.

No modelo apresentado no item 4.6 em que é ajustado um modelo ARMA(r,s)GARCH(p,q) aos retornos intradiários e depois agregam-se as previsões para $\mathrm{k}$ períodos, dada a informação até o instante $\mathrm{T}$, tem-se que a previsão da média do retorno de $\mathrm{k}$ períodos é dada por

$$
\hat{r}_{T}(k)=\sum_{p=1}^{k} \hat{r}_{T, p},
$$

onde $\hat{r}_{T, p}$ é a previsão de horizonte $p$ dada a informação até o instante T, usando a expressão (4.6), enquanto a volatilidade é dada por (4.17) ou (4.18).

Outra possibilidade de estimação de VaR é a não paramétrica, que será apresentada a seguir.

\subsection{VaR não paramétrico}

O VaR não paramétrico, também conhecido como Simulação Histórica (denotado por HS), não assume nenhuma distribuição paramétrica, e sim a distribuição empírica dos retornos históricos de $\Delta C(k)$ em (5.1), sendo o VaR definido como o percentil $\alpha$ dessa distribuição. A premissa assumida é que os retornos são independentes e identicamente distribuídos. 
Dados os retornos $r_{1}, \ldots, r_{T}$, considere as estatísticas de ordem $r_{(1)} \leq r_{(2)} \leq \ldots \leq r_{(T)}$. Um estimador consistente do $\alpha$-quantil da distribuição (desconhecida) dos retornos é dado pelo próprio $\alpha$-quantil empírico definido a seguir (Morettin, 2004):

$$
q_{\alpha}= \begin{cases}r_{(i)}, & \text { se } \alpha=\alpha_{i}, \mathrm{i}=1, \ldots, \mathrm{T} \\ \left(1-f_{i}\right) r_{(i)}+f_{i} r_{(i+1)}, & \text { se } \alpha_{\mathrm{i}}<\alpha<\alpha_{i+1} \\ r_{(1)}, & \text { se } \alpha<\alpha_{1} \\ r_{(T)}, & \text { se } \alpha>\alpha_{T}\end{cases}
$$

onde $\quad \alpha_{i}=(i-0,5) / T$,

$$
f_{i}=\left(\alpha-\alpha_{i}\right) /\left(\alpha_{i+1}-\alpha_{i}\right) \text {. }
$$

Utilizando (5.8) na definição do VaR em (5.2), de forma análoga a (5.3) e (5.4), também é possível calcular o VaR unitário por

$$
\begin{aligned}
& \operatorname{VaR}(t, k, \alpha)=q_{\alpha}, \text { para posições compradas; } \\
& \operatorname{VaR}(t, k, \alpha)=-q_{1-\alpha}, \text { para posições vendidas. }
\end{aligned}
$$

Note que aqui que a distribuição empírica geralmente não é simétrica, como é em (5.5) e (5.6).

Nesse trabalho, o VaR não paramétrico será calculado por (5.9) utilizando uma janela de 250 dias (aproximadamente um ano de dados), que é comumente utilizada na literatura. 


\subsection{Extensões para o VaR Multivariado}

Apesar desse trabalho estudar somente um único ativo (IBVSP), serão comparados de forma breve alguns métodos para o cálculo do VaR para carteiras (ou VaR Multivariado), com o intuito de dar subsídios para o uso prático dos modelos apresentados no Capítulo 4 no cálculo do VaR. Basicamente serão comentados os dois modelos mais empregados nas instituições para cálculo de VaR, que são a Simulação Histórica (HS) e o Riskmetrics, e também metodologias alternativas, como por exemplo a Agregação de Portfólios (PA). Essa última é relativamente pouco divulgada, em relação às duas anteriores, apesar de não haver razões para isso, pois em estudos comparativos apresenta vantagens tanto de performance como de praticidade, o que a torna uma metodologia competitiva.

\subsubsection{Simulação Histórica (HS)}

Esse é o modelo mais simples para o cálculo de VaR de portfólios, bastando apenas se ter disponível uma série de histórica de retornos da carteira de ativos em questão e aplicar diretamente (5.8). Como foi visto na seção anterior, o HS é não paramétrico, já que não é ajustado nenhuma distribuição paramétrica, e sim a distribuição empírica. Isso é uma vantagem considerável em relação a outros métodos, pois permite de maneira simples a característica de caudas pesadas dos retornos financeiros. No entanto, é necessário determinar o tamanho da janela histórica dos retornos para se construir a distribuição empírica e calcular (5.8). A determinação da janela não é um problema trivial, pois para janelas maiores, há um aumento na precisão das estimativas, mas podem conter dados irrelevantes e deixar de detectar mudanças importantes no processo subjacente (Jorion, 2001). Se por outro lado, uma janela muito curta é selecionada, em momentos de mercado com pouca volatilidade pode-se subestimar demasiadamente o risco, o que é algo totalmente indesejável.

Há diversos estudos no sentido de amenizar os problemas do VaR histórico. Uma alternativa simples e de fácil implementação foi proposta por Boudoukh et al. (1998) que 
consiste em atribuir pesos decrescentes com o tempo para cada observação, de forma a aumentar a probabilidade dos eventos mais recentes em relação às observações mais antigas. Essa abordagem pode, por exemplo, resolver os conhecidos "saltos" do modelo básico do VaR histórico, onde o $\mathrm{VaR}$ pode sofrer grandes mudanças só pelo fato de ser retirada uma única observação antiga da janela de cálculo, já que são atribuídas probabilidades iguais para todos os elementos. Estudos empíricos dos autores indicam que o método possui resultados melhores que o modelo básico HS e do RiskMetrics, principalmente em casos de séries com caudas pesadas.

Hull e White (1998) propuseram um modelo mais sofisticado para cálculo do VaR, em relação ao anterior, que utiliza em conjunto os modelos GARCH ou EWMA para o calculo da volatilidade atual para ajustar a volatilidade histórica. Para o cálculo do VaR de uma carteira no final do dia N-1 (isto é, para o dia N), considere uma carteira composta por um determinado número de variáveis de mercado, sendo que a cada uma delas é aplicada a metodologia abaixo.

\section{Defina:}

$h_{t, j}$ : variação percentual histórica da variável $\mathrm{j}$ no dia t do período coberto pela amostra histórica $(\mathrm{t}<\mathrm{N})$;

$\sigma_{t, j}^{2}$ : estimativa histórica GARCH/EWMA da variância diária da variação percentual da variável $\mathrm{j}$ feita para o dia $\mathrm{t}$, no final do dia $\mathrm{t}-1$.

No final do dia N-1, é realizada a estimativa GARCH/EWMA mais recente da variância diária da variável $\mathrm{j}$ para o dia $\mathrm{N}\left(\sigma_{N, j}^{2}\right)$. Assume-se que a distribuição de probabilidade de $h_{t, j} / \sigma_{t, j}$ seja estacionária. Conseqüentemente, substitui-se cada $h_{t, j}$ por $h_{t, j}^{*}$ onde

$$
h_{t, j}^{*}=\sigma_{N, j} \frac{h_{t, j}}{\sigma_{t, j}},
$$

e é estabelecida a t-ésima variação amostral da variável j por $h_{t, j}^{*}$ ao invés de $h_{t, j}$.

Os autores analisaram nove anos de dados diários de doze taxas de câmbio e cinco índices de ações, obtendo resultados substancialmente melhores se comparados com o modelo 
básico de VaR histórico, e também em relação ao modelo de Boudoukh et al. (1998) descrito anteriormente.

\subsubsection{Modelo RiskMetrics}

Uma referência para o cálculo do VaR em carteiras é o RiskMetrics (1996), que utiliza um modelo EWMA com um único parâmetro para estimar a matriz de covariâncias. Jorion (2001) alerta que em geral a matriz de covariância calculada pela metodologia do RiskMetrics geralmente não é positiva definida, pois é necessário ter um número de observações pelo menos igual ao número de ativos para garantir que a matriz de covariância seja positiva definida. Isso ocorre em especial porque o número de observações efetivas é muito menor, devido ao rápido decaimento dos pesos. Em termos práticos, 99,9\% da informação está contida nos últimos $\log (0.001) / \log (\lambda)$ dias (Mina e Xiao, 2001). Por exemplo, se é utilizado $\lambda=0.94$ (o sugerido pelo RiskMetrics para o VaR diário), então $99.9 \%$ da informação está contido nos últimos 112 dias, já para $\lambda=0.97$ tem-se 227 dias.

O leitor pode vir a sugerir que cada elemento da matriz de correlação seja estimada de forma independente por um modelo EWMA com um parâmetro cada, por exemplo. Contudo tal procedimento não garante que a matriz de correlação seja positiva semi-definida, ou seja, pode gerar diversas distorções nas previsões, como por exemplo obter uma volatilidade negativa para o portfólio. Esse é o motivo pelo qual a metodologia Riskmetrics utiliza apenas um único valor de $\lambda$ para todas as séries, sendo adotado o valor de 0.94 para horizonte diário (para mais detalhes veja RiskMetrics, 1996). 


\subsubsection{Agregação de Portfólios (PA)}

É comum encontrar na bibliografia sobre risco a citação de modelos GARCH como uma possibilidade para o cálculo de volatilidade, mas dificilmente encontra-se detalhes sobre esses modelos e muito menos a metodologia para o cálculo do VaR de carteiras, quando muito exemplos com alguns poucos ativos, o que não acontece na prática, já que as instituições financeiras possuem em geral uma quantidade muito grande de ativos.

De fato, a abordagem baseada em modelos tipo GARCH possui a desvantagem de ser difícil quando envolve muitos ativos, pois seria necessário ajustar um modelo heterocesdástico condicional multivariado, que é uma tarefa complicada e muitas vezes impossível, pois a quantidade de parâmetros a serem estimados aumenta rapidamente com o número de séries, tornando o processo inviável.

Para ilustrar, tomando o GARCH multivariado mais genérico para uma carteira com cem ativos distintos, já é preciso estimar mais de 51 milhões de parâmetros (ordem de $O\left(N^{4}\right)$ ). Conseqüentemente, pesquisas se concentram em achar restrições plausíveis sobre a matriz de covariâncias que reduzam o número total de parâmetros a serem estimados, de tal forma que a matriz seja positiva semi-definida. Como exemplo dessas simplificações, pode-se citar o modelo DVEC de Bollerslev, Engle e Wooldridge (1988) e o modelo BEKK de Engle e Kroner (1995).

Mesmo assim os modelos acima apresentam um grande número de parâmetros para estimação, algo em torno da ordem de $O\left(N^{2}\right)$. Outro método de modelagem GARCH multivariada consiste em transformar a série temporal multivariada em séries temporais não correlacionadas, e para cada uma dessas séries aplica-se o GARCH univariado (um exemplo, entre outros, é o modelo DCC (Dynamic Conditional Correlation) de Engle, 2002). Essa nova classe de modelos possui a vantagem de permitir a implementação para muitas séries, no entanto tal simplificação pode ser muito restritiva, o que impulsiona pesquisas para permitir especificações mais genéricas na dinâmica das correlações.

Uma solução alternativa muito mais simples e sem o grande esforço computacional e os problemas de estimação dos modelos multivariados GARCH (impactando tanto na confiabilidade como no tempo de resposta, que na prática são variáveis importantes, se não 
decisivas na escolha do modelo de risco) foi proposta inicialmente por Zangari (1997), que a nomeou por Agregação de Portfólios (será denotado por PA). Consiste no cálculo da volatilidade diretamente nos retornos históricos da carteira, com processo semelhante ao que é feito para o cálculo do VaR pelo método HS, só que ao invés de serem calculados os percentis da distribuição empírica dos retornos da carteira, é ajustado algum modelo heterocedástico univariado, já que o retorno da carteira é a média ponderada dos retornos individuais de cada ativo da carteira, tornando o problema univariado. Em outras palavras, o retorno da carteira contém teoricamente toda a informação relevante dos retornos individuais.

Ao mesmo tempo, também são resolvidas algumas deficiências do VaR por HS, como a demora em capturar mudanças do padrão da volatilidade (veja Figura 7.2 e comentário no Capítulo 7), dificuldade em estimar percentis muito pequenos, dificuldade ou total inviabilidade (necessidade de um grande histórico de dados) para previsão de VaR para horizontes maiores que um dia, etc. Para ilustrar, se por exemplo for utilizada uma janela anual (250 dias úteis) e se ocorrerem três eventos extremos negativos numa semana, a estimação do VaR a $1 \%$, pode ser superestimada e manter-se constante por quase um ano a frente.

Zangari aponta também para a superioridade ao modelo multivariado do RiskMetrics (1996). Por exemplo, o cálculo da matriz de covariância é sensível a precisão numérica e a ocorrência de valores discrepantes, interferindo significantemente no resultado do cálculo do VaR. Contudo o retorno da carteira é mais suavizado, devido a ponderação dos retornos individuais. Além disso, não necessita, a princípio, de aproximações para o cálculo do risco de instrumentos não-lineares. Por transformar o problema multivariado em univariado, oferece maior liberdade e facilidade de modelagem, permitindo o uso de modelos mais sofisticados, inclusive adaptar aos modelos de volatilidade apresentados nesse texto que consideram a informação intradiária.

Berkowitz e O'Brien (2002) estimaram um modelo simples ARMA+GARCH para os valores de $\mathrm{P} \& \mathrm{~L}$ diários de cinco grandes instituições financeiras, obtendo resultados superiores ao próprio VaR publicado pela metodologia dessas instituições. Apesar desse estudo poder ter sido prejudicado pelo fato dos autores não dispunham do clean $P \& L$ para calcular o VaR, isto é, não foram retirados taxas, impostos e receitas financeiras que não são sujeitas as variações de mercado. No entanto, também foi observado que em períodos de crise, os modelos dessas 
instituições apresentam respostas lentas, tendo falhas em série, o que é uma constatação mais séria de problemas nos modelos de risco dessas instituições.

Brooks e Persand (2003) estudaram o histórico de mais de 18 anos de dados diários de uma carteira composta por três ativos (long Govt Bond, FTSE All Share e Reuters Commodities) e uma das conclusões empíricas dos autores é que modelagem da volatilidade do portfolio pelo método PA é uma solução muito mais prática e com resultados mais acurados do que os obtidos por modelo GARCH multivariado.

Pelo exposto acima, verifica-se a facilidade e bom desempenho da metodologia de agregação de portfólios (PA) para o cálculo da medida de risco VaR. No entanto, para o gerenciamento de risco, há situações em que é necessário a matriz de covariâncias do portfólio de ativos, como por exemplo análises de risco e retorno de Markowitz (1952), entre outros, e portanto nesses casos há a necessidade dos uso de modelos multivariados, como os da família GARCH. 


\section{Back-Testing}

Neste capítulo apresentaremos o procedimento de avaliação do desempenho dos modelos na previsão da volatilidade, bem como dos intervalos de confiança, relacionados com a medida de risco VaR.

Para avaliar os modelos baseados em dados diários, foram realizados exercícios de previsão um-passo-à-frente (um dia) fora da amostra, simulando o que acontece em geral na prática num sistema de cálculo de risco, mantendo uma janela móvel com tamanho fixo da amostra de estimação (838 dias). Em outras palavras, inicialmente estima-se o modelo sem as últimas 471 observações e, então, é realizada a previsão da volatilidade do dia seguinte (observação 839), descarta-se a observação inicial e incorpora-se a primeira observação do conjunto das 471 observações reservadas, reestima-se o modelo e obtém-se a previsão do dia seguinte, repetindo este procedimento por 471 vezes. Embora mais trabalhoso (são feitas 471 estimações para cada modelo), esse procedimento possui as seguintes qualidades: manutenção do tamanho da amostra constante e atualização constante das estimativas dos parâmetros. $\mathrm{O}$ fato de utilizar uma janela móvel de estimação se baseia na premissa que o tamanho da amostra é suficiente (838 dias ou 3,3 anos) para estimação, e também não são incorporados dados muito antigos que não são mais relevantes no contexto de um mercado financeiro em evolução (Brooks e Persand, 2003).

Apesar de ser usual o exercício de previsão dentro da amostra, utilizando todo o conjunto de observações disponível para estimação e previsão, este não será feito nesse trabalho, pois não há nenhuma garantia que um modelo com bom ajuste dentro da amostra, mantenha a performance para a previsão fora da amostra.

Um procedimento análogo aos dos dados diários acima foi aplicado aos dados intradiários. Também foi considerada a mesma janela móvel de 838 dias, só que contendo os 
respectivos dados intradiários (24302 para dados de quarto de hora e 5866 para dados horários), e a cada um dos passos a janela movia $k$ dados intradiários, de forma que sempre é feita a previsão de $k$ passos à frente $(k=7$ ou $k=29)$ no último período de cada dia, cobrindo sempre o dia seguinte inteiro, e assim são obtidas previsões comparáveis às geradas pelos modelos baseados em dados diários. Ou seja, são realizados o mesmo número de estimações por modelo (471) que o procedimento utilizando dados diários, pois foram descartadas todas as previsões que em $k$ passos fossem compostas por frações de dois dias.

\subsection{Avaliação das estimativas de volatilidade}

A avaliação da acurácia preditiva dos modelos de volatilidade é geralmente baseada em funções de perda, as quais comparam os valores previstos de volatilidade $h_{t}^{2}$ com os retornos ao quadrado $r_{t}^{2}$, sendo esse último assumido ser estimativa da "verdadeira" volatilidade ocorrida em t. No entanto, como já foi mencionado no item 2.4, segundo Andersen e Bollerslev (1998), a volatilidade realizada é uma melhor estimativa da volatilidade, e o uso de retornos ao quadrado distorce a avaliação dos modelos de previsão de volatilidade. Os autores argumentam que esse é o motivo pelo qual é encontrado para os modelos GARCH um desempenho relativamente fraco na previsão da volatilidade, apesar desses capturarem os fatos estilizados das séries financeiras, como por exemplo, agrupamentos de volatilidade. Portanto serão utilizadas as definições de volatilidade realizada (2.7), como a estimativa da volatilidade latente.

Serão utilizadas cinco medidas: erro médio (ME), proporção de subestimações (UP), erro absoluto médio (MAE), raiz quadrada do erro quadrático médio (RMSE) e erro absoluto médio ponderado (WMAE). As expressões dessas medidas, para a previsão fora da amostra um-passoà-frente, são as seguintes:

$$
M E=\frac{1}{T} \sum_{t=1}^{T}\left(\hat{h}_{t}^{2}-\sigma_{t}^{2}\right),
$$




$$
\begin{gathered}
U P=\frac{1}{T} \sum_{t=1}^{T} \mathrm{I}_{t}, \text { onde } I_{t}=\left\{\begin{array}{l}
1, \text { se } \hat{\mathrm{h}}_{\mathrm{t}}^{2}< \\
0, \text { c.c. }
\end{array}\right. \\
M A E=\frac{1}{T} \sum_{t=1}^{T}\left|\hat{h}_{t}^{2}-\sigma_{t}^{2}\right|, \\
R M S E=\sqrt{\frac{1}{T} \sum_{t=1}^{T}\left(\hat{h}_{t}^{2}-\sigma_{t}^{2}\right)^{2},} \\
W M A E=\frac{1}{W} \sum_{t=1}^{T}\left|\hat{h}_{t}^{2}-\sigma_{t}^{2}\right| \cdot w_{t},
\end{gathered}
$$

onde:

$$
W=\sum_{t=1}^{T} w_{t} \text { e } \mathrm{w}_{\mathrm{t}}=\left\{\begin{array}{l}
1, \text { se }\left|\hat{\mathrm{h}}_{\mathrm{t}}^{2}-\sigma_{\mathrm{t}}^{2}\right| \leq 2 \\
5, \text { se } 2<\left|\hat{\mathrm{h}}_{\mathrm{t}}^{2}-\sigma_{\mathrm{t}}^{2}\right| \leq 4 \\
10, \text { c.c. }
\end{array}\right.
$$

As duas primeiras medidas ME e UP dão uma indicação da direção do erro da previsão, já que as demais dão somente uma medida de variabilidade e não de nível. O RMSE é uma função que penaliza de forma mais severa grandes erros na previsão em relação ao MAE. Já o WMAE é uma tentativa de capturar de forma simplificada uma função utilidade que aumenta a penalidade na medida que o erro aumenta, já que erros maiores possuem impactos desproporcionais em relação a sua magnitude para o investidor. Porém o WMAE possui um grau de subjetividade, que são as definições dos intervalos e dos pesos associados, mas mesmo assim, essa medida será muito útil para complementar a informação das demais. 


\subsection{Avaliação do VaR}

Além da avaliação da previsão das volatilidades acima, serão avaliados os intervalos de confiança com coeficiente de confiança $(1-2 \alpha) \%$, de $90 \%, 95 \%$ e $98 \%$ para a previsão fora da amostra, com o intuito de avaliar a freqüência dos retornos que caem fora do intervalo, utilizando a média e a variância condicionais estimadas. Quanto mais próxima de $2 \alpha \%$ (no caso bicaudal) for a proporção de retornos observados fora do intervalo de confiança, maior a aderência da previsão ao intervalo. No entanto, serão analisados independentemente a cauda inferior e superior, para evitar casos em que a subestimação de uma cauda seja compensada pela superestimação da outra, mascarando o desempenho para fins de VaR. Dessa maneira também é possível avaliar os modelos em relação à captura do efeito de assimetria dos retornos discutidos anteriormente.

Apesar do esforço para se ter um bom tamanho de amostra para uma boa avaliação dos modelos, no caso de avaliação dos intervalos de confiança, a amostra é relativamente pequena para o uso de técnicas sofisticadas, então optou-se por utilizar técnicas mais simples, como a análise descritiva de proporção de falhas e o teste de Kupiec.

Kupiec (1995) sugere dois testes para verificar a acurácia dos modelos de risco (VaR), o do tempo até a primeira falha e o da proporção de falhas. O primeiro teste se apóia na idéia de que quanto mais cedo ocorrer a primeira falha, mais alta é a verdadeira probabilidade de falha. Este teste é aplicado cada vez que ocorre um retorno fora do intervalo estimado pelo VaR. No entanto, o teste do tempo até a primeira falha tem um baixo poder, ou seja, a probabilidade de aceitação da hipótese nula é muito grande, tornando-o pouco útil para avaliar a precisão de sistemas de riscos, pois é preciso uma grande discrepância entre a probabilidade esperada e a observada para que ocorra uma rejeição do modelo. Outro problema, apontado pelo autor, é que este tipo de teste ignora a informação sobre o número total de falhas. $\mathrm{O}$ autor sugere que seja feito o teste de proporção de falhas para complementar o anterior. Contudo, pelos problemas mencionados anteriormente, e adicionado o fato de que na literatura somente o teste de proporção de falhas foi consagrado, não será utilizado o teste até a primeira falha. 
A probabilidade de serem observados $x$ falhas, não levando em consideração a ordem da ocorrência das falhas numa dada amostra de tamanho $n$, é dado pela distribuição binomial abaixo:

$$
\left(\begin{array}{l}
n \\
x
\end{array}\right)(1-p)^{n-x} p^{x},
$$

onde $p$ é a probabilidade de falha, supondo eventos independentes.

Kupiec (1995) sugere um teste de razão de verossimilhanças para testar a hipótese nula $p=p^{*}$, que é uniformemente mais poderoso para um dado tamanho de amostra. A estatística do teste da razão de verossimilhanças é dada por

$$
\left.R V=-2 \log \mid\left(1-p^{*}\right)^{n-x}\left(p^{*}\right)^{x}\right]+2 \log \left[(1-x / n)^{n-x}(x / n)^{x}\right]
$$

Sob a hipótese nula, RV tem distribuição qui-quadrado com 1 grau de liberdade. O problema deste teste, como apontado por Kupiec, é seu baixo poder para amostras pequenas, ou seja, este teste tem uma alta probabilidade de aceitar a hipótese nula quando ela é falsa em amostras com número de observações limitado. 


\section{Resultados Empíricos}

\subsection{Ajuste dos Modelos}

Como foi explicado no Capítulo 6, todos os modelos foram reestimados com uma janela móvel por 471 vezes, no entanto serão apresentados aqui o ajuste dos modelos somente na amostra base.

Inicialmente verificou-se no Capítulo 3 a presença de autocorrelação nos retornos, e portanto, conforme apontado no Capítulo 4, é necessário retirar essa autocorrelação antes do ajuste dos modelos da família GARCH. Assim a equação (4.6) é dado por modelos AR, de ordem 4 para os dados diários, ordem 5 para os dados horários e de ordem 2 para o de 15 minutos (os parâmetros são disponibilizados na Tabela A.1).

Da mesma forma que os modelos GARCH, o AR foi reestimado 471 vezes por janela móvel e foi feita a previsão dos retornos para o cálculo do VaR definido em (5.5) e (5.6). No entanto, além dessas previsões apresentarem valores próximos de zero, para a série em estudo (IBVSP), verifica-se que tais previsões não fornecem informação adicional. Fazendo uma análise rápida, verifica-se que o percentual de acertos do sinal dos retornos previstos (tanto para as séries diárias como intradiárias por (5.7)) é de 50\%. Isto é, a chance do modelo AR acertar se haverá uma alta ou baixa no IBVSP é a mesma a de jogar uma moeda. Portanto assume-se média zero nas equações do $\mathrm{VaR}$, o que é uma prática comum. Todavia esses ajustes AR continuarão sendo usados para retirar a autocorrelação dos retornos como em (4.6) e para calcular a agregação de previsões de volatilidade de (4.18).

Em geral, pode-se observar pela Tabela A.9 que a autocorrelação dos resíduos foi retirada. Considerando um nível descritivo de $1 \%$, rejeita-se a hipótese de ruído branco apenas para o ajuste dos modelos para os dados de 15 minutos. Tal resultado pode ser explicado pelo 
grande tamanho de amostra (mais de 24 mil observações), que pode tornar o teste significativo mesmo para pequenas autocorrelações. Mesmo aumentando o grau do AR, o teste é rejeitado, o que fez com que fosse mantido a ordem 2 do AR, baseado na observação da autocorrelação parcial (ver Figura A.7), onde é verificado somente que as duas primeiras autocorrelações se destacam das demais.

Antes de estimar um modelo ARCH completo para uma série temporal, é geralmente recomendado testar a presença de efeitos $\mathrm{ARCH}$ (Engle, 1982) nos resíduos. Se não há efeitos $\mathrm{ARCH}$, então o modelo $\mathrm{ARCH}$ é desnecessário. Mas como é verificado na Tabela A.8, o efeito $\mathrm{ARCH}$ é significativo para as séries analisadas, o que já era esperado pela análise dos correlogramas (ver Figura A.9) no Capítulo 3.

Após o ajuste dos modelos GARCH, verifica-se que não há evidências de que os resíduos possuem efeitos ARCH (ver Tabela A.9), o que é uma indicação que a ordem dos modelos GARCH está adequada. Para os dados diários, o $\operatorname{GARCH}(1,1)$ foi suficiente, mas para os dados intradiários, verificou-se que após o ajuste ordem $(1,1)$ ainda havia presença de autocorrelação no quadrado dos retornos, sendo necessário aumentar a ordem para $(1,2)$ para não haver autocorrelações remanescentes, e assim melhor capturar a dinâmica da série.

Observando as Tabelas A.2, A.3, A.4 e A.5, verifica-se que o coeficiente do efeito de assimetria é significante, pode-se então supor que o IBVSP possui a característica de efeitos assimétricos, segundo o teste $\mathrm{t}$, calculado apartir de erros padrões baseados no método de quase máxima verossimilhança (QMLE), que é referido como um estimador robusto (veja Zivot e Wang, 2003).

Nas séries de volatilidade VR e de GK, observa-se que as autocorrelações decaem de forma lenta (ver Figura A.8) o que é um indício de memória longa. Este fato é confirmado quando são ajustados os modelos FARIMA de (4.14), pois são encontrados estimativas de $d$ entre 0 e 0,5 (ver Tabelas A.6 e A.7) o que implica que as séries são estacionárias e possuem memória longa. Foram estimados os modelos FARIMA $(0, \mathrm{~d}, 0)$ (conhecido como ruído branco 
fracionário), FARIMA(1,d,0), FARIMA(0,d,1) e FARIMA(1,d,1), sendo que este último não foi possível ser ajustado para a série GK devido a problemas de estimação encontrados no S-Plus.

\subsection{Resultados}

Segue uma análise descritiva dos resultados finais, divididos por avaliação de volatilidade (baseados na Tabela 7.1) e de VaR (baseados na Tabela 7.2 e Figuras 7.1 a 7.6).

\subsubsection{Resultados da avaliação da previsão da volatilidade}

Dentre os modelos gaussianos tradicionais baseados em dados diários, não foram encontradas grandes diferenças entre eles, com exceção do modelo RiskMetrics que apareceu como o pior segundo todos os critérios de variabilidade analisados (a não ser o MAE, onde teve resultados levemente superiores ao do TGARCH e GARCH). Os modelos com efeito assimétrico não mostraram serem em geral superiores ao modelo básico GARCH.

Quando são comparados os resultados de RMSE e WMAE dos modelos com distribuição t-Student sempre se obtém resultados ligeiramente melhores em relação aos modelos tradicionais gaussianos, mas é encontrado um efeito oposto para a medida MAE (exceto o TGARCH). Uma explicação plausível é que os modelos com distribuição t-Student são melhores em situações de maior volatilidade, fato que não se repete em situação de baixa volatilidade.

Verifica-se que a adição da informação intradiária por meio de covariável (VR ou GK), produz resultados significantemente superiores ao modelo tradicional de dados diários, exceto os modelos GARCH e o TGARCH, que pioraram com adição da covariável. Note que esses modelos possuem basicamente a mesma equação de volatilidade condicional (ver Capítulo 4), enquanto os demais possuem estruturas diferenciadas. 
Os piores modelos foram os GARCH ajustados em dados intradiários com previsões agrupadas para período diário, denotado Sih-XGARCH para a base horária e Sim-XGARCH para a de 15 minutos. Claramente esses modelos estão superestimando as previsões, já que possuem os mais altos valores de ME, os menores índices de subestimação de volatilidade (UP), que também se reflete a valores em torno do dobro que o melhor modelo para o MAE, reduzindo para 50\% no RMSE e $40 \%$ para o WMAE. No entanto, foi feito um teste rústico sem grandes pretensões, que consiste em desconsiderar o efeito ARMA na agregação de volatilidades de (4.18), considerando somente a equação (4.17), e com isso foi verificado que as previsões melhoram significantemente, portanto tais modelos não devem ser descartados para a previsão de volatilidade, merecendo uma atenção especial no futuro.

Já os modelos FARIMA apresentaram resultados totalmente diferenciados em relação aos modelos GARCH. Numa primeira observação, o desempenho foi surpreendente para o critério MAE, chegando a quase $50 \%$ melhor que o RiskMetrics. No entanto, há sinais claros de subestimação em períodos de alta volatilidade. Com relação ao critério RMSE já não apresentam resultados gritantes, mas ainda assim muito bons, bem próximos do melhor modelo.

Para o WMAE, os resultados são em torno de $10 \%$ pior que o melhor modelo. Mais grave é a constatação de erro médio (ME) negativo (são os únicos) e níveis de $47 \%$ de UP (para VR, sendo que o GK é mais de $60 \%$, exceto o FARIMA(0,d,0) que é de $24 \%$ ), muito acima dos $20 \%$ (em torno de) dos demais. Pode-se concluir que os modelos FARIMA, quando comparados aos demais modelos, apresentam excelentes resultados em períodos de baixa volatilidade, no entanto em períodos de alta, tendem a subestimar acentuadamente a volatilidade. Essa subestimação de volatilidade é totalmente indesejada para fins de análise de risco.

Curiosamente dentre os modelos da classe FARIMA, não são encontrados diferenças significativas (em menor grau para GK) entre o ruído fracionário e os com termos AR ou MA. Mas com ambos os termos (FARIMA(1,d,1)-VR) foi o pior modelo de todos com erros extremamente altos de previsão, que provavelmente foi devido a problemas na estimação (veja Figura 7.6). O que colabora com essa hipótese é o fato que para a variável GK, foram encontrados problemas no S-Plus que impossibilitaram o ajuste do $\operatorname{FARIMA}(1, \mathrm{~d}, 1)$. 
Baseado nos comentários acima e na Tabela 7.1, conclui-se que o melhor modelo geral é o "PGARCH(1,1) t +VR" segundo os critérios ME, RMSE e WMAE. Para termos comparativos, o modelo Riskmetrics possui erros de previsão médios mais altos de 14,0\%(MAE), $12.7 \%$ (RMSE) e $10.6 \%$ (WMAE) do que o modelo eleito.

De uma forma geral, os modelos GARCH com covariável VR possuem resultados relativamente melhores que a GK, o mesmo acontece para os modelos FARIMA, o que parece refletir a teoria em que a volatilidade realizada possui melhor informação que por Garman-Klass. No entanto, tais diferenças não são grandes, o melhor modelo baseado em GK, que é o"PGARCH(1,1)+GK" possui valores de MAE, RMSE e WMAE em média apenas $2 \%$ maiores em relação ao melhor modelo, que é o "PGARCH(1,1)t +VR". Tal fato traz grandes consequiências práticas, pois como já foi dito, o histórico de dados para se calcular a volatilidade por Garman-Klass é muito mais fácil de ser obtido do que o para volatilidade realizada, sobretudo para séries financeiras brasileiras, o que aumenta em muito as possibilidades de uso prático desses modelos. 
Tabela 7.1 Avaliação da previsão da volatilidade

\begin{tabular}{|c|c|c|c|c|c|c|c|c|c|c|c|c|c|c|c|}
\hline \multirow[t]{2}{*}{ Modelo } & \multirow[t]{2}{*}{ Var. } & \multirow[t]{2}{*}{ Cov. } & \multicolumn{2}{|c|}{ ME } & \multicolumn{2}{|c|}{ UP } & \multicolumn{3}{|c|}{ MAE } & \multicolumn{3}{|c|}{ RMSE } & \multicolumn{3}{|c|}{ WMAE } \\
\hline & & & $M$ & R & M & R & $M$ & $\mathbf{R}$ & D & M & $\mathbf{R}$ & D & M & $\mathbf{R}$ & D \\
\hline RiskMetrics & 1d & & 1.12 & 9 & $20.2 \%$ & 35 & 1.90 & 21 & $49.5 \%$ & 2.55 & 24 & $12.7 \%$ & 3.25 & 23 & $10.6 \%$ \\
\hline GARCH $(1,1)$ & 1d & & 1.32 & 25 & $14.4 \%$ & 9 & 1.98 & 30 & $55.7 \%$ & 2.47 & 17 & $9.1 \%$ & 3.08 & 7 & $4.7 \%$ \\
\hline $\operatorname{EGARCH}(1,1)$ & 1d & & 1.17 & 12 & $19.7 \%$ & 31 & 1.89 & 18 & $48.5 \%$ & 2.47 & 17 & $8.9 \%$ & 3.17 & 15 & $7.8 \%$ \\
\hline PGARCH $(1,1)$ & 1d & & 1.23 & 19 & $18.0 \%$ & 16 & 1.88 & 16 & $47.9 \%$ & 2.52 & 22 & $11.1 \%$ & 3.22 & 20 & $9.5 \%$ \\
\hline $\operatorname{TGARCH}(1,1)$ & 1d & & 1.25 & 22 & $18.3 \%$ & 17 & 1.91 & 23 & $49.8 \%$ & 2.51 & 21 & $11.0 \%$ & 3.18 & 16 & $8.2 \%$ \\
\hline GARCH $(1,1) t$ & 1d & & 1.30 & 24 & $14.4 \%$ & 9 & 1.97 & 28 & $55.3 \%$ & 2.45 & 14 & $8.3 \%$ & 3.02 & 5 & $2.6 \%$ \\
\hline EGARCH $(1,1) t$ & 1d & & 1.20 & 16 & $18.9 \%$ & 20 & 1.91 & 23 & $49.9 \%$ & 2.46 & 16 & $8.4 \%$ & 3.15 & 13 & $6.9 \%$ \\
\hline PGARCH $(1,1) t$ & 1d & & 1.32 & 25 & $17.0 \%$ & 12 & 1.94 & 27 & $52.8 \%$ & 2.48 & 19 & $9.6 \%$ & 3.12 & 11 & $5.9 \%$ \\
\hline TGARCH $(1,1) t$ & 1d & & 1.18 & 13 & $19.5 \%$ & 28 & 1.85 & 15 & $45.5 \%$ & 2.45 & 14 & $8.2 \%$ & 3.18 & 16 & $7.9 \%$ \\
\hline GARCH $(1,1)$ & 1d & VR & 1.25 & 22 & $17.0 \%$ & 12 & 1.99 & 31 & $56.2 \%$ & 2.63 & 28 & $16.1 \%$ & 3.29 & 26 & $11.7 \%$ \\
\hline $\operatorname{EGARCH}(1,1)$ & $1 d$ & VR & 1.03 & 6 & $21.4 \%$ & 39 & 1.80 & 11 & $41.3 \%$ & 2.36 & 8 & $4.2 \%$ & 2.98 & 3 & $1.2 \%$ \\
\hline PGARCH $(1,1)$ & 1d & VR & 0.97 & 2 & $19.1 \%$ & 23 & 1.76 & 8 & $38.1 \%$ & 2.32 & 6 & $2.6 \%$ & 2.95 & 2 & $0.4 \%$ \\
\hline $\operatorname{TGARCH}(1,1)$ & $1 d$ & VR & 1.16 & 11 & $19.1 \%$ & 23 & 1.90 & 21 & $49.3 \%$ & 2.52 & 22 & $11.4 \%$ & 3.18 & 16 & $8.1 \%$ \\
\hline GARCH $(1,1) t$ & $1 d$ & VR & 1.23 & 19 & $17.0 \%$ & 12 & 1.97 & 28 & $55.1 \%$ & 2.59 & 26 & $14.5 \%$ & 3.25 & 23 & $10.6 \%$ \\
\hline $\operatorname{EGARCH}(1,1) t$ & 1d & VR & 1.11 & 8 & $19.3 \%$ & 25 & 1.84 & 14 & $44.8 \%$ & 2.40 & 12 & $5.9 \%$ & 3.03 & 6 & $2.8 \%$ \\
\hline PGARCH $(1,1) t$ & 1d & VR & 0.90 & 1 & $21.0 \%$ & 37 & 1.72 & 6 & $35.5 \%$ & 2.27 & 1 & - & 2.94 & 1 & - \\
\hline $\operatorname{TGARCH}(1,1)\}$ & 1d & VR & 1.18 & 13 & $18.5 \%$ & 19 & 1.92 & 26 & $51.2 \%$ & 2.55 & 24 & $12.7 \%$ & 3.18 & 16 & $8.2 \%$ \\
\hline GARCH $(1,1)$ & 1d & GK & 1.22 & 17 & $16.8 \%$ & 11 & 1.89 & 18 & $48.6 \%$ & 2.63 & 28 & $16.1 \%$ & 3.32 & 28 & $12.7 \%$ \\
\hline $\operatorname{EGARCH}(1,1)$ & $1 d$ & GK & 1.10 & 7 & $19.5 \%$ & 28 & 1.79 & 10 & $40.9 \%$ & 2.40 & 12 & $6.0 \%$ & 3.09 & 8 & $4.9 \%$ \\
\hline PGARCH $(1,1)$ & 1d & GK & 1.00 & 4 & $18.3 \%$ & 17 & 1.76 & 8 & $38.3 \%$ & 2.31 & 5 & $2.2 \%$ & 3.01 & 4 & $2.4 \%$ \\
\hline $\operatorname{TGARCH}(1,1)$ & 1d & GK & 1.22 & 17 & $19.3 \%$ & 25 & 1.91 & 23 & $49.9 \%$ & 2.74 & 31 & $20.8 \%$ & 3.40 & 30 & $15.5 \%$ \\
\hline GARCH(1,1)t & 1d & GK & 1.23 & 19 & $17.8 \%$ & 15 & 1.89 & 18 & $49.0 \%$ & 2.59 & 26 & $14.3 \%$ & 3.30 & 27 & $12.2 \%$ \\
\hline EGARCH $(1,1) \mathrm{t}$ & 1d & GK & 1.13 & 10 & $20.0 \%$ & 33 & 1.82 & 13 & $43.5 \%$ & 2.39 & 11 & $5.7 \%$ & 3.10 & 9 & $5.4 \%$ \\
\hline PGARCH $(1,1) t$ & 1d & GK & 1.02 & 5 & $19.3 \%$ & 25 & 1.75 & 7 & $37.5 \%$ & 2.35 & 7 & $3.8 \%$ & 3.10 & 9 & $5.2 \%$ \\
\hline TGARCH $(1,1) t$ & $1 d$ & GK & 1.19 & 15 & $19.7 \%$ & 31 & 1.88 & 16 & $47.8 \%$ & 2.65 & 30 & $16.8 \%$ & 3.36 & 29 & $14.2 \%$ \\
\hline FARIMA $(1,1)$ & VR & & 6.13 & 35 & $48.6 \%$ & 44 & 8.34 & 40 & $556.1 \%$ & 35.94 & 40 & $1486.6 \%$ & 18.69 & 40 & $535.3 \%$ \\
\hline FARIMA $(1,0)$ & VR & & $(0.42)$ & 37 & $47.1 \%$ & 43 & 1.27 & 1 & $0.2 \%$ & 2.28 & 3 & $0.5 \%$ & 3.15 & 13 & $7.2 \%$ \\
\hline FARIMA $(0,1)$ & VR & & $(0.45)$ & 38 & $46.9 \%$ & 42 & 1.28 & 3 & $0.5 \%$ & 2.30 & 4 & $1.4 \%$ & 3.22 & 20 & $9.4 \%$ \\
\hline FARIMA $(0,0)$ & VR & & $(0.41)$ & 36 & $46.3 \%$ & 41 & 1.27 & 1 & - & 2.27 & 1 & $0.3 \%$ & 3.14 & 12 & $6.7 \%$ \\
\hline FARIMA $(1,0)$ & GK & & $(0.87)$ & 40 & $62.0 \%$ & 45 & 1.29 & 5 & $1.6 \%$ & 2.38 & 9 & $5.2 \%$ & 3.28 & 25 & $11.3 \%$ \\
\hline FARIMA $(0,1)$ & GK & & $(0.85)$ & 39 & $63.5 \%$ & 46 & 1.28 & 3 & $0.9 \%$ & 2.38 & 9 & $4.9 \%$ & 3.23 & 22 & $9.8 \%$ \\
\hline FARIMA $(0,0)$ & $\mathrm{GK}$ & & 0.97 & 2 & $23.6 \%$ & 40 & 1.81 & 12 & $42.0 \%$ & 2.49 & 20 & $10.1 \%$ & 3.40 & 30 & $15.4 \%$ \\
\hline Sih-GARCH $(1,2) \mathrm{t}$ & $1 \mathrm{~h}$ & & 2.15 & 31 & $11.9 \%$ & 4 & 2.62 & 38 & $105.8 \%$ & 3.42 & 38 & $50.9 \%$ & 4.13 & 37 & $40.5 \%$ \\
\hline Sih-EGARCH $(1,2) t$ & $1 \mathrm{~h}$ & & 2.10 & 29 & $11.0 \%$ & 3 & 2.55 & 34 & $100.4 \%$ & 3.27 & 32 & $44.3 \%$ & 3.99 & 32 & $35.7 \%$ \\
\hline Sih-PGARCH $(1,2) \mathrm{t}$ & 1h & & 2.15 & 31 & $10.6 \%$ & 1 & 2.58 & 36 & $102.9 \%$ & 3.34 & 35 & $47.3 \%$ & 4.08 & 35 & $38.7 \%$ \\
\hline Sih-TGARCH $(1,2) t$ & $1 \mathrm{~h}$ & & 2.12 & 30 & $11.9 \%$ & 4 & 2.57 & 35 & $101.8 \%$ & 3.37 & 36 & $48.8 \%$ & 4.09 & 36 & $39.0 \%$ \\
\hline Sim-GARCH $(1,2) t$ & $15 \mathrm{~m}$ & & 1.96 & 28 & $13.0 \%$ & 7 & 2.44 & 33 & $91.8 \%$ & 3.32 & 34 & $46.5 \%$ & 4.03 & 33 & $37.1 \%$ \\
\hline Sim-EGARCH $(1,2) t$ & $15 \mathrm{~m}$ & & 2.26 & 34 & $10.8 \%$ & 2 & 2.66 & 39 & $109.0 \%$ & 3.47 & 39 & $53.1 \%$ & 4.21 & 39 & $43.0 \%$ \\
\hline Sim-PGARCH $(1,2) t$ & $15 \mathrm{~m}$ & & 1.93 & 27 & $13.2 \%$ & 8 & 2.43 & 32 & $90.9 \%$ & 3.30 & 33 & $45.6 \%$ & 4.05 & 34 & $37.6 \%$ \\
\hline Sim-TGARCH $(1,2) t$ & $15 \mathrm{~m}$ & & 2.16 & 33 & $12.1 \%$ & 6 & 2.58 & 36 & $102.9 \%$ & 3.41 & 37 & $50.5 \%$ & 4.13 & 37 & $40.4 \%$ \\
\hline
\end{tabular}

\section{Notas}

(1) Além do valor das funções de perda, foram também disponibilizadas as posições relativas de cada modelo. Naturalmente, é apenas uma informação para facilitar a leitura da tabela, não tendo a pretensão de ordenar os modelos, mesmo porque nem sempre as diferenças são significativas.

(2) No caso $\mathrm{ME}$ a posição relativa é feita em duas etapas: primeiro há uma ordenação ascendente dos valores positivos de ME, para depois seguir a contagem para os valores negativos de ME, de forma descendente. Esse procedimento é baseado no fato que é desejável que o ME 
fosse próximo de zero, mas não negativo, pois a subestimação da volatilidade possui efeitos assimétricos para o investidor.

(3) Informação da diferença relativa de cada modelo em relação ao melhor modelo, dentro de cada uma das funções de perda MAE, RMSE e WMAE.

(4) Os três melhores modelos para cada critério foram destacados.

(5) t significa distribuição t-Student.

(6) Também foi estimado um caso particular do modelo PGARCH em (4.12), fixando $d=1$ (ao invés de estimar o valor de $d$ ), que é uma escolha popular, pois é considerado um modelo robusto para valores discrepantes. No entanto não foram encontrados resultados muito diferentes, sendo que em geral, a estimação de $d$ produz resultados melhores do que se fixarmos $d=1$. Com isso, não serão reportados os resultados obtidos, para deixar o texto mais conciso.

\subsubsection{Resultados da avaliação da previsão do VaR}

A avaliação dos resultados aqui é uma tarefa mais difícil que a anterior, pois para avaliação de intervalo de confiança, mesmo para uma amostra de teste de 3,3 anos (471 pontos), o tamanho da amostra é ainda muito reduzido, em especial para altos coeficientes de confiança, que é justamente o interesse na metodologia Valor em Risco. Por exemplo, para o VaR a 1\%, na amostra considerada espera-se encontrar 4.7 falhas, o que é um número muito pequeno, pois um modelo com apenas uma única falha a mais do esperado pode ser considerado comparativamente muito pior que os demais, mas na verdade não há evidências suficientes para tal afirmação.

Para fornecer mais subsídios para a avaliação, foram feitos alguns gráficos de BackTestting, na tentativa de melhor descrever o comportamento dos modelos.

Confirmando o observado na avaliação de volatilidade da seção anterior (veja a Tabela 7.2), em geral os modelos FARIMA subestimaram o intervalo de confiança, sendo inclusive rejeitado pelo teste de hipótese de Kupiec ao nível de 5\%. A exceção é o FARIMA(0,d,0) GK, que subestimou levemente a cauda inferior em relação a média dos modelos, mas teve excelentes 
resultados para cauda superior para qualquer valor de $\alpha$, o que lhe confere o melhor modelo geral para a cauda superior (veja Figura 7.3).

Também seguindo a análise na seção anterior, em geral os modelos Sih-XGarch e SimXGarch superestimaram o $\mathrm{VaR}$, ao ponto de serem rejeitados pelo teste de Kupiec ao nível de $5 \%$ (veja tabela 7.2). No entanto aqui, para $\alpha=2.5 \%$ e $5 \%$, onde quase todos os demais modelos subestimaram a cauda inferior (para $\alpha=2.5 \%$ a única exceção é o $\operatorname{Garch}(1,1) t+\mathrm{GK}$,), esses modelos tiveram excelente desempenho. Para a cauda superior e $\alpha=5 \%$, os modelos SimXGarch e os XGarch+VR e XGarch+GK tiveram os melhores resultados.

Os modelos em base diária tiveram bons resultados, inclusive para $\alpha=1 \%$ (veja Figura 7.1), exceto o modelo Riskmetrics que subestimou a cauda inferior, tendo o dobro de falhas do que o esperado (veja Figura 7.5). Também subestimou a cauda inferior para $\alpha=5 \%$, e em menor grau $\alpha=2.5 \%$, o que lhe confere um desempenho geral abaixo da média dos outros modelos, lembrando que a subestimação do VaR não é desejável.

Para $\alpha=1 \%$, os modelos XGarch+VR e XGarch+GK tiveram em geral excelentes resultados, mas para $\alpha=2.5 \%$ e $5 \%$, tenderam a subestimar a cauda inferior, com exceção do $\operatorname{Garch}(1,1) \mathrm{t}+\mathrm{GK}$ que teve o melhor resultado que todos os modelos para $\alpha=2.5 \%$. Já para cauda superior tiveram bons resultados.

O modelo HS obteve em geral bons resultados para cauda inferior, no entanto subestimou acentuadamente a cauda superior para $\alpha=2.5 \%$ e 5\%, tendo portanto resultados abaixo da média dos outros modelos. Além disso, verifica-se pela Figura 7.2 as respostas lentas as alterações do nível da volatilidade, em relação ao modelo $\operatorname{Garch}(1,1) t+G K$. Por exemplo, nos períodos de maior volatilidade, entre Set e Out/01 e entre Jun e Out/02, quando há uma falha, ou mesmo algumas falhas quase que seguidas, o modelo HS reage para cada falha com apenas um leve aumento do intervalo, não sendo, no entanto suficiente para evitar falhas subseqüentes. Isso não acontece em geral para o modelo Garch, que se adapta rapidamente ao incremento de volatilidade do mercado. Já em períodos de menor volatilidade, o HS tendeu a superestimar o $\mathrm{VaR}$, o que lhe rendeu uma taxa de falhas menor ao Garch, que obteve mais falhas (apesar destas não serem muito distantes do intervalo). Ou seja, se não fossem esses períodos de baixa 
volatilidade que o-HS superestima a volatilidade, os resultados seriam bem piores do que os reportados na Tabela 7.2 .

A análise acima está alinhada com o que foi discutido no Capítulo 5, onde são mencionadas as qualidades da metodologia de Agregação de Portfólio (PA) em relação à Simulação Histórica (HS).

Tabela 7.2 Avaliação da previsão do VaR

\begin{tabular}{|c|c|c|c|c|c|c|c|c|c|c|c|c|c|c|}
\hline \multirow{3}{*}{ Modelo } & \multirow{3}{*}{ Var. } & \multirow{3}{*}{ Cov. } & \multicolumn{4}{|c|}{$1.0 \%$} & \multicolumn{4}{|c|}{$2.5 \%$} & \multicolumn{4}{|c|}{$5.0 \%$} \\
\hline & & & \multicolumn{2}{|c|}{$\%$ Falhas } & \multicolumn{2}{|c|}{ Ordem } & \multicolumn{2}{|c|}{$\%$ Falhas } & \multicolumn{2}{|c|}{ Ordem } & \multicolumn{2}{|c|}{$\%$ Falhas } & \multicolumn{2}{|c|}{ Ordem } \\
\hline & & & Inf & Sup & Inf & Sup & Inf & Sup & Inf & Sup & Inf & Sup & Inf & Sup \\
\hline RiskMetrics & 1d & & $2.1 \%$ & $0.6 \%$ & 35 & 20 & $3.4 \%$ & $1.5 \%$ & 17 & 25 & $6.6 \%$ & $4.7 \%$ & 28 & 3 \\
\hline GARCH $(1,1)$ & 1d & & $1.3 \%$ & $0.4 \%$ & 26 & 25 & $3.0 \%$ & $1.9 \%$ & 11 & 9 & $5.1 \%$ & $3.6 \%$ & 11 & 25 \\
\hline $\operatorname{EGARCH}(1,1)$ & $1 d$ & & $1.1 \%$ & $0.6 \%$ & 1 & 20 & $4.0 \%$ & $2.3 \%$ & 34 & 1 & $6.4 \%$ & $3.6 \%$ & 25 & 25 \\
\hline PGARCH $(1,1)$ & 1d & & $1.1 \%$ & $0.8 \%$ & 1 & 2 & $3.4 \%$ & $1.9 \%$ & 17 & 9 & $5.9 \%$ & $3.6 \%$ & 18 & 25 \\
\hline $\operatorname{TGARCH}(1,1)$ & 1d & & $1.1 \%$ & $0.8 \%$ & 1 & 2 & $3.6 \%$ & $2.1 \%$ & 25 & 3 & $5.9 \%$ & $3.4 \%$ & 18 & 30 \\
\hline GARCH $(1,1) t$ & 1d & & $0.8 \%$ & $0.4 \%$ & 10 & 25 & $3.2 \%$ & $1.9 \%$ & 12 & 9 & $5.1 \%$ & $3.4 \%$ & 1 & 30 \\
\hline $\operatorname{EGARCH}(1,1) t$ & 1d & & $0.6 \%$ & $0.6 \%$ & 13 & 20 & $3.6 \%$ & $2.1 \%$ & 25 & 3 & $5.7 \%$ & $3.8 \%$ & 15 & 20 \\
\hline PGARCH $(1,1) t$ & 1d & & $0.4 \%$ & $0.6 \%$ & 16 & 20 & $3.4 \%$ & $1.7 \%$ & 17 & 21 & $5.5 \%$ & $3.2 \%$ & 12 & 32 \\
\hline TGARCH $(1,1) t$ & $1 d$ & & $0.4 \%$ & $0.8 \%$ & 16 & 2 & $3.6 \%$ & $1.9 \%$ & 25 & 9 & $5.7 \%$ & $4.0 \%$ & 15 & 14 \\
\hline GARCH $(1,1)$ & $1 d$ & VR & $1.5 \%$ & $0.8 \%$ & 31 & 2 & $3.4 \%$ & $1.9 \%$ & 17 & 9 & $5.9 \%$ & $4.2 \%$ & 18 & 11 \\
\hline $\operatorname{EGARCH}(1,1)$ & $1 d$ & VR & $1.3 \%$ & $0.8 \%$ & 26 & 2 & $3.6 \%$ & $2.1 \%$ & 25 & 3 & $6.6 \%$ & $4.0 \%$ & 28 & 14 \\
\hline PGARCH $(1,1)$ & 1d & VR & $1.5 \%$ & $0.8 \%$ & 31 & 2 & $3.8 \%$ & $1.9 \%$ & 33 & 9 & $6.2 \%$ & $3.6 \%$ & 22 & 25 \\
\hline TGARCH $(1,1)$ & 1d & VR & $1.9 \%$ & $1.1 \%$ & 33 & 1 & $3.2 \%$ & $2.1 \%$ & 12 & 3 & $6.8 \%$ & $3.8 \%$ & 33 & 20 \\
\hline GARCH $(1,1) t$ & 1d & VR & $1.1 \%$ & $0.8 \%$ & 1 & 2 & $3.2 \%$ & $1.7 \%$ & 12 & 21 & $6.2 \%$ & $4.0 \%$ & 22 & 14 \\
\hline EGARCH $(1,1) t$ & $1 d$ & VR & $0.6 \%$ & $0.8 \%$ & 13 & 2 & $3.4 \%$ & $1.9 \%$ & 17 & 9 & $6.8 \%$ & $4.0 \%$ & 33 & 14 \\
\hline PGARCH $(1,1) t$ & 1d & VR & $0.8 \%$ & $0.8 \%$ & 10 & 2 & $4.0 \%$ & $1.9 \%$ & 34 & 9 & $6.6 \%$ & $4.2 \%$ & 28 & 11 \\
\hline TGARCH $(1,1) t$ & 1d & VR & $1.1 \%$ & $0.8 \%$ & 1 & 2 & $3.2 \%$ & $1.9 \%$ & 12 & 9 & $6.8 \%$ & $4.2 \%$ & 33 & 11 \\
\hline GARCH $(1,1)$ & 1d & GK & $1.3 \%$ & $0.8 \%$ & 26 & 2 & $3.2 \%$ & $2.1 \%$ & 12 & 3 & $5.5 \%$ & $4.7 \%$ & 12 & 3 \\
\hline $\operatorname{EGARCH}(1,1)$ & 1d & GK & $1.1 \%$ & $0.8 \%$ & 1 & 2 & $3.4 \%$ & $2.1 \%$ & 17 & 3 & $6.6 \%$ & $3.8 \%$ & 28 & 20 \\
\hline PGARCH $(1,1)$ & Id & GK & $1.3 \%$ & $0.8 \%$ & 26 & 2 & $3.6 \%$ & $1.7 \%$ & 25 & 21 & $5.9 \%$ & $3.8 \%$ & 18 & 20 \\
\hline $\operatorname{TGARCH}(1,1)$ & Id & GK & $1.3 \%$ & $0.8 \%$ & 26 & 2 & $3.6 \%$ & $1.9 \%$ & 25 & 9 & $6.2 \%$ & $4.7 \%$ & 22 & 3 \\
\hline GARCH $(1,1) t$ & 1d & GK & $0.8 \%$ & $0.6 \%$ & 10 & 20 & $2.5 \%$ & $1.9 \%$ & 1) & 9 & $5.5 \%$ & $4.7 \%$ & 12 & 3 \\
\hline EGARCH $(1,1) t$ & $1 d$ & GK & $0.6 \%$ & $0.8 \%$ & 13 & 2 & $3.6 \%$ & $1.9 \%$ & 25 & 9 & $6.6 \%$ & $4.0 \%$ & 28 & 14 \\
\hline PGARCH $(1,1) t$ & 1d & GK & $1.1 \%$ & $0.8 \%$ & 1 & 2 & $3.4 \%$ & $1.5 \%$ & 17 & 25 & $6.4 \%$ & $4.5 \%$ & 25 & 10 \\
\hline TGARCH $(1,1) t$ & 1d & GK & $1.1 \%$ & $0.8 \%$ & 1 & 2 & $3.4 \%$ & $1.7 \%$ & 17 & 21 & $5.7 \%$ & $4,7 \%$ & 15. & 3 \\
\hline FARIMA(1,1) & VR & & $6.8 \%^{*}$ & $8.3 \%^{*}$ & 41 & 41 & $9.1 \%{ }^{*}$ & $9.8 \%^{*}$ & 41 & 41 & $11.9 \%^{*}$ & $12.1 \%^{*}$ & 41 & 40 \\
\hline FARIMA $(1,0)$ & VR & & $4.2 \% *$ & $2.5 \%^{*}$ & 38 & 36 & $7.4 \%$ & $6.6 \%^{*}$ & 37 & 36 & $8.9 \%{ }^{*}$ & $10.6 \%$ & 36 & 37 \\
\hline FARIMA(0,1) & VR & & $3.8 \%$ & $2.8 \% *$ & 36 & 38 & $7.0 \% *$ & $6.6 \%^{*}$ & 36 & 36 & $8.9 \%{ }^{*}$ & $10.2 \%^{*}$ & 36 & 36 \\
\hline $\operatorname{IMA}(0,0)$ & VR & & $4.0 \%$ & $2.5 \% *$ & 37 & 36 & $7.4 \%$ * & $6.6 \%^{*}$ & 37 & 36 & $9.1 \%$ & $10.6 \%$ & 38 & 37 \\
\hline $\operatorname{FARIMA}(1,0)$ & GK & & $5.7 \%{ }^{*}$ & $4.5 \%^{*}$ & 40 & 39 & $8.3 \%^{*}$ & $8.1 \%{ }^{*}$ & 40 & 40 & $11.5 \% \%^{*}$ & $12.5 \%^{*}$ & 40 & 41 \\
\hline FARIMA $(0,1)$ & GK & & $5.5 \%$ & $5.3 \% *$ & 39 & 40 & $7.9 \%$ & $7.9 \% *$ & 39 & 39 & $11.3 \%=$ & $11.7 \%$ & 39 & 39 \\
\hline FARIMA $(0,0)$ & GK & & $1.9 \%$ & $0.8 \%$ & 33 & 2 & $3.6 \%$ & $2.3 \%$ & 25 & 1 & $6.4 \%$ & $4.9 \%$ & 25 & 2 \\
\hline Sih-GARCH $(1,2) \mathrm{t}$ & $1 \mathrm{~h}$ & & $0.2 \%$ & $0.2 \%$ & 18 & 27 & $2.3 \%$ & $0.8 \%^{*}$ & 2 & 29 & $4.9 \%$ & $3.0 \%$ & 4 & 35 \\
\hline Sih-EGARCH $(1,2) \mathrm{t}$ & 1h & & $0.2 \%$ & $0.2 \%$ & 18 & 27 & $2.1 \%$ & $0.8 \%{ }^{*}$ & 3 & 29 & $4.5 \%$ & $3.6 \%$ & 6 & 25 \\
\hline Sih-PGARCH $(1,2) \mathrm{t}$ & $1 \mathrm{~h}$ & & $0.2 \%$ & $0.2 \%$ & 18 & 27 & $2.1 \%$ & $0.8 \% *$ & 3 & 29 & $4.5 \%$ & $3.2 \%$ & 6 & 32 \\
\hline Sih-TGARCH $(1,2) \mathrm{t}$ & $1 \mathrm{~h}$ & & $0.2 \%$ & $0.2 \%$ & 18 & 27 & $2.1 \%$ & $0.8 \%^{*}$ & 3 & 29 & $5.1 \%$ & $3.2 \%$ & 1 & 32 \\
\hline Sim-GARCH $(1,2) t$ & $15 \mathrm{~m}$ & & $0.2 \%$ & $0.2 \%$ & 18 & 27 & $2.1 \%$ & $0.8 \%^{*}$ & 3 & 29 & $5.3 \%$ & $4.7 \%$ & 10 & 3 \\
\hline $\operatorname{Sim}$ EGARCH $(1,2) t$ & $15 \mathrm{~m}$ & & $0.2 \%$ & $0.2 \%$ & 18 & 27 & $1.7 \%$ & $1.1 \% *$ & 8 & 28 & $4.5 \%$ & $4.0 \%$ & 6 & 14 \\
\hline Sim-PGARCH $(1,2) t$ & $15 \mathrm{~m}$ & & $0.0 \%$ & $0.2 \%$ & 25 & 27 & $1.9 \%$ & $1.3 \%$ & 7 & 27 & $5.3 \%$ & $5.1 \%$ & 10 & 1 \\
\hline Sim-TGARCH $(1,2) \mathrm{t}$ & $15 \mathrm{~m}$ & & $0.2 \%$ & $0.2 \%$ & 18 & 27 & $1.5 \%$ & $0.8 \%$ * & 9 & 29 & $4.5 \%$ & $3.8 \%$ & 6 & 20 \\
\hline HS & 1d & & $1.1 \%$ & $1.5 \%$ & 1 & 35 & $2.8 \%$ & $3.0 \%$ & 10 & 35 & $4.9 \%$ & $4.7 \%$ & 4 & 3 \\
\hline
\end{tabular}

* hipótese que $\mathrm{p}=\mathrm{p}^{*}$ do teste Kupiec rejeitado ao nível de 5\% 
(1) Além da taxa de falhas, foram também disponibilizadas as posições relativas de cada modelo em relação ao erro entre o observado e o esperado. O esperado foi definido como a taxa de falhas truncada esperada, isto é, tomou-se o inteiro mais próximo. Por exemplo, para $1 \%$ temse 4.71 falhas, que foi arredondado para 5.

(2) A ordenação relativa é feita em duas etapas: primeiro, há uma ordenação ascendente dos erros positivos, para depois seguir a contagem para erros negativos, de forma descendente. Esse procedimento é baseado no fato que é desejável que o erro fosse próximo de zero, mas não negativo, pois a subestimação do $\mathrm{VaR}$ possui efeitos assimétricos para o investidor. Naturalmente, é apenas uma informação para facilitar a leitura da tabela, não tendo a pretensão de ordenar os modelos, mesmo porque nem sempre as diferenças são significativas.

(3) Os três melhores modelos para cada critério foram destacados.

(4) t significa distribuição t-Student

Figura 7.1 Back-Testing do VaR a 1\% - RiskMetrics x PGarch $(1,1) \mathrm{t}+\mathrm{GK}$

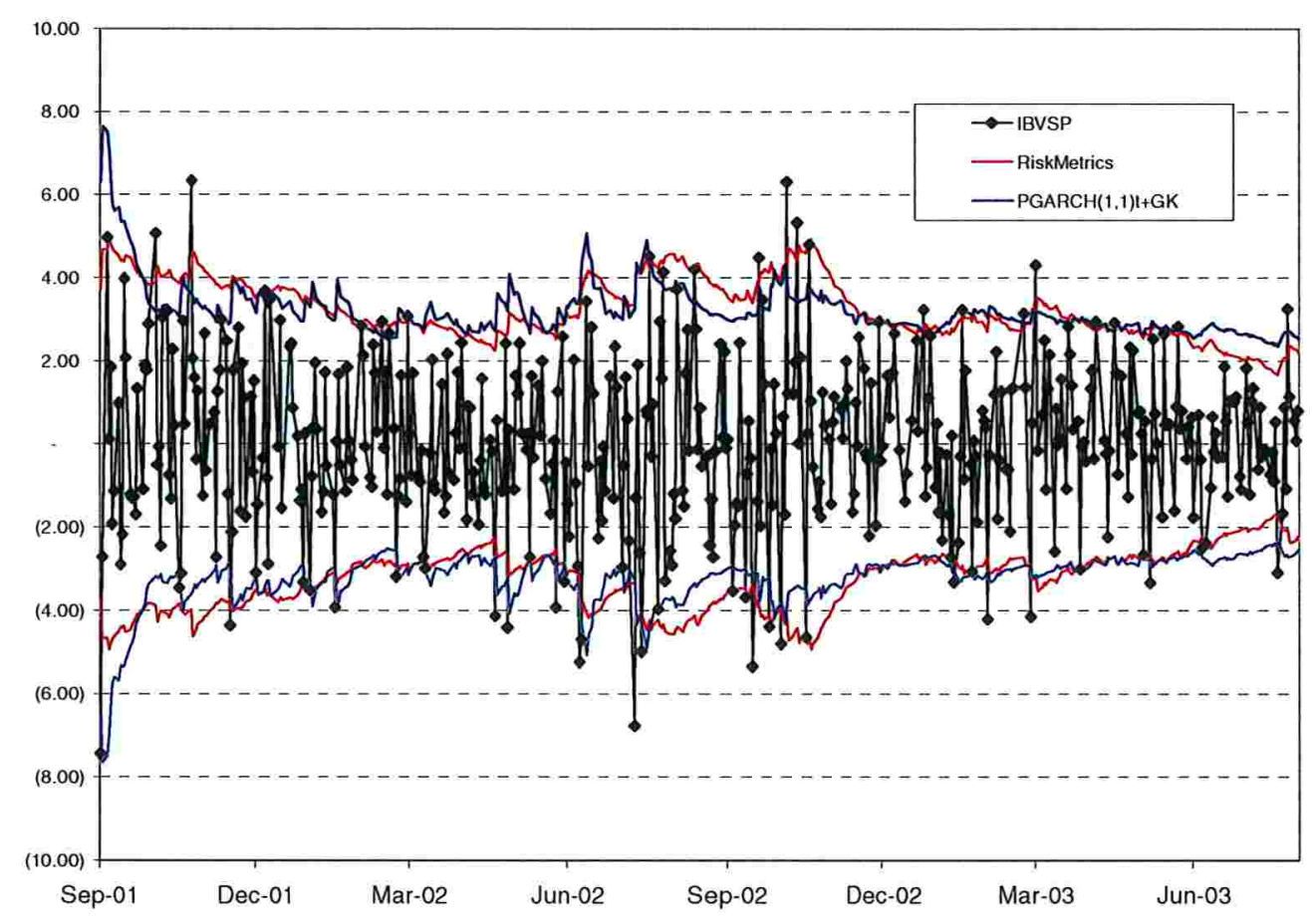


Figura 7.2 Back-Testing do VaR a $2.5 \%$ - HS x Garch $(1,1) \mathrm{t}+\mathrm{GK}$

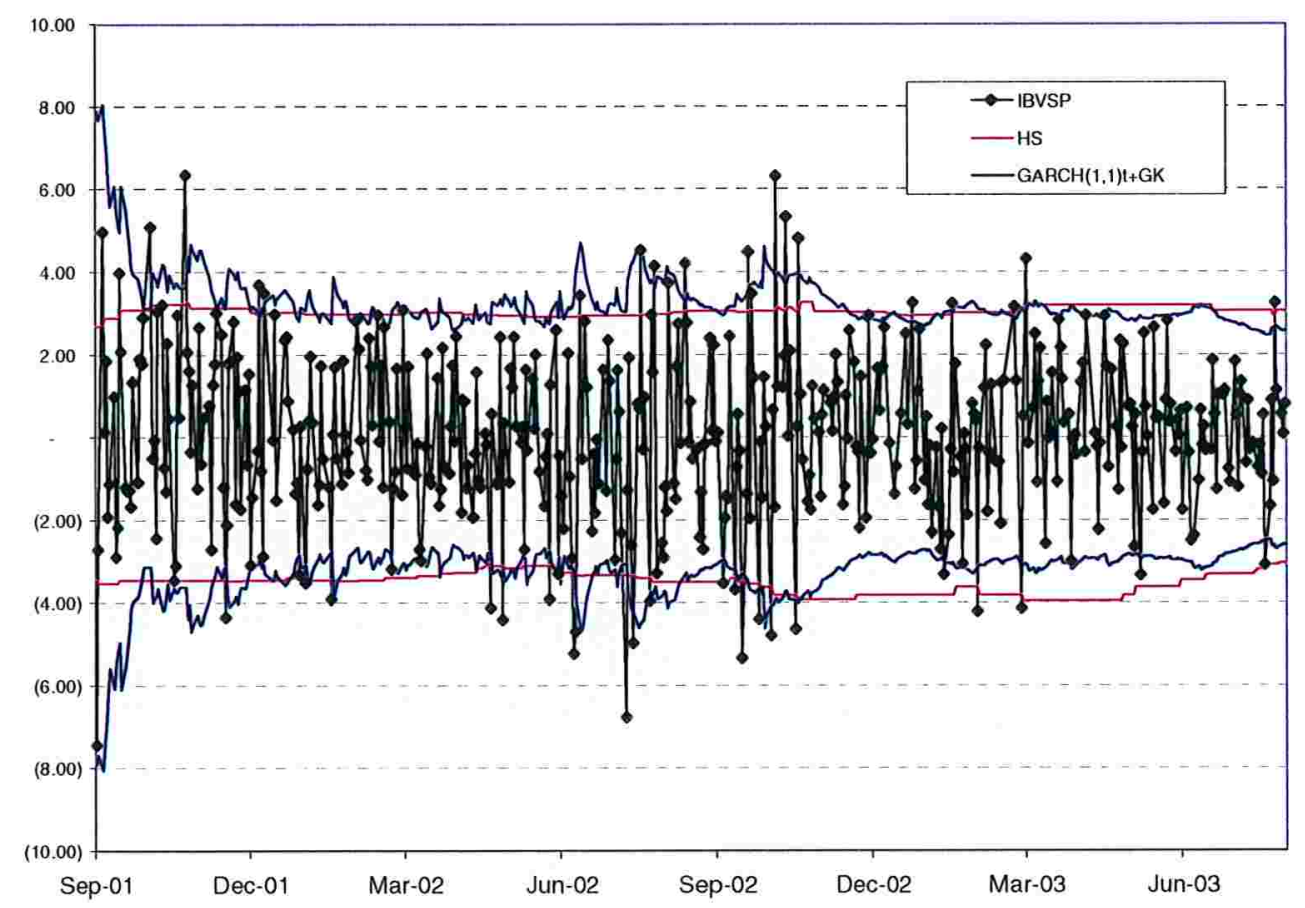

Figura 7.3 Back-Testing do VaR a 2.5\% -FARIMA(0,d,0)-GK x EGarch $(1,1)$

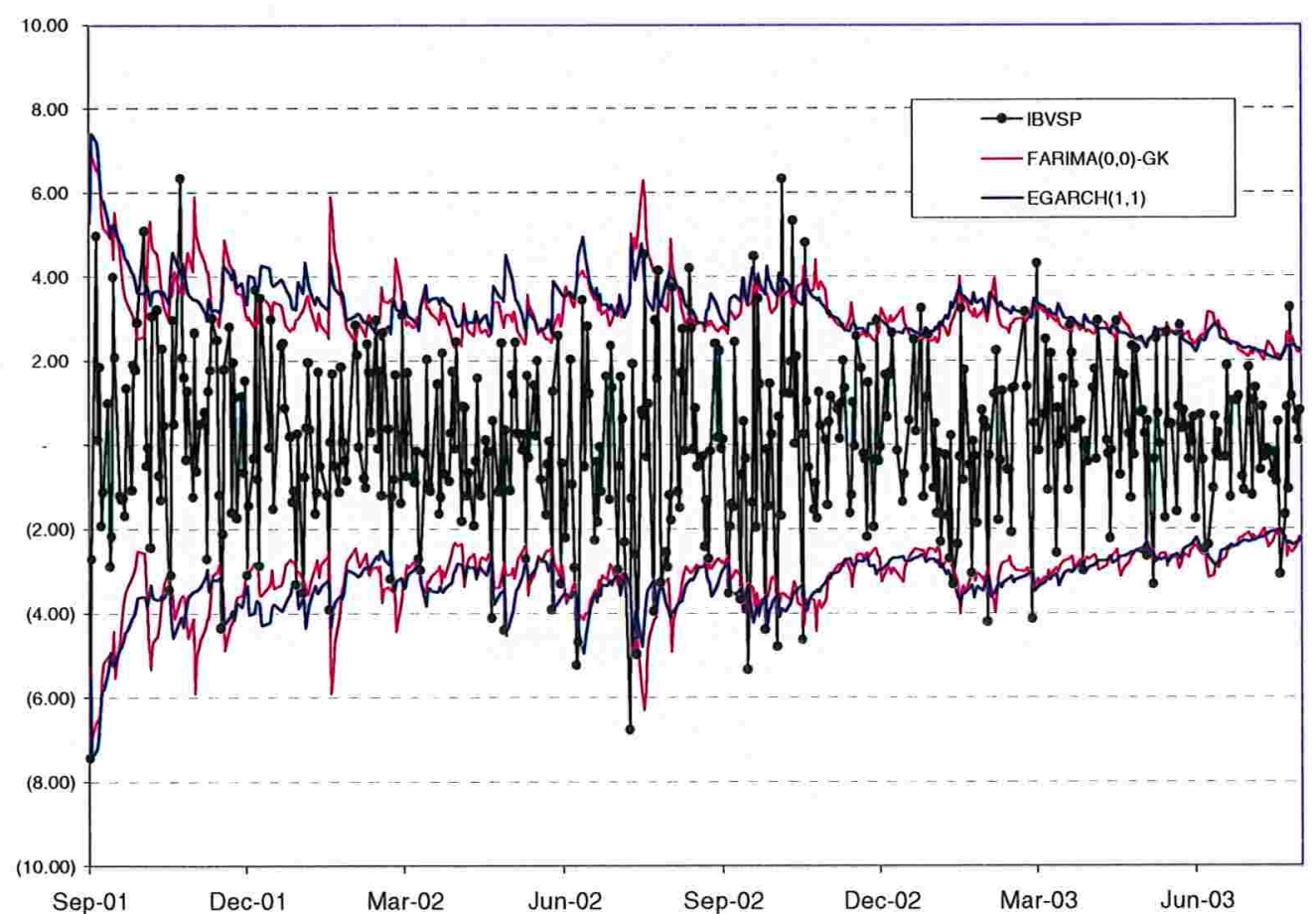


Figura 7.4 Back-Testing do VaR a $2.5 \%-\operatorname{Garch}(1,1) \times \operatorname{Garch}(1,1) \mathrm{t}+\mathrm{GK}$

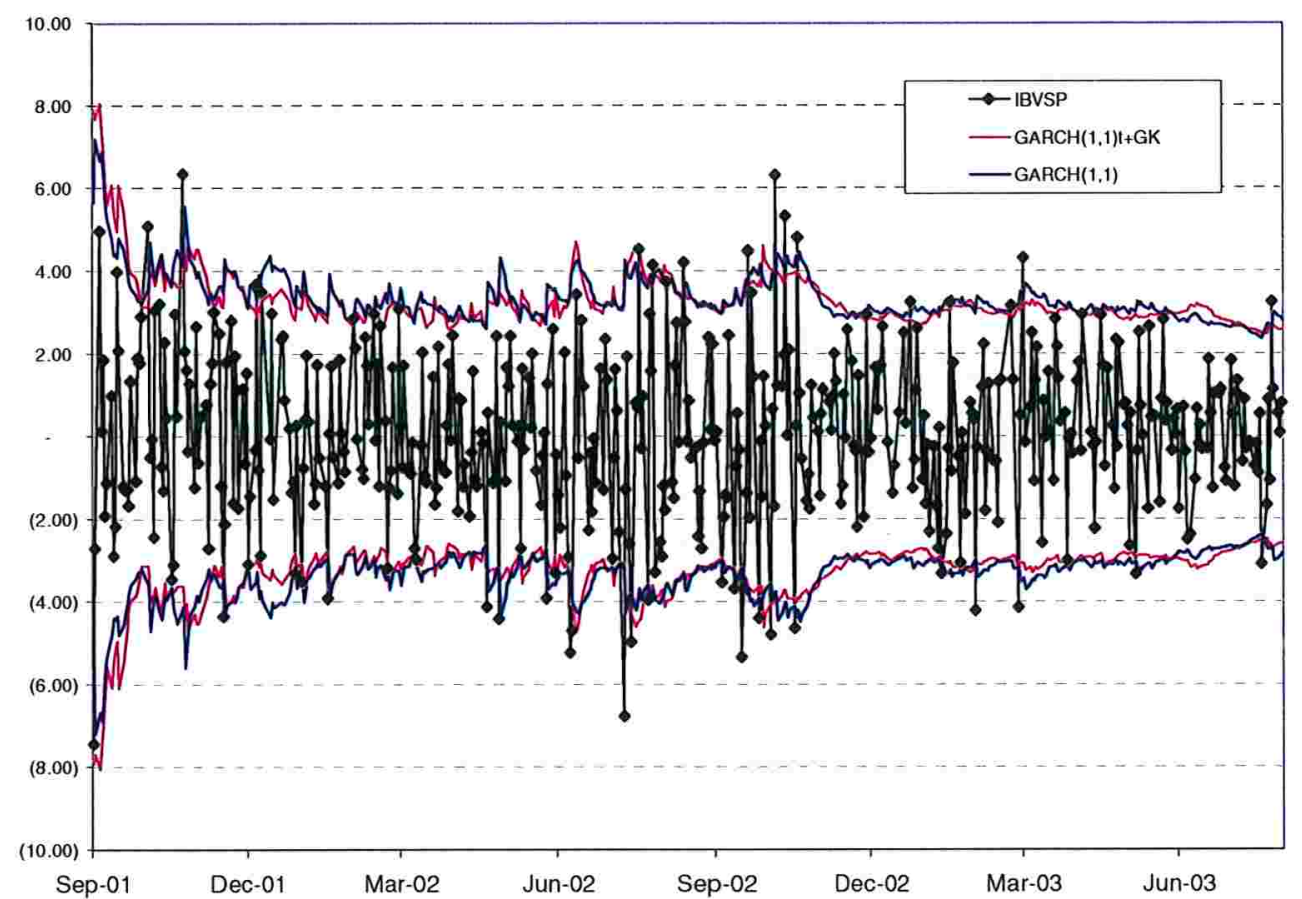

Figura 7.5 Back-Testing do VaR a 5\% -Riskmetrics x Sih-TGarch $(1,2) \mathrm{t}$

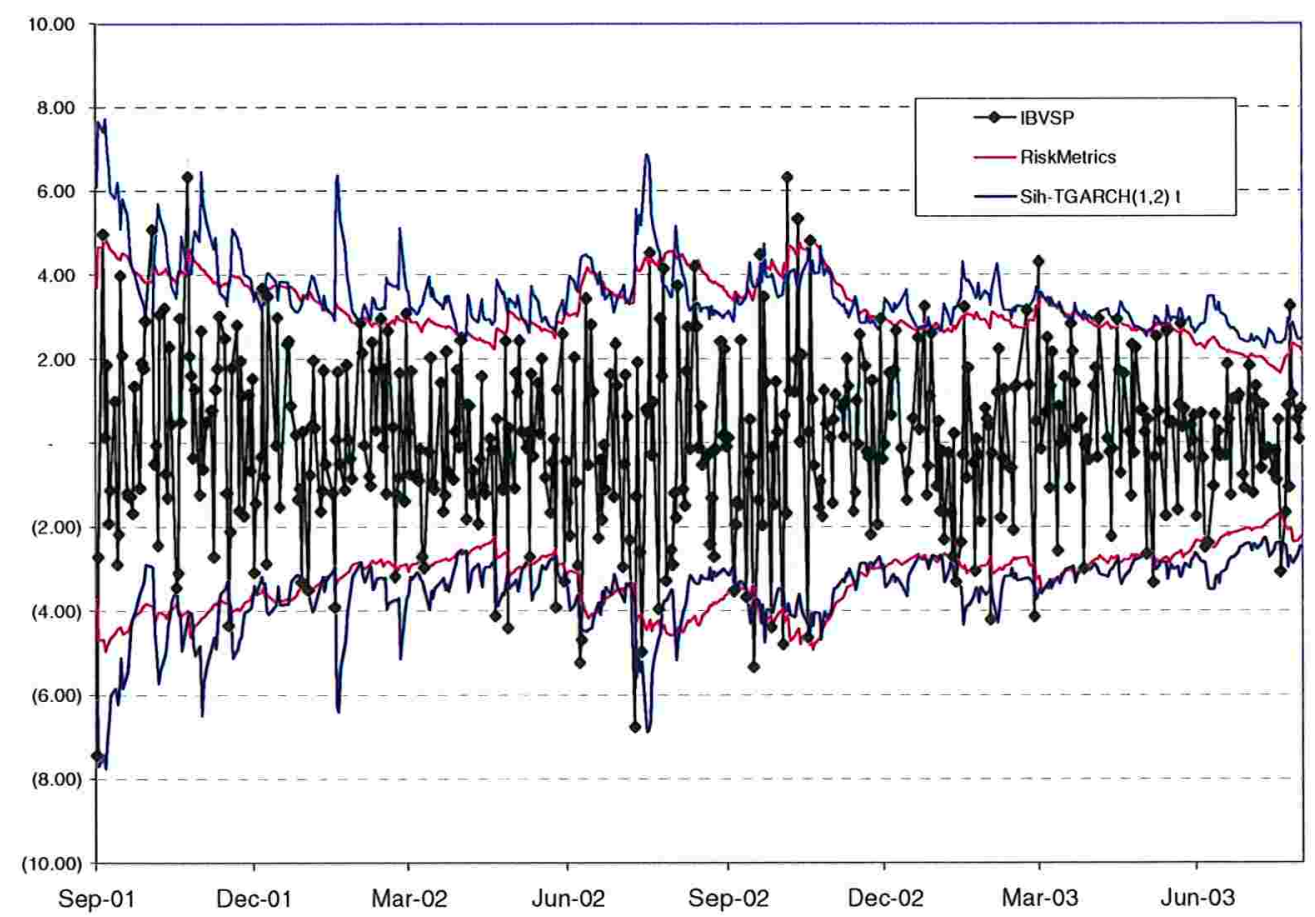


Figura 7.6 Back-Testing do VaR a 5\%-Garch $(1,1)$ x FARIMA(1,d,1)-VR

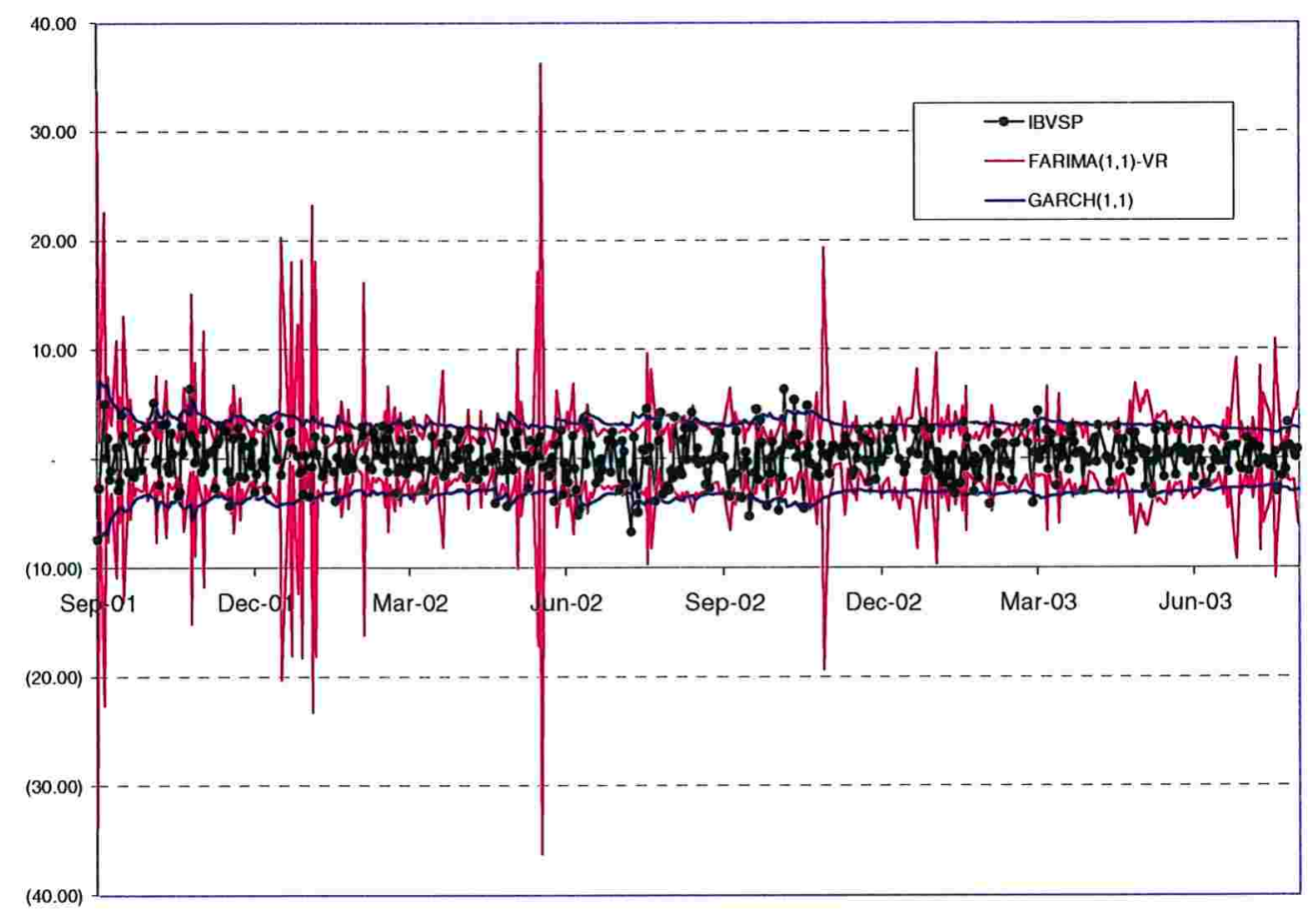




\section{Conclusões}

Naturalmente, há a necessidade de serem feitos mais estudos, com amostras maiores e outras séries, mas pode-se concluir que é viável utilizar dados intradiários para a previsão de volatilidade diária de índice de ações. E mais, há indícios de terem resultados melhores que os modelos tradicionais com dados de fechamento, como o Riskmetrics. O melhor modelo encontrado para a previsão de volatilidade é de um modelo $\operatorname{PGARCH}(1,1)$ com distribuição tStudent adicionado a volatilidade realizada (que é baseada em retornos intradiários) como covariável na equação da volatilidade condicional. Outra possibilidade baseada em dados intradiários que apresentou resultados dignos de nota, foi a modelagem direta da volatilidade realizada por modelos FARIMA. Tais modelos apresentaram desempenho muito superior aos modelos GARCH para períodos de baixa volatilidade, no entanto em períodos de alta, subestimam acentuadamente a volatilidade, sendo que o mesmo não acontece com modelos da família GARCH. Essa subestimação não torna o modelo FARIMA empregável para fins de risco, no entanto pode ser que seja possível combinar a característica desses dois modelos, já que possuem qualidades distintas, e prover melhores estimativas de volatilidade do que considerando um ou outro.

A dificuldade de se obter dados intradiários, seja por falta de liquidez, ou simplesmente por não haver histórico de dados intradiários de séries financeiras brasileiras, é um problema prático sério. Isso motivou o estudo de uma alternativa, e foi encontrada a volatilidade por Garman-Klass, que utiliza apenas dados de abertura, fechamento, máximo e mínimo, que são facilmente encontrados em provedores de informação. Além da praticidade, apresentaram apenas resultados levemente inferiores ao da volatilidade realizada e tal fato aumenta em muito as possibilidades de uso prático desses modelos e tornando necessário, é claro, um estudo complementar para analisar as técnicas utilizadas aqui em outros ativos. Outra possibilidade seria estudar algumas aproximações, o que já é uma prática comum nos sistemas de risco das instituições financeiras, devido a problemas de falta de histórico. Por exemplo, os dados 
intradiários do BBVSP poderiam ser utilizados como uma aproximação para as ações negociadas na BOVESPA que não possuam liquidez (ou série histórica). Naturalmente pode-se implementar aproximações mais sofisticadas, mas de qualquer forma é preciso verificar se a aproximação não perde todo o benefício da inclusão do dado intradiário, necessitando também um estudo específico.

Nesse trabalho foi analisada uma única série, que é o IBSVP, no entanto foram apresentadas metodologias capazes de fornecer subsídios para o uso dos modelos desse trabalho para uma futura extensão para o cálculo do Valor em Risco de carteiras, já que na prática as instituições financeiras possuem um grande número de ativos. Em particular a estimação de matrizes de grande dimensão por modelos multivariados GARCH é uma tarefa difícil, se não inviável, para ser utilizado na prática em um sistema de risco de uma instituição. A dificuldade aumenta se for adicionada uma covariável, como aconteceu no melhor modelo encontrado. Mesmo para os modelos FARIMA, ainda não há a versão multivariada disponível nos programas computacionais estatísticos comerciais.

Isso motivou a procura na literatura de metodologias alternativas, sendo encontradas duas técnicas que são relativamente desconhecidas em relação às duas mais utilizadas, que são a Simulação Histórica e o Riskmetrics. Estudos empíricos relataram resultados superiores a essas metodologias populares, e, além disso, não apresentam grandes complicações para a implementação. A primeira é a técnica conhecida como Agregação de Portfólio, criada por Zangari (1997), consiste em agregar os retornos do portfólio da mesma forma que é feita com a Simulação Histórica, e após esse processo é ajustado um modelo heterocedástico condicional, como da família GARCH univariado, pois transformou o problema multivariado em univariado. A outra metodologia é uma variação do HS proposta por Hull e White (1998) para incluir a dinâmica da volatilidade condicional, que tem em seu processo ajuste de modelos GARCH univariados para cada série, para depois utilizar, com base nos resíduos, uma Simulação Histórica, o que confere um trabalho adicional em relação à agregação de portfólios. No entanto, sua adaptação pode ser mais imediata uma vez que não é necessário criar a volatilidade realizada agregada do portfólio, que com uma primeira sugestão pode ser calculada diretamente em relação aos retornos intradiários da carteira, mas tal proposição deve ser verificada, assim como a volatilidade de uma carteira por Garman-Klass. 
Já os resultados obtidos com a estimação do Valor em -Risco são mais difíceis de obter conclusões generalizadas, pois não há um modelo que seja sempre melhor para posições compradas e para posições vendidas, e nem para qualquer valor de $\alpha$. Tal dificuldade é ampliada pois para avaliação do VaR para probabilidades baixas ( $\alpha=1 \%$ ou $2,5 \%$ ), o tamanho da amostra não é suficiente para conclusões mais robustas.

$\mathrm{O}$ fato mais importante encontrado é que as duas metodologias de $\mathrm{VaR}$ mais utilizadas, Riskmetric e HS, apresentaram desempenho abaixo da média dos outros modelos. O Riskmetrics subestimou o VaR da posição comprada, enquanto o HS subestimou para posição vendida. Também foi constatada a lenta resposta do modelo HS para mudanças do nível da volatilidade, o que é melhor capturado pelos modelos da família Garch. O que é uma indicação que a metodologia de Agregação de Portfólio pode oferecer resultados superiores à metodologia básica de Simulação Histórica.

Apesar de modelos em base diária da família Garch também terem tido em muitos casos resultados igualmente bons, de forma geral os modelos que levam em conta informação intradiária (exceto FARIMA, a não ser FARIMA(0,d,0)-GK) foram melhores como pode-se observar pelo resumo da Tabela 7.2 abaixo:

Tabela 8.1 Melhores modelos para o VaR

\begin{tabular}{|l|l|l|l|l|l|}
\hline \multicolumn{1}{|c|}{ Inf } & \multicolumn{1}{c|}{$2.5 \%$} & \multicolumn{2}{c|}{ Sup } & \multicolumn{1}{c|}{ Inf } & Sup \\
\hline \multicolumn{1}{|c|}{ Inf } & Inf & \multicolumn{1}{c|}{ Sup } \\
PGARCH(1,1) & TGARCH(1,1)+VR & GARCH(1,1)t+GK & EGARCH(1,1) & GARCH(1,1) & Sim-PGARCH(1,2) t \\
TGARCH(1,1) & & & FARIMA(0,0) GK & GARCH(1,1)t & \\
GARCH(1,1)t+VR & & & & & \\
TGARCH(1,1)t+VR & & & & & \\
EGARCH(1,1)+GK & & & & & \\
PGARCH(1,1)t+GK & & & & & \\
TGARCH(1,1)t+GK & & & & & \\
HS & & & & & \\
\hline
\end{tabular}

Como muitos autores afirmam, os dados de alta freqüência abriram um novo campo para finanças. Pelos bons resultados dos modelos com base em informação intradiária encontrados nesse trabalho, tanto para o cálculo do $\mathrm{VaR}$ (com as ressalvas já mencionadas), como para a previsão de volatilidade, pode-se então propor que tais modelos ofereçam aplicações viáveis com ganhos de performance para o gerenciamento de risco. 


\section{Apêndices}

\section{A.1 Figuras}

Figura A.1 Evolução da cotação do IBVSP

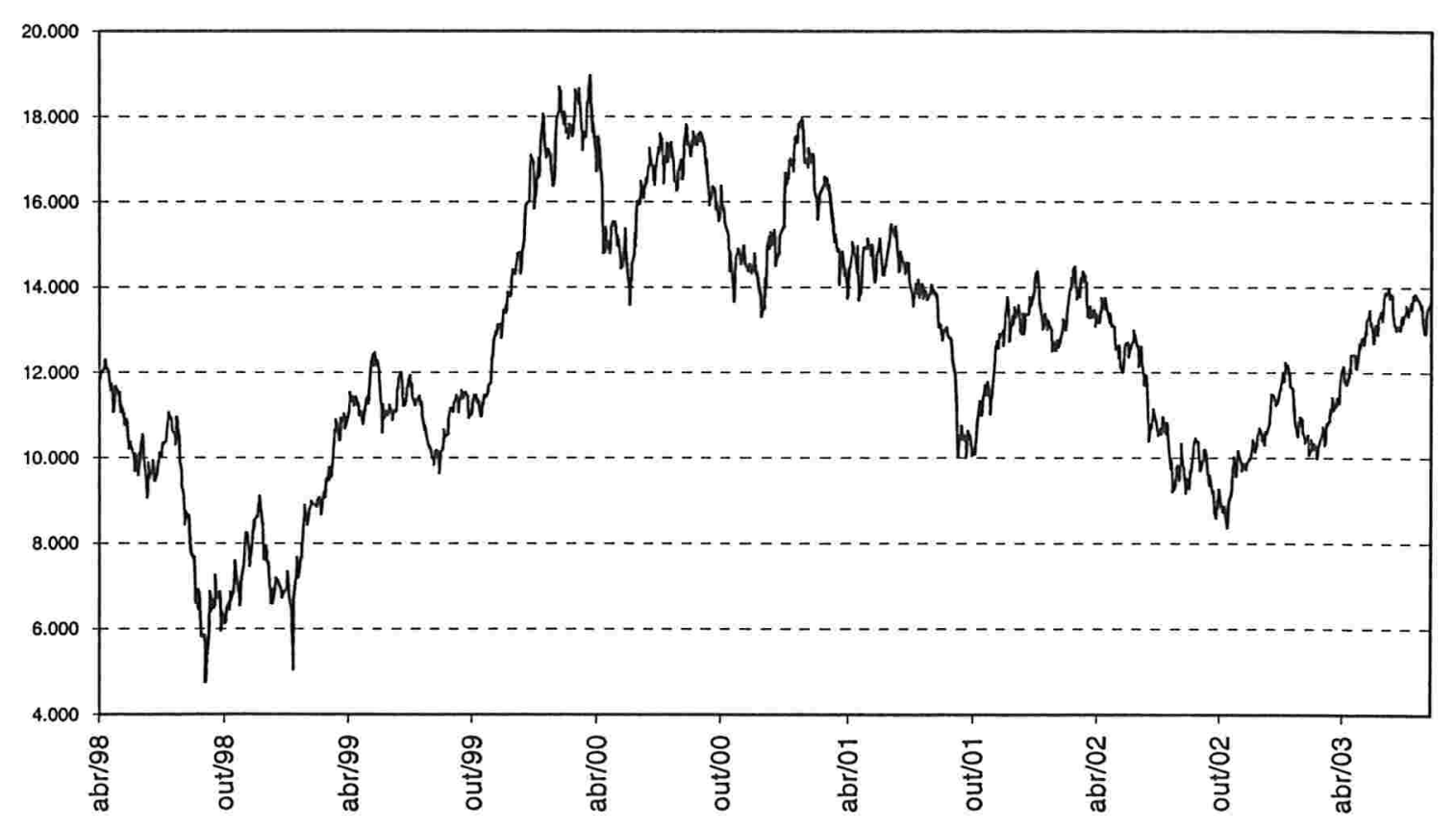


Figura A.2 Evolução dos log-retorno do IBVSP
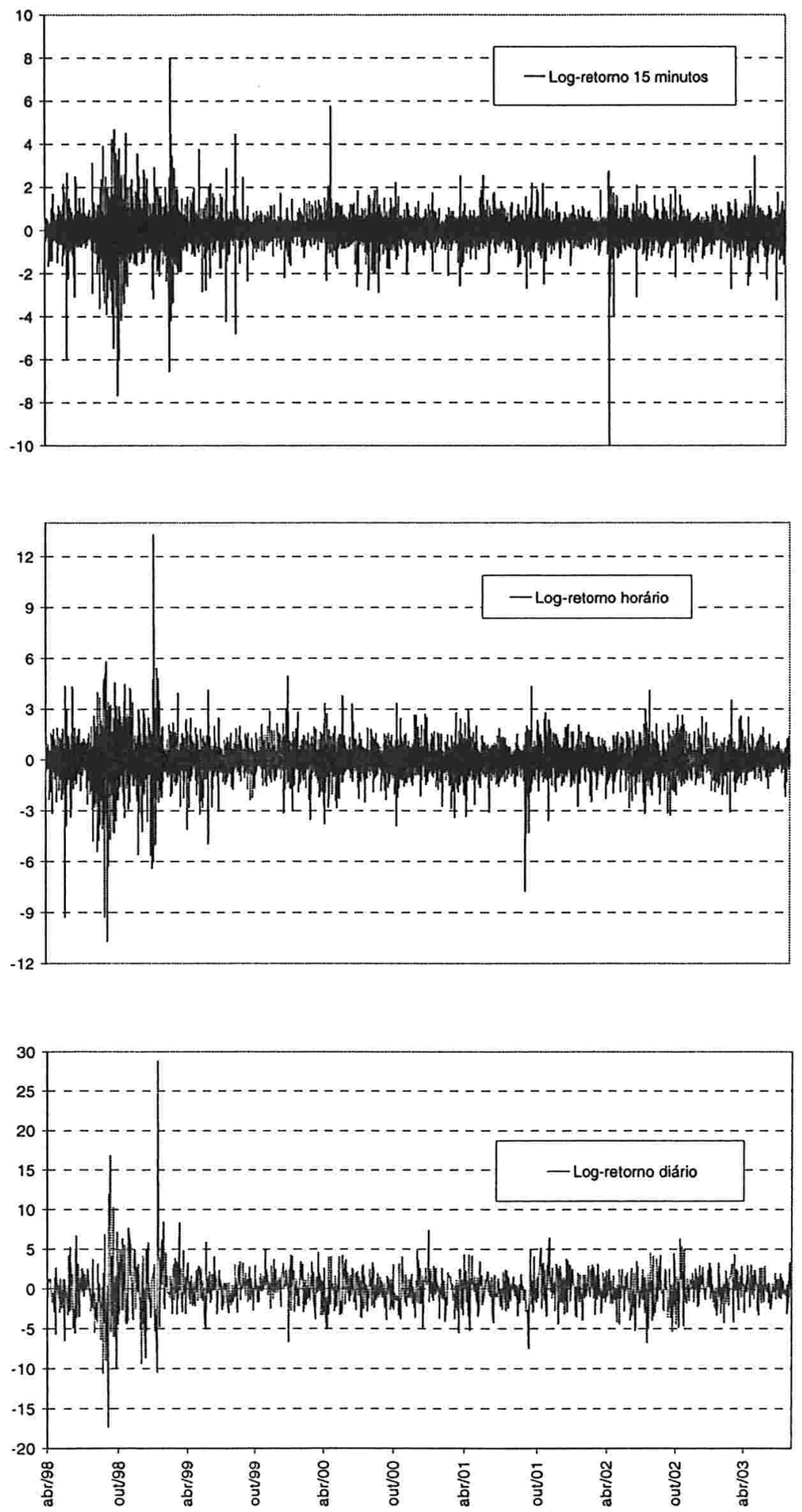
Figura A.3 Volatilidade realizada e Garman-Klass e seus logaritmos

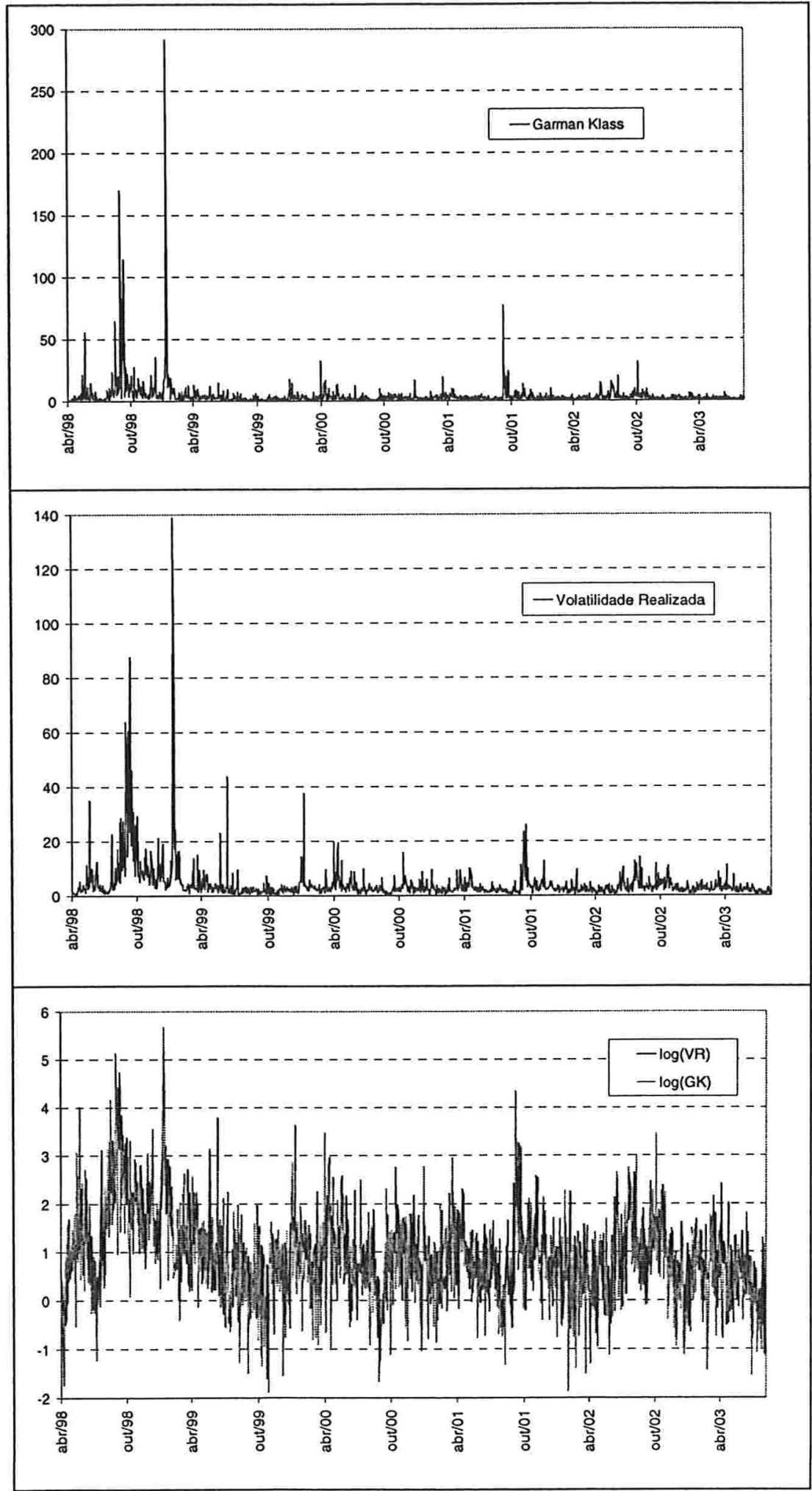


Figura A.4 Histograma do log-retorno
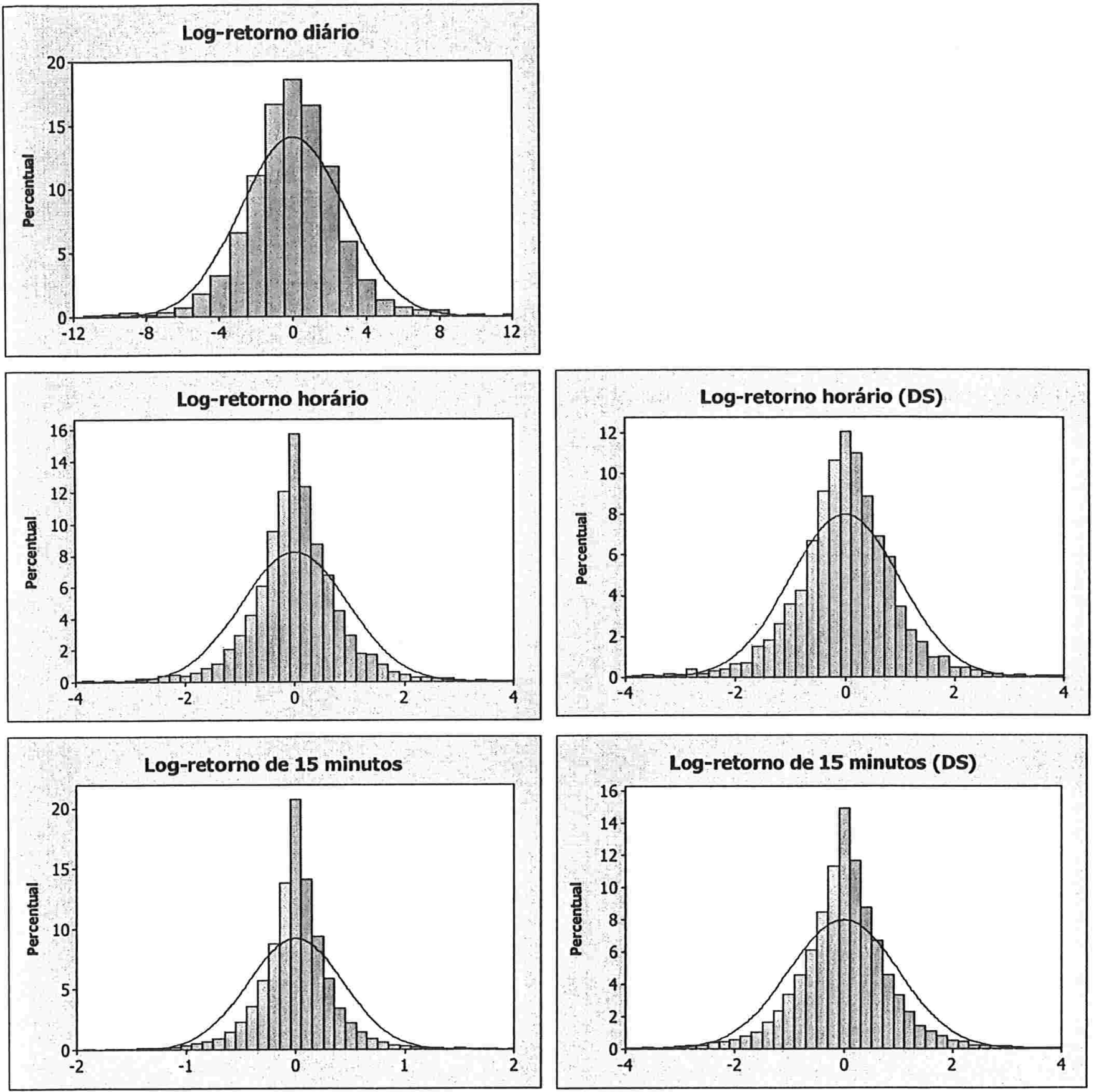

Obs.: DS denota séries dessazonalizadas 
Figura A.5 Histograma da volatilidade
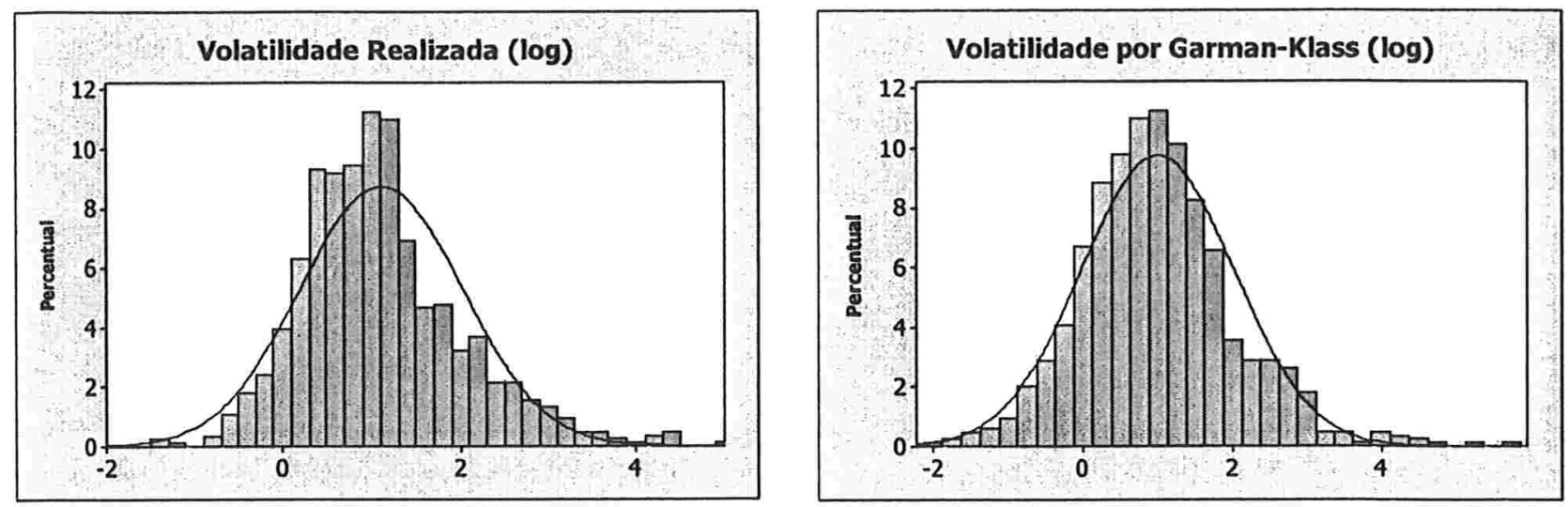

Figura A.6 Volatilidade Sazonal Horária e de 15 minutos
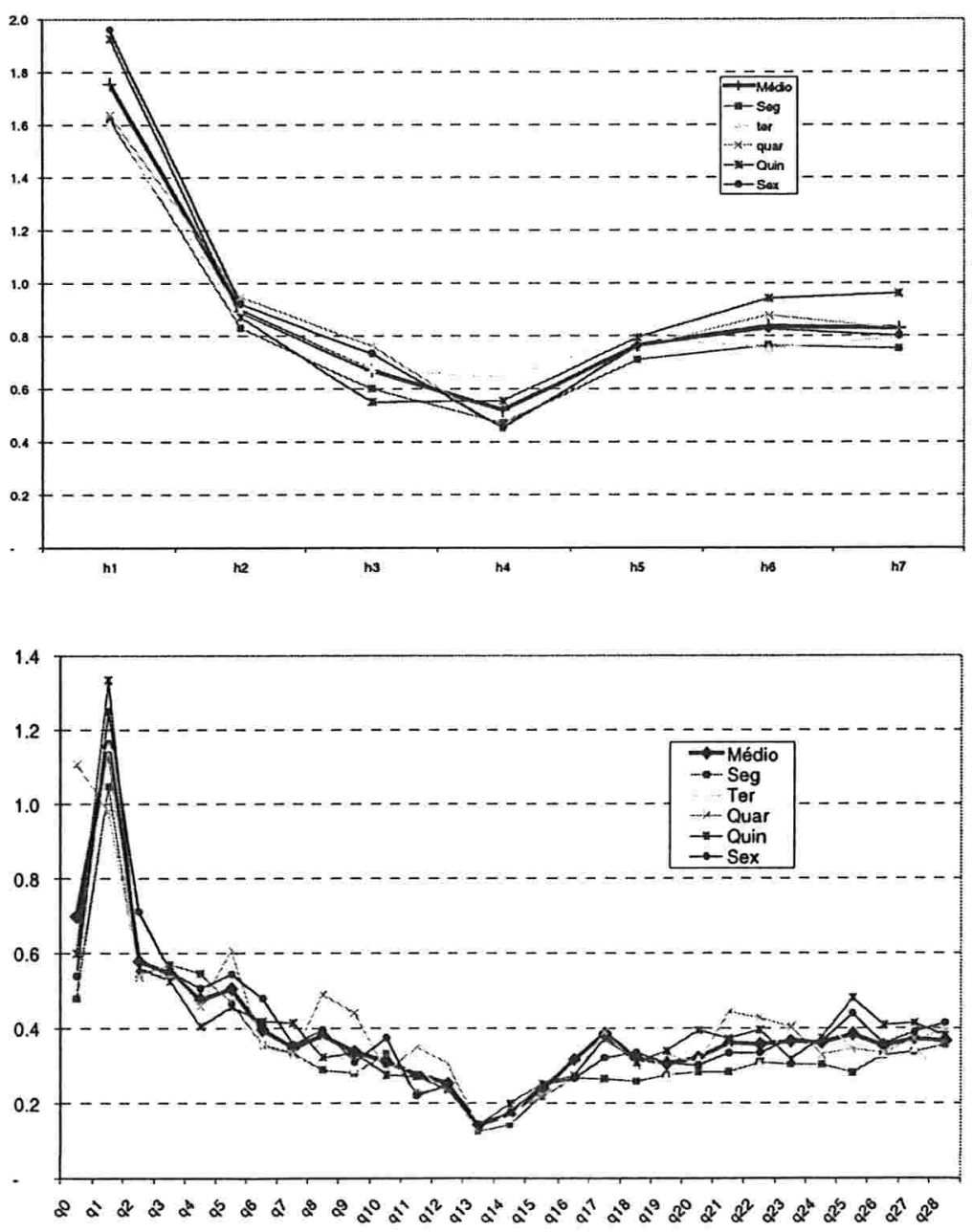
Figura A.7 Correlogramas dos retornos
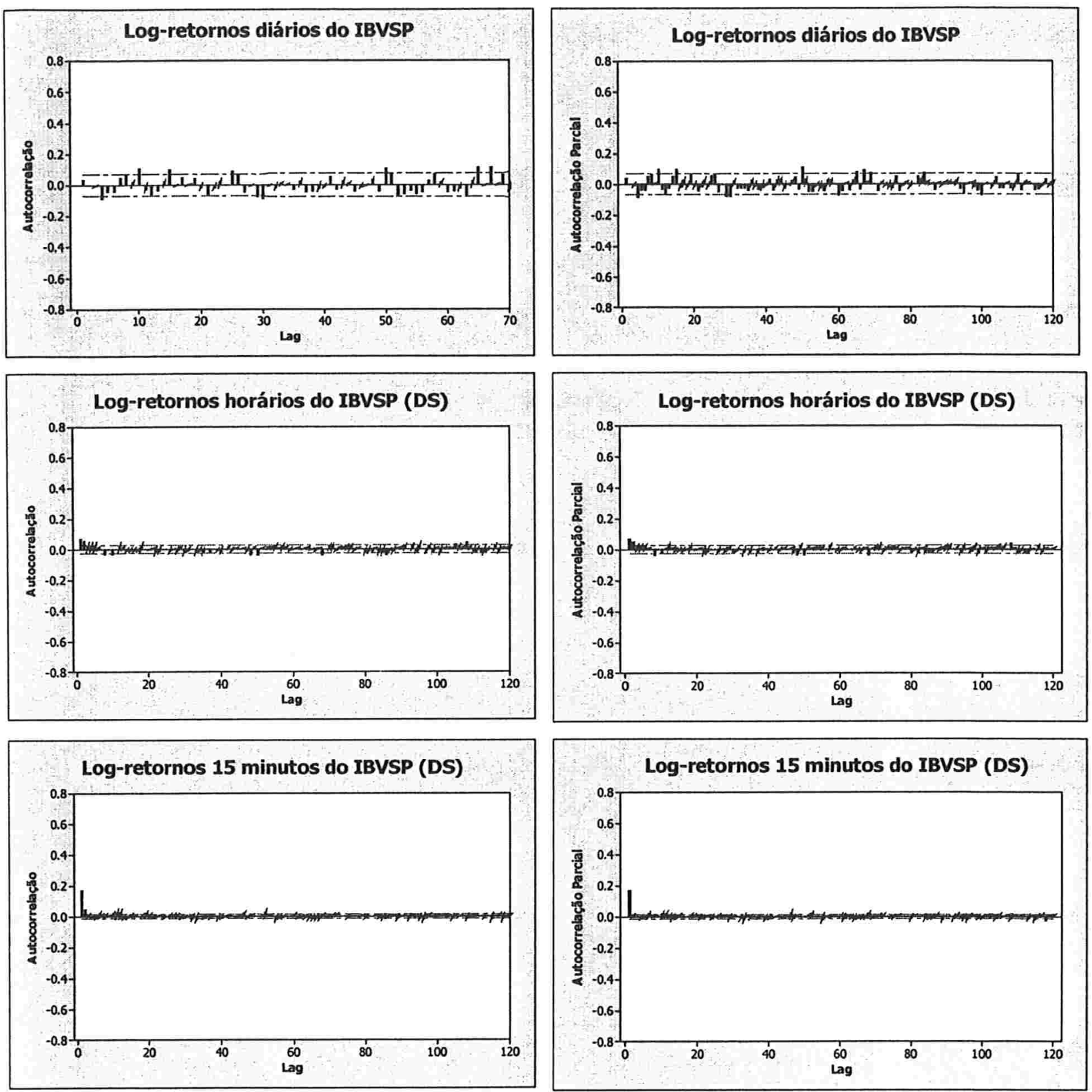
Figura A.8 Correlogramas da Volatilidade
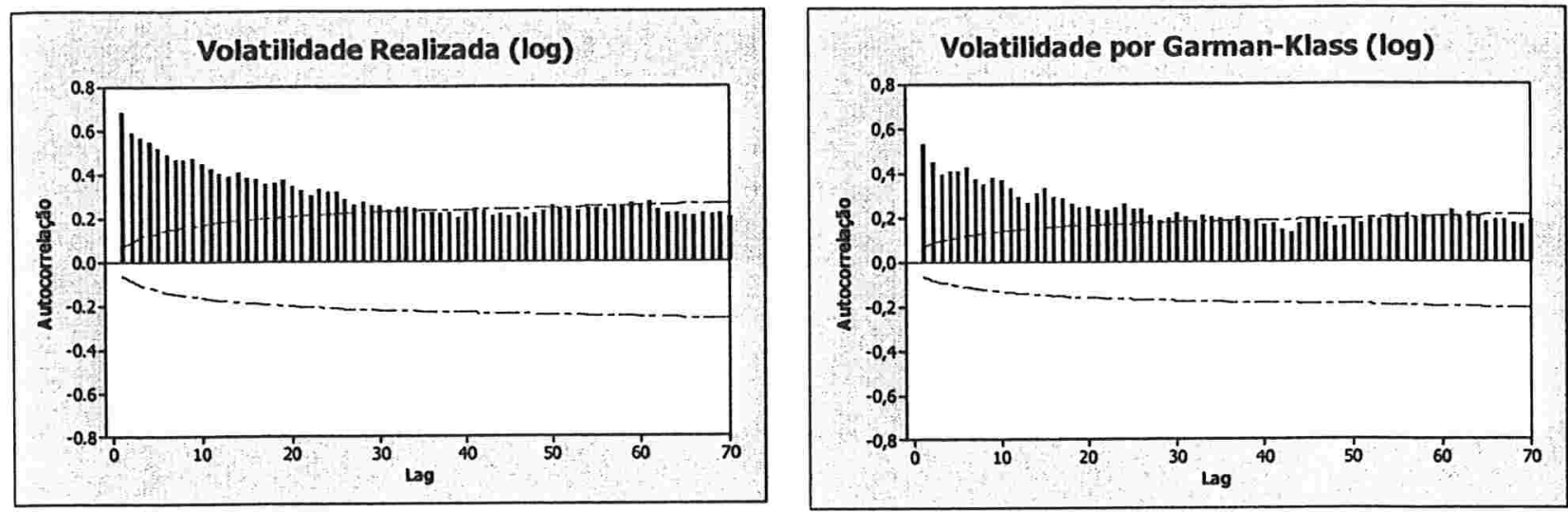

Obs.: DS denota séries dessazonalizadas 
Figura A.9 Correlogramas dos Quadrados dos Retornos
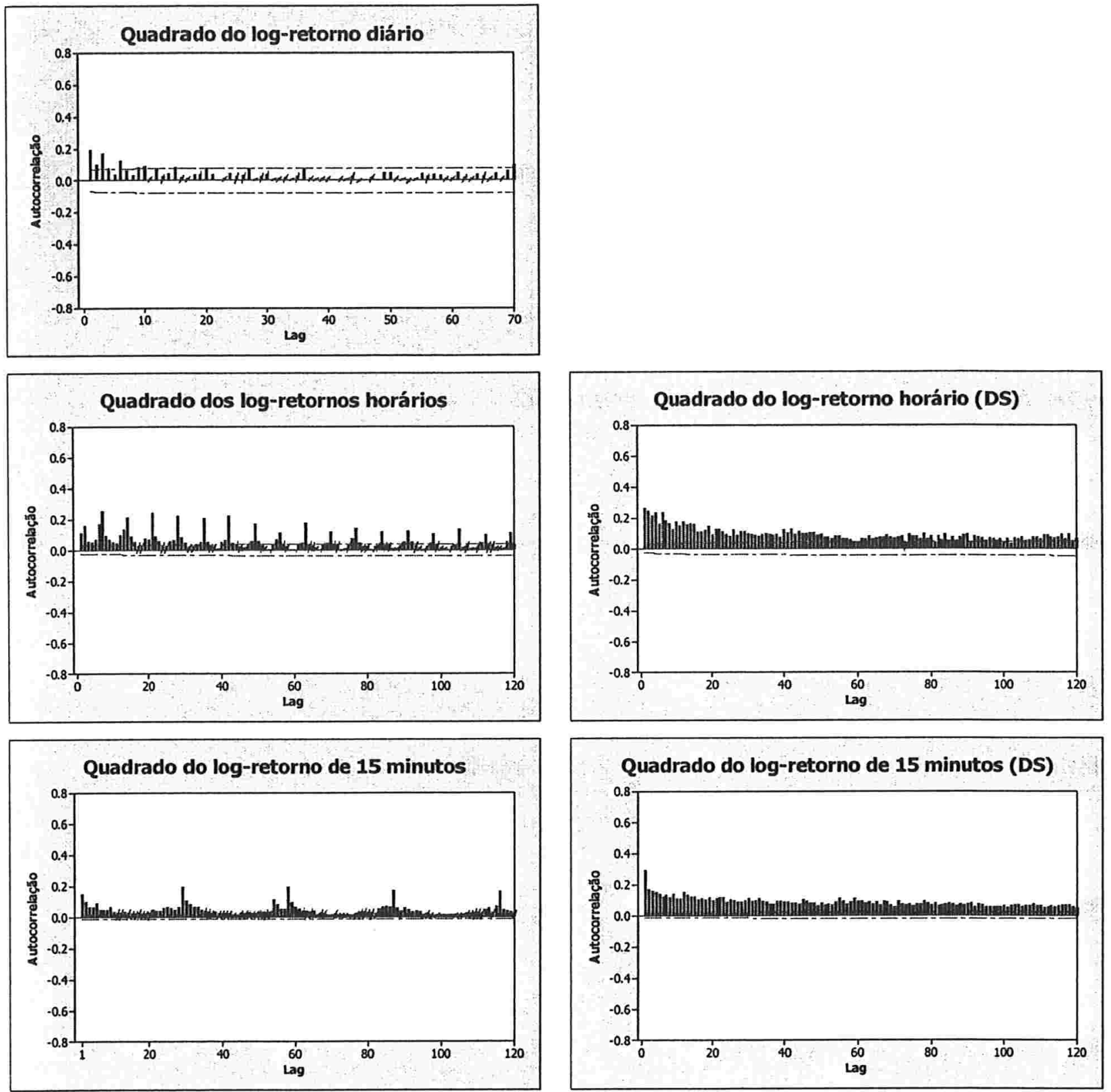

Obs.: DS denota séries dessazonalizadas 


\section{A.2 Tabelas}

Tabela A.1 Parâmetros ARMA

\begin{tabular}{|c|c|c|c|c|c|}
\hline Variable & Coef. & Value & std.Error & t value & $\operatorname{Pr}(>|t|)$ \\
\hline \multirow{4}{*}{$\log (1 d)$} & $\operatorname{AR}(1)$ & 0.036 & 0.035 & 1.03 & 0.30 \\
\hline & $\operatorname{AR}(2)$ & 0.002 & 0.035 & 0.05 & 0.96 \\
\hline & $\operatorname{AR}(3)$ & -0.005 & 0.035 & -0.15 & 0.88 \\
\hline & $\operatorname{AR}(4)$ & -0.088 & 0.035 & -2.52 & 0.01 \\
\hline \multirow{5}{*}{$\log (1 \mathrm{~h})$} & $\operatorname{AR}(1)$ & 0.061 & 0.013 & 4.66 & 0.00 \\
\hline & $A R(2)$ & 0.048 & 0.013 & 3.7 & 0.00 \\
\hline & $\operatorname{AR}(3)$ & 0.016 & 0.013 & 1.19 & 0.23 \\
\hline & $\operatorname{AR}(4)$ & 0.019 & 0.013 & 1.43 & 0.15 \\
\hline & $\operatorname{AR}(5)$ & 0.021 & 0.013 & 1.64 & 0.10 \\
\hline \multirow{2}{*}{$\log (15 m)$} & $\operatorname{AR}(1)$ & 0.164 & 0.006 & 25.62 & 0.00 \\
\hline & $\operatorname{AR}(2)$ & 0.015 & 0.006 & 2.33 & 0.02 \\
\hline
\end{tabular}

Tabela A.2 Parâmetros GARCH - Log-retorno diário

\begin{tabular}{|c|c|c|c|c|c|c|c|c|c|}
\hline Model & Coef. & Value & Std.Error & t value & $\operatorname{Pr}(>|t|)$ & Value & Std.Error & t value & $\operatorname{Pr}(>|t|)$ \\
\hline \multirow{4}{*}{$\operatorname{GARCH}(1,1)$} & C & 0.004 & 0.073 & 0.056 & 0.478 & 0.013 & 0.072 & 0.174 & 0.431 \\
\hline & A & 0.305 & 0.142 & 2.145 & 0.016 & 0.298 & 0.157 & 1.899 & 0.029 \\
\hline & ARCH (1) & 0.164 & 0.055 & 3.005 & 0.001 & 0.135 & 0.049 & 2.769 & 0.003 \\
\hline & GARCH (1) & 0.797 & 0.059 & 13.403 & 0.000 & 0.820 & 0.063 & 12.992 & 0.000 \\
\hline \multirow{5}{*}{$\operatorname{EGARCH}(1,1)$} & ]c & -0.068 & 0.075 & -0.897 & 0.185 & -0.040 & 0.072 & -0.559 & 0.288 \\
\hline & A & -0.102 & 0.036 & -2.827 & 0.002 & -0.098 & 0.031 & -3.106 & 0.001 \\
\hline & ARCH (1) & 0.211 & 0.056 & 3.758 & 0.000 & 0.195 & 0.053 & 3.684 & 0.000 \\
\hline & GARCH (1) & 0.963 & 0.018 & 52.544 & 0.000 & 0.967 & 0.017 & 55.742 & 0.000 \\
\hline & LEV (1) & -0.499 & 0.121 & -4.106 & 0.000 & -0.503 & 0.118 & -4.277 & 0.000 \\
\hline \multirow{6}{*}{$\operatorname{PGARCH}(1,1)$} & c & -0.052 & 0.086 & -0.602 & 0.274 & -0.041 & 0.076 & -0.541 & 0.294 \\
\hline & A & 0.217 & 0.316 & 0.689 & 0.246 & 0.117 & 0.117 & 1.000 & 0.159 \\
\hline & ARCH (1) & 0.098 & 0.072 & 1.354 & 0.088 & 0.098 & 0.046 & 2.107 & 0.018 \\
\hline & GARCH (1) & 0.850 & 0.062 & 13.666 & 0.000 & 0.879 & 0.045 & 19.600 & 0.000 \\
\hline & POWER & 1.669 & 1.166 & 1.432 & 0.076 & 1.288 & 0.771 & 1.671 & 0.048 \\
\hline & LEV (1) & -0.604 & 0.310 & -1.952 & 0.026 & -0.574 & 0.169 & -3.391 & 0.000 \\
\hline \multirow{6}{*}{$\operatorname{TGARCH}(1,1)$} & $\bar{c}$ & -0.045 & 0.076 & -0.597 & 0.275 & -0.022 & 0.073 & -0.305 & 0.380 \\
\hline & A & 0.337 & 0.150 & 2.252 & 0.012 & 0.228 & 0.204 & 1.117 & 0.132 \\
\hline & ARCH (1) & 0.008 & 0.021 & 0.363 & 0.358 & 0.001 & 0.018 & 0.072 & 0.471 \\
\hline & GARCH (1) & 0.831 & 0.055 & 15.002 & 0.000 & 0.880 & 0.089 & 9.867 & 0.000 \\
\hline & GAMMA (1) & 0.226 & 0.084 & 2.699 & 0.004 & 0.165 & 0.109 & 1.511 & 0.066 \\
\hline & & \multicolumn{4}{|c|}{ Normal } & \multicolumn{4}{|c|}{ t-student } \\
\hline
\end{tabular}


Tabela A.3 Parâmetros GARCH+VR - Log-retorno diário

\begin{tabular}{|c|c|c|c|c|c|c|c|c|c|}
\hline Model & Coef. & value & sta.Error & $t$ value & $\operatorname{Pr}(>|t|)$ & Value & std.Exror & t value & $\operatorname{Px}(>|t|)$ \\
\hline \multirow{5}{*}{$\begin{array}{c}\operatorname{GARCH}(1,1) \\
+\operatorname{VR}\end{array}$} & c & -0.042 & 0.074 & -0.567 & 0.285 & -0.037 & 0.074 & -0.493 & 0.311 \\
\hline & A & 0.571 & 0.395 & 1.447 & 0.074 & 0.503 & 0.368 & 1.366 & 0.086 \\
\hline & $\mathrm{ARCH}(1)$ & 0.044 & 0.037 & 1.196 & 0.116 & 0.047 & 0.037 & 1.267 & 0.103 \\
\hline & GARCH (1) & 0.505 & 0.219 & 2.303 & 0.011 & 0.550 & 0.224 & 2.460 & 0.007 \\
\hline & VR & 0.507 & 0.237 & 2.143 & 0.016 & 0.451 & 0.249 & 1.814 & 0.035 \\
\hline \multirow{6}{*}{$\begin{array}{c}\text { EGARCH }(1,1) \\
+V R\end{array}$} & c & -0.054 & 0.075 & -0.713 & 0.238 & -0.044 & 0.072 & -0.611 & 0.271 \\
\hline & A & 0.019 & 0.077 & 0.251 & 0.401 & -0.021 & 0.052 & -0.394 & 0.347 \\
\hline & ARCH (1) & 0.184 & 0.062 & 2.981 & 0.001 & 0.176 & 0.067 & 2.641 & 0.004 \\
\hline & GARCH (1) & 0.874 & 0.028 & 30.725 & 0.000 & 0.911 & 0.076 & 12.009 & 0.000 \\
\hline & $\operatorname{LEV}(1)$ & -0.739 & 0.299 & -2.469 & 0.007 & -0.688 & 0.170 & -4.045 & 0.000 \\
\hline & JVR & 0.009 & 0.000 & 8332.666 & 0.000 & 0.006 & 0.006 & 0.909 & 0.182 \\
\hline \multirow{7}{*}{$\begin{array}{c}\operatorname{PGARCH}(1,1) \\
+\mathrm{VR}\end{array}$} & c & -0.035 & 0.122 & -0.283 & 0.389 & -0.032 & 0.071 & -0.449 & 0.327 \\
\hline & A & 0.190 & 0.565 & 0.337 & 0.368 & 0.220 & 0.103 & 2.144 & 0.016 \\
\hline & ARCH (1) & 0.031 & 0.019 & 1.581 & 0.057 & 0.052 & 0.017 & 3.143 & 0.001 \\
\hline & GARCH (1) & 0.854 & 0.324 & 2.634 & 0.004 & 0.833 & 0.054 & 15.520 & 0.000 \\
\hline & POWER & 1.615 & 0.066 & 24.405 & 0.000 & 1.395 & 0.032 & 43.755 & 0.000 \\
\hline & LEV (1) & -1.000 & 2.386 & -0.419 & 0.338 & -0.998 & 0.115 & -8.714 & 0.000 \\
\hline & VR & 0.044 & 0.032 & 1.367 & 0.086 & 0.030 & 0.000 & 1740.062 & 0.000 \\
\hline \multirow{7}{*}{$\begin{array}{c}\operatorname{TGARCH}(1,1) \\
+\mathrm{VR}\end{array}$} & c & -0.022 & 0.072 & -0.301 & 0.382 & -0.020 & 0.073 & -0.274 & 0.392 \\
\hline & A & 0.478 & 0.212 & 2.257 & 0.012 & 0.491 & 0.226 & 2.176 & 0.015 \\
\hline & ARCH (1) & -0.053 & 0.016 & -3.306 & 0.000 & -0.051 & 0.020 & -2.572 & 0.005 \\
\hline & GARCH (1) & 0.638 & 0.174 & 3.665 & 0.000 & 0.617 & 0.184 & 3.354 & 0.000 \\
\hline & GAMMA (1) & 0.231 & 0.061 & 3.761 & 0.000 & 0.238 & 0.070 & 3.398 & 0.000 \\
\hline & JVR & 0.310 & 0.230 & 1.350 & 0.089 & 0.331 & 0.238 & 1.394 & 0.082 \\
\hline & & \multicolumn{4}{|c|}{ Normal } & \multicolumn{4}{|c|}{ t-Student } \\
\hline
\end{tabular}

Tabela A.4 Parâmetros GARCH+GK - Log-retorno diário

\begin{tabular}{|c|c|c|c|c|c|c|c|c|c|}
\hline Model & Coef. & Value & std.Error & t value & $\operatorname{Pr}(>|t|)$ & Value & Sta.Error & $t$ value & $\operatorname{Px}(>|t|)$ \\
\hline \multirow{5}{*}{$\begin{array}{c}\operatorname{GARCH}(1,1) \\
+\mathrm{GK}\end{array}$} & $\bar{c}$ & -0.046 & 0.075 & -0.610 & 0.271 & -0.038 & 0.073 & -0.524 & 0.300 \\
\hline & A & 0.338 & 0.156 & 2.164 & 0.015 & 0.236 & 0.134 & 1.759 & 0.039 \\
\hline & ARCH (1) & 0.025 & 0.039 & 0.654 & 0.257 & 0.020 & 0.036 & 0.557 & 0.289 \\
\hline & GARCH (1) & 0.707 & 0.076 & 9.265 & 0.000 & 0.757 & 0.080 & 9.507 & 0.000 \\
\hline & GK & 0.302 & 0.102 & 2.970 & 0.002 & 0.260 & 0.088 & 2.957 & 0.002 \\
\hline \multirow{6}{*}{$\begin{array}{c}\operatorname{EGARCH}(1,1) \\
+G \mathrm{~K}\end{array}$} & lc & -0.063 & 0.075 & -0.842 & 0.200 & -0.039 & 0.072 & -0.545 & 0.293 \\
\hline & A & -0.029 & 0.046 & -0.633 & 0.263 & -0.056 & 0.045 & -1.226 & 0.110 \\
\hline & ARCH (1) & 0.183 & 0.050 & 3.698 & 0.000 & 0.169 & 0.054 & 3.134 & 0.001 \\
\hline & GARCH (1) & 0.917 & 0.045 & 20.191 & 0.000 & 0.946 & 0.037 & 25.342 & 0.000 \\
\hline & $\operatorname{LEV}(1)$ & -0.645 & 0.176 & -3.662 & 0.000 & -0.607 & 0.177 & -3.441 & 0.000 \\
\hline & GK & 0.005 & 0.004 & 1.275 & 0.101 & 0.002 & 0.003 & 0.930 & 0.176 \\
\hline \multirow{7}{*}{$\begin{array}{c}\operatorname{PGARCH}(1,1) \\
+G \mathrm{~K}\end{array}$} & c & -0.043 & 0.076 & -0.567 & 0.285 & -0.031 & 0.072 & -0.439 & 0.330 \\
\hline & A & 0.145 & 0.087 & 1.658 & 0.049 & 0.205 & 0.187 & 1.096 & 0.137 \\
\hline & ARCH (1) & 0.031 & 0.014 & 2.256 & 0.012 & 0.046 & 0.035 & 1.299 & 0.097 \\
\hline & GARCH (1) & 0.896 & 0.045 & 19.732 & 0.000 & 0.849 & 0.124 & 6.823 & 0.000 \\
\hline & POWER & 1.535 & 0.034 & 45.231 & 0.000 & 1.456 & 0.471 & 3.094 & 0.001 \\
\hline & LEV (1) & -0.995 & 0.111 & -8.952 & 0.000 & -1.000 & 2.157 & -0.464 & 0.322 \\
\hline & GK & 0.019 & 0.000 & 3706.838 & 0.000 & 0.029 & 0.000 & 2059.386 & 0.000 \\
\hline \multirow{7}{*}{$\begin{array}{c}\operatorname{TGARCH}(1,1) \\
+G \mathrm{~K}\end{array}$} & c & -0.013 & 0.074 & -0.172 & 0.432 & -0.012 & 0.074 & -0.166 & 0.434 \\
\hline & A & 0.394 & 0.156 & 2.521 & 0.006 & 0.318 & 0.160 & 1.989 & 0.024 \\
\hline & ARCH (1) & -0.055 & 0.025 & -2.209 & 0.014 & -0.045 & 0.024 & -1.877 & 0.030 \\
\hline & GARCH (1) & 0.749 & 0.078 & 9.584 & 0.000 & 0.782 & 0.091 & 8.588 & 0.000 \\
\hline & GAMMA (1) & 0.215 & 0.070 & 3.065 & 0.001 & 0.185 & 0.073 & 2.542 & 0.006 \\
\hline & $\mathrm{GK}$ & 0.191 & 0.094 & 2.033 & 0.021 & 0.166 & 0.089 & 1.870 & 0.031 \\
\hline & & \multicolumn{4}{|c|}{ Normal } & \multicolumn{4}{|c|}{ t-student } \\
\hline
\end{tabular}


Tabela A.5 Parâmetros GARCH - Log-retorno horário e de 15 minutos

\begin{tabular}{|c|c|c|c|c|c|c|c|c|c|}
\hline Model & Coeรี. & Value & std.Error & t value & $\operatorname{Pr}(>|t|)$ & Value & std.Exror & t value & $\operatorname{Px}(>|t|)$ \\
\hline \multirow{5}{*}{$\operatorname{GARCH}(1,2)$} & C & 0.006 & 0.009 & 0.655 & 0.256 & 0.002 & 0.004 & 0.473 & 0.318 \\
\hline & A & 0.017 & 0.004 & 3.995 & 0.000 & 0.020 & 0.004 & 5.131 & 0.000 \\
\hline & ARCH (1) & 0.105 & 0.013 & 8.081 & 0.000 & 0.117 & 0.013 & 9.318 & 0.000 \\
\hline & GARCH (1) & 0.090 & 0.031 & 2.939 & 0.002 & 0.357 & 0.044 & 8.065 & 0.000 \\
\hline & GARCH (2) & 0.788 & 0.036 & 21.635 & 0.000 & 0.508 & 0.046 & 11.093 & 0.000 \\
\hline \multirow{6}{*}{ EGARCH $(1,2)$} & c & -0.003 & 0.009 & -0.326 & 0.372 & -0.002 & 0.004 & -0.500 & 0.309 \\
\hline & A & -0.146 & 0.016 & -8.901 & 0.000 & -0.131 & 0.012 & -10.922 & 0.000 \\
\hline & $\mathrm{ARCH}(1)$ & 0.189 & 0.021 & 8.922 & 0.000 & 0.176 & 0.015 & 11.371 & 0.000 \\
\hline & GARCH (1) & 0.180 & 0.039 & 4.599 & 0.000 & 0.398 & 0.047 & 8.388 & 0.000 \\
\hline & GARCH (2) & 0.807 & 0.040 & 20.227 & 0.000 & 0.591 & 0.048 & 12.353 & 0.000 \\
\hline & LEV (1) & -0.343 & 0.072 & -4.756 & 0.000 & -0.174 & 0.033 & -5.266 & 0.000 \\
\hline \multirow{7}{*}{ PGARCH $(1,2)$} & ]c & -0.003 & 0.010 & -0.314 & 0.377 & -0.002 & 0.004 & -0.554 & 0.290 \\
\hline & A & 0.014 & 0.004 & 3.677 & 0.000 & 0.016 & 0.003 & 4.680 & 0.000 \\
\hline & ARCH (1) & 0.099 & 0.013 & 7.489 & 0.000 & 0.118 & 0.012 & 9.802 & 0.000 \\
\hline & GARCH (1) & 0.139 & 0.063 & 2.223 & 0.013 & 0.343 & 0.043 & 8.004 & 0.000 \\
\hline & GARCH (2) & 0.765 & 0.063 & 12.239 & 0.000 & 0.551 & 0.045 & 12.200 & 0.000 \\
\hline & POWER & 1.331 & 0.136 & 9.782 & 0.000 & 1.224 & 0.085 & 14.415 & 0.000 \\
\hline & LEV (1) & -0.321 & 0.088 & -3.637 & 0.000 & -0.148 & 0.030 & -4.941 & 0.000 \\
\hline \multirow{6}{*}{$\operatorname{TGARCH}(1,2)$} & ]c & -0.001 & 0.009 & -0.082 & 0.468 & -0.001 & 0.004 & -0.296 & 0.384 \\
\hline & A & 0.016 & 0.004 & 3.969 & 0.000 & 0.015 & 0.003 & 5.348 & 0.000 \\
\hline & $\mathrm{ARCH}(1)$ & 0.062 & 0.013 & 4.688 & 0.000 & 0.080 & 0.011 & 7.610 & 0.000 \\
\hline & GARCH (1) & 0.097 & 0.036 & 2.686 & 0.004 & 0.347 & 0.051 & 6.856 & 0.000 \\
\hline & GARCH (2) & 0.789 & 0.041 & 19.431 & 0.000 & 0.538 & 0.052 & 10.272 & 0.000 \\
\hline & GAMMA (1) & 0.068 & 0.016 & 4.332 & 0.000 & 0.039 & 0.008 & 5.013 & 0.000 \\
\hline
\end{tabular}

Tabela A.6 Parâmetros FARIMA - Volatilidade Realizada

\begin{tabular}{|c|c|c|c|c|c|}
\hline Model & Coef. & Value & std.Exror & t value & $\operatorname{Pr}(>|t|)$ \\
\hline \multirow{3}{*}{$\operatorname{FARIMA}(1, d, 1)$} & d & 0.308 & 0.058 & 5.330 & 0.000 \\
\hline & $\operatorname{AR}(1)$ & 0.908 & 0.030 & 30.768 & 0.000 \\
\hline & MA (1) & 0.823 & 0.022 & 37.810 & 0.000 \\
\hline \multirow{2}{*}{$\operatorname{FARIMA}(1, d, 0)$} & d & 0.447 & 0.043 & 10.445 & 0.000 \\
\hline & $\operatorname{AR}(1)$ & -0.022 & 0.055 & -0.400 & 0.689 \\
\hline \multirow{2}{*}{$\operatorname{FARTMA}(0, d, 1)$} & d & 0.450 & 0.043 & 10.574 & 0.000 \\
\hline & MA (1) & 0.028 & 0.054 & 0.514 & 0.608 \\
\hline FARIMA $(0, d, 0)$ & d & 0.438 & 0.027 & 16.158 & 0.000 \\
\hline
\end{tabular}

Tabela A.7 Parâmetros FARIMA - Garman-Klass

\begin{tabular}{|c|c|c|c|c|c|}
\hline Model & Coef. & Value & Std.Exror & t value & $\operatorname{Pr}(>|t|)$ \\
\hline \multirow{2}{*}{$\operatorname{FARIMA}(1, d, 0)$} & d & 0.378 & 0.041 & 9.135 & 0.000 \\
\hline & $\operatorname{AR}(1)$ & -0.067 & 0.053 & -1.270 & 0.205 \\
\hline \multirow{2}{*}{$\operatorname{FARIMA}(0, d, 1)$} & d & 0.389 & 0.041 & 9.538 & 0.000 \\
\hline & $M A(1)$ & 0.086 & 0.052 & 1.666 & 0.096 \\
\hline $\operatorname{FARIMA}(0, d, 0)$ & $\mathrm{d}$ & 0.345 & 0.027 & 12.749 & 0.000 \\
\hline
\end{tabular}


Tabela A.8 Teste ML dos log-retornos

\begin{tabular}{|c|c|c|c|}
\hline & $\log (1 d)$ & $\log (15 m)$ DS & $\log (1 h) D S$ \\
\hline Stat & 63.84 & 3098.45 & 929.37 \\
\hline p-value & 0.000 & 0.000 & 0.000 \\
\hline
\end{tabular}

Tabela A.9 Testes de qualidade de ajuste dos resíduos GARCH padronizados

\begin{tabular}{|c|c|c|c|c|c|c|c|c|}
\hline \multirow{3}{*}{ Model } & \multirow{3}{*}{ Variable } & \multirow{3}{*}{ Covariate } & \multicolumn{4}{|c|}{ Ljung-Box Test } & \multicolumn{2}{|c|}{ Arch Test } \\
\hline & & & \multicolumn{2}{|c|}{ std. residuals } & \multicolumn{2}{|c|}{ squared std. residuals } & & \\
\hline & & & Statistic & P-value & Statistic & P-value & Statistic & P-value \\
\hline GARCH $(1,1)$ & $1 \mathrm{~d}$ & & 18.18 & 0.110 & 9.13 & 0.692 & 8.30 & 0.761 \\
\hline $\operatorname{EGARCH}(1,1)$ & $1 d$ & & 20.18 & 0.064 & 9.23 & 0.683 & 8.32 & 0.760 \\
\hline PGARCH $(1,1)$ & $1 d$ & & 19.59 & 0.075 & 11.15 & 0.516 & 10.00 & 0.616 \\
\hline $\operatorname{TGARCH}(1,1)$ & $1 d$ & & 19.72 & 0.073 & 12.31 & 0.421 & 11.25 & 0.507 \\
\hline GARCH $(1,1) t$ & 1d & & 17.52 & 0.131 & 9.64 & 0.648 & 9.34 & 0.673 \\
\hline EGARCH $(1,1) \mathrm{t}$ & $1 d$ & & 19.61 & 0.075 & 8.85 & 0.716 & 8.10 & 0.778 \\
\hline PGARCH $(1,1) t$ & $1 d$ & & 19.21 & 0.084 & 9.71 & 0.641 & 8.75 & 0.724 \\
\hline TGARCH $(1,1) t$ & 1d & & 18.57 & 0.100 & 10.21 & 0.598 & 9.57 & 0.654 \\
\hline GARCH $(1,1)$ & $1 d$ & VR & 19.58 & 0.075 & 11.15 & 0.516 & 10.30 & 0.590 \\
\hline $\operatorname{EGARCH}(1,1)$ & $1 d$ & VR & 20.60 & 0.057 & 11.70 & 0.470 & 10.49 & 0.573 \\
\hline PGARCH(1,1) & 1d & VR & 18.67 & 0.097 & 9.80 & 0.634 & 9.49 & 0.661 \\
\hline $\operatorname{TGARCH}(1,1)$ & 1d & VR & 21.77 & 0.040 & 10.05 & 0.612 & 8.88 & 0.713 \\
\hline GARCH $(1,1) t$ & $1 d$ & VR & 19.48 & 0.078 & 10.89 & 0.538 & 10.02 & 0.614 \\
\hline $\operatorname{EGARCH}(1,1) \mathrm{t}$ & 1d & VR & 19.99 & 0.067 & 10.47 & 0.575 & 9.45 & 0.664 \\
\hline PGARCH $(1,1) t$ & 1d & VR & 19.39 & 0.079 & 10.02 & 0.614 & 9.19 & 0.686 \\
\hline TGARCH $(1,1) \mathrm{t}$ & 1d & VR & 21.90 & 0.039 & 10.44 & 0.577 & 9.00 & 0.703 \\
\hline $\operatorname{GARCH}(1,1)$ & $1 d$ & GK & 21.62 & 0.042 & 8.15 & 0.773 & 7.60 & 0.816 \\
\hline EGARCH(1,1) & $1 d$ & GK & 20.82 & 0.053 & 10.59 & 0.565 & 9.39 & 0.669 \\
\hline PGARCH $(1,1)$ & 1d & GK & 18.47 & 0.102 & 10.11 & 0.606 & 9.66 & 0.646 \\
\hline $\operatorname{TGARCH}(1,1)$ & 1d & GK & 22.78 & 0.030 & 11.25 & 0.508 & 10.16 & 0.602 \\
\hline GARCH $(1,1) t$ & $1 d$ & GK & 21.46 & 0.044 & 7.96 & 0.788 & 7.69 & 0.809 \\
\hline $\operatorname{EGARCH}(1,1) t$ & $1 d$ & GK & 19.76 & 0.072 & 9.08 & 0.696 & 8.22 & 0.768 \\
\hline PGARCH $(1,1) t$ & $1 d$ & GK & 20.07 & 0.066 & 10.07 & 0.610 & 9.10 & 0.695 \\
\hline TGARCH $(1,1) \mathrm{t}$ & 1d & GK & 22.37 & 0.034 & 10.32 & 0.588 & 9.34 & 0.674 \\
\hline GARCH $(1,2) t$ & $1 \mathrm{~h}$ & & 12.33 & 0.420 & 2.72 & 0.997 & 2.73 & 0.997 \\
\hline $\operatorname{EGARCH}(1,2) \mathrm{t}$ & $1 \mathrm{~h}$ & & 11.82 & 0.460 & 4.38 & 0.976 & 4.33 & 0.977 \\
\hline PGARCH $(1,2) t$ & $1 \mathrm{~h}$ & & 12.34 & 0.419 & 5.99 & 0.916 & 5.93 & 0.920 \\
\hline TGARCH $(1,2) t$ & $1 \mathrm{~h}$ & & 12.80 & 0.384 & 3.25 & 0.994 & 3.27 & 0.993 \\
\hline GARCH $(1,2) t$ & $15 \mathrm{~m}$ & & 44.61 & 0.000 & 6.49 & 0.889 & 0.59 & 0.935 \\
\hline $\operatorname{EGARCH}(1,2) \mathrm{t}$ & $15 \mathrm{~m}$ & & 40.41 & 0.000 & 9.51 & 0.659 & 0.84 & 0.709 \\
\hline PGARCH $(1,2) t$ & $15 \mathrm{~m}$ & & 40.29 & 0.000 & 16.64 & 0.164 & 1.48 & 0.237 \\
\hline $\operatorname{TGARCH}(1,2) \mathrm{t}$ & $15 \mathrm{~m}$ & & 44.42 & 0.000 & 7.53 & 0.821 & 0.68 & 0.869 \\
\hline
\end{tabular}




\section{Referências}

Andersen, T. and Bollerslev, T. (1998). Answering the skeptics: yes, standard volatility models do provide accurate forecasts. International Economic Review, 39, 885-905.

Barbosa, P. A. (2002). Investigating High Frequency Exchange Rate from the Brazilian Sisbex Market. Disponível em http://www.cvm.gov.br/port/public/publ/publ.asp.

Berkowitz, J. and O'Brien, J. (2002). How Accurate are value-at-risk models at commercial banks?, Journal of Finance, 57, 1093-1112.

Black, F. (1976). Studies in stock price volatility changes. Proceedings of the 1976 Business Meeting of the Business and Economics Statistics Section, American Statistical Association, 177-181.

Bollerslev, T. (1986) Generalized autoregressive conditional heteroskedasticity. Journal of Econometrics, 31, 307-327.

Bollerslev, T., Engle, R. F., and Wooldridge, J. M. (1988). A capital-asset pricing model with time-varying covariances, Journal of Political Economy, 96, 116-131.

Bollerslev, T., Engle, R. F., and Nelson, D. (1994). ARCH Models, Handbook of Econometric, 4, 2961-3035.

Bourdoukh, J., Richardson, M., and Whitelaw, R. (1998). The best of both worlds, Risk, 11, 6467.

Box, G. E. P. and G. M. Jenkins (1970). Time Series Analysis: Forecasting and Control, San Francisco: Holden-Day. 
Brooks, C. and Persand, G. (2003). Volatility forecasting for risk management, Journal of Forecasting, 22, 1-22.

Chong, J. (2004). Value at risk from econometric models and implied from currency options, Journal of Forecasting, 23, 603-620.

Ding, Z., Granger, C. W. J., and Engle, R.F. (1993). A long memory property of stock market returns and a new model, Journal of Empirical Finance, 1, 83-106.

Engle, R. F. (1982). Autoregressive conditional heteroskedasticity with estimates of the variance of united kingdom inflation, Econometrica, 50, 987-1007.

Engle, R. F. (2002). Dynamic conditional correlation - a simple class of multivariate garch models, Journal of Business and Economic Statistics, 20, 339- 350.

Engle, R. F. and Kroner, K. F. (1995). Multivariate Simultaneous GARCH, Econometric Theory, 11, $122-150$.

Garman, M. B., and Klass, M. J. (1980). On the estimation of security price volatility from historical data, Journal of Business, 53, 67-78.

Glosten, L. R., Jagannathan, R., and Runkle, D. E. (1993). On the relation between the expected value and the volatility of the nominal excess return on stocks, Journal of Finance, 48, 17791801.

Granger, C. W. J. and R. Joyeux (1980). An introduction to long memory time series models and fractional differencing, Journal of Time Series Analysis, 1, 15-29.

Giot, P., (2000). Intraday value-at-risk. Department of Quantitative Economics, Maastricht University (Holland) and Center for Operations Research and Econometrics (CORE), UCL (Belgium). 
Giot, P., Laurent S., (2004). Modelling daily value-at-risk using realized volatility and arch type models, Journal of Empirical Finance, 11, 379-398.

Hamilton, J.D. (1994). Time Series Analysis. New Jersey: Princeton University Press.

Hansen, P.H. and Lunde, A. (2004?). A forecast comparison of volatility models: does anything beat a $\operatorname{GARCH}(1,1)$ ?, Journal of Applied Econometrics, forthcoming.

Hol, E. and S.J. Koopman (2002). Stock index volatility forecasting with high frequency data, Discussion Paper No. 2002-068/4, Tinbergen Institute.

Hosking, J.R.M. (1981). Fractional differencing, Biometrika, 68, 165-176.

Jarque, C. M., and Bera, A. K. (1987). A test for normality of observations and regression residuals. International Statistical Review, 55, 163-172

Hull, J., and White, A., (1998). Incorporating volatility updating into the historical simulation method for value at risk, Journal of Risk, 1, 5-19.

Jorion, P. (2001). Value-at-Risk: The New Benchmark for Managing Financial Risk, 2/E. McGraw-Hill.

Kupiec, P. (1995). Techniques for verifying the accuracy of risk measurement models, Journal of Derivatives, 2, 73-84.

Ljung, G. M., and Box, G. E. P. (1978). On a measure of lack of fit in time series models, Biometrika, 65, 297-303.

Mina, J., and Xiao, J. Y. (2001). Return to RiskMetrics: The Evolution of a Standard. New York: J. P. Morgan RiskMetrics Group.

Markowitz, H.M. (1952). Portfolio selection, Journal of Finance, 7, 77-91. 
Moreira, J. M. S. e Lemgruber, E. F. (2004). O uso de dados de alta freqüência na estimação da volatilidade e do valor em risco para o IBOVESPA, Rev. Bras. Econ., 58, 100-120.

Morettin, P. A. (2004). Econometria Financeira: Um Curso de Séries Temporais Financeiras. IME-USP (versão preliminar).

Mota, B., S, e Fernandes, M. (2004). Desempenho de estimadores de volatilidade na bolsa de valores de São Paulo, Rev. Bras. Econ., 58, 429-448.

Nelson, D.B. (1991). Conditional heteroskedasticity in asset returns: a new approach, Econometrica, 59, 347-370.

Oomen, R. (2001). Using high frequency stock market index data to calculate, model and forecast realized return variance, Working Paper 2001/6, European University Institute.

Pong, S., Shackleton, B. M., Taylor, S. J. and Xu, X. (2004). Forecasting currency volatility: A comparison of implied volatilities and AR(FI)MA models, Journal of Banking \& Finance, 28, 2541-2563.

Riskmetrics Group (1996), Riskmetrics - Technical Document, New York - J. P.Morgan.

Royston, J. P. (1982). An extension of shapiro and wilk's w test for normality to large samples. Applied Statistics, 31, 115-124.

Tsay, R.S. (2002). Analysis of Financial Time Series. New York: John Wiley \& Sons.

Zangari, P. (1997). Streamlining the Market Risk Measurement Process, RiskMetrics Monitor, 1, 29-35.

Zivot, E. and J. Wang (2003). Modeling Financial Time Series with S-PLUS. New York: Springer-Verlag. 